Legend
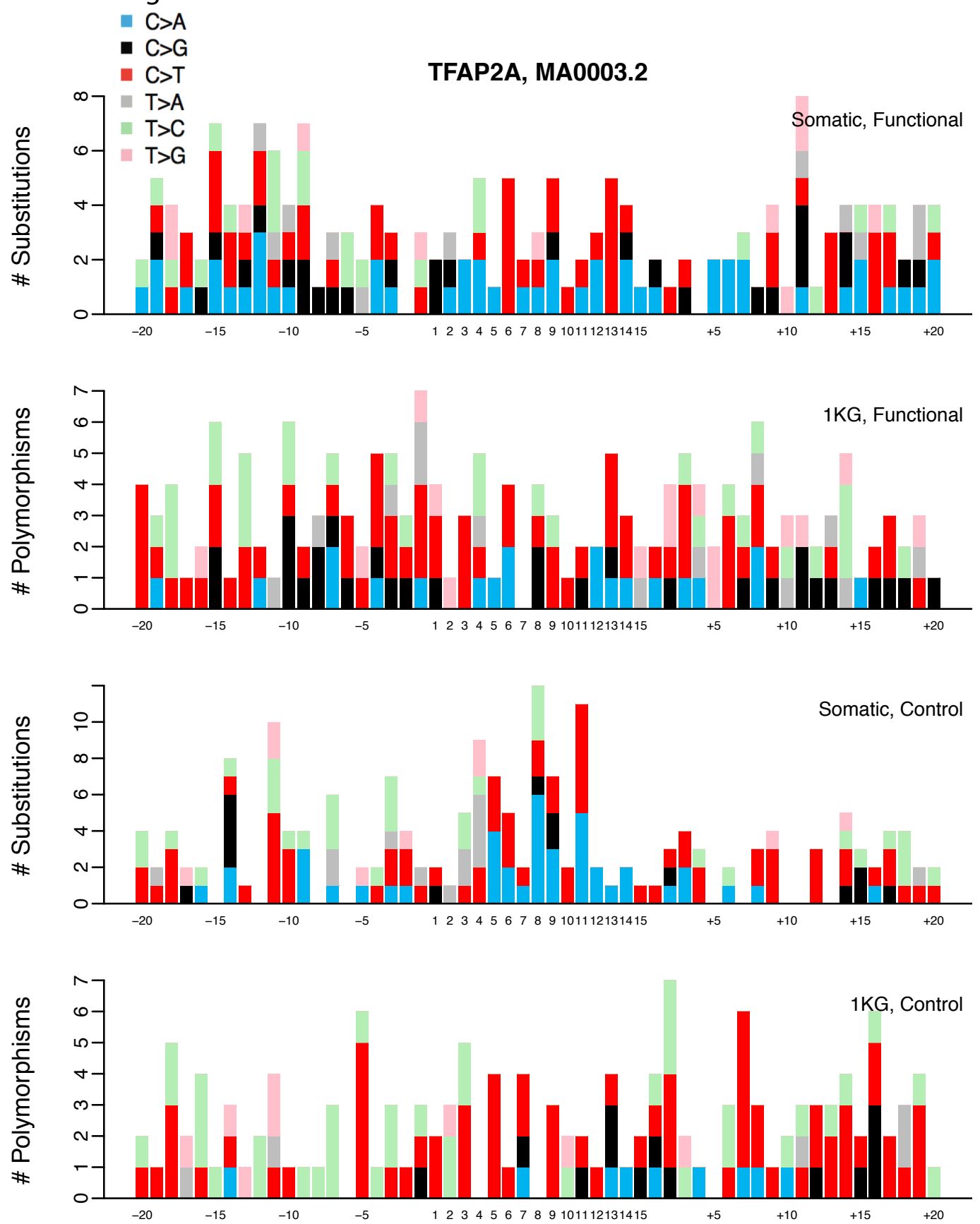

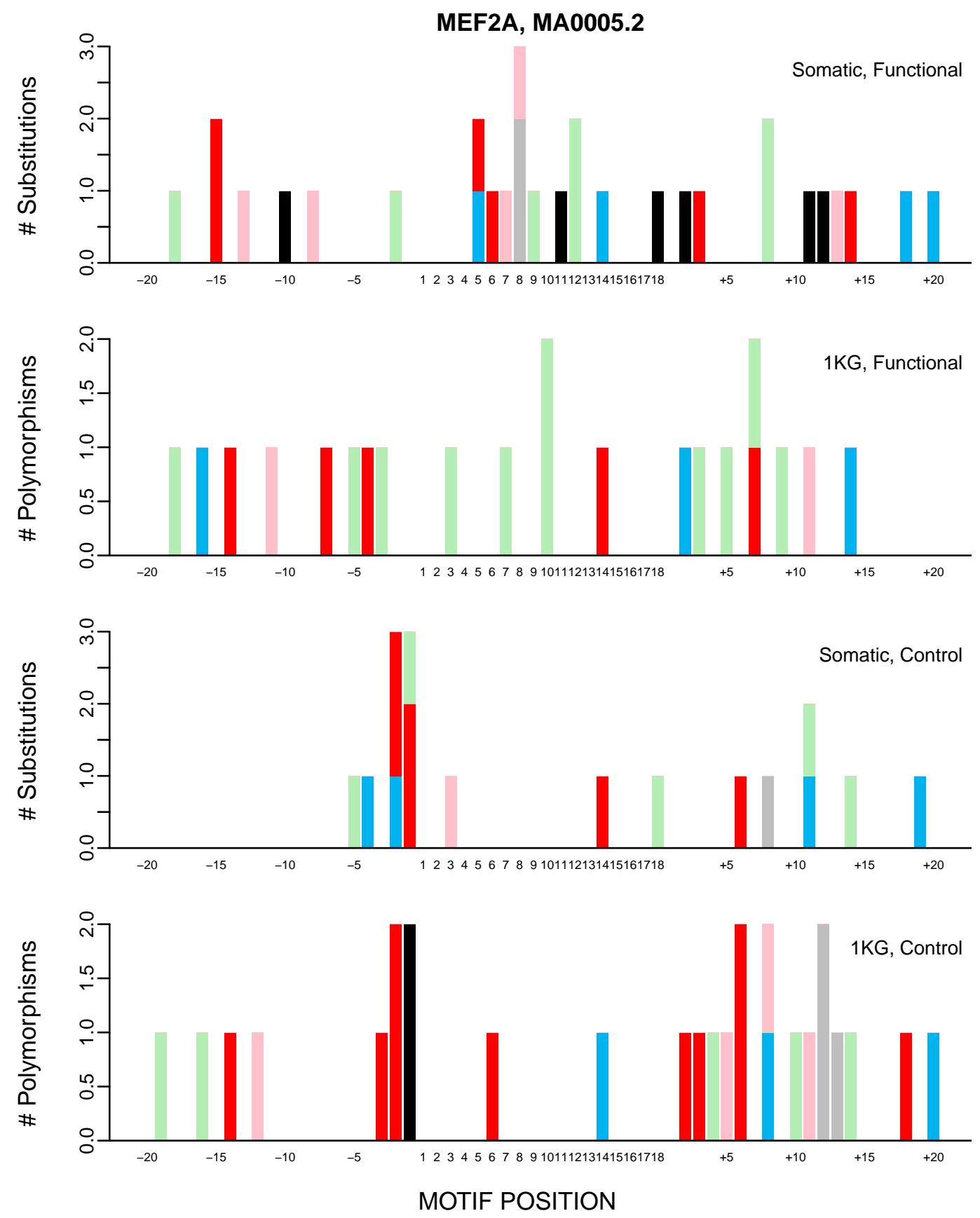


\section{AR, MA0007.2}
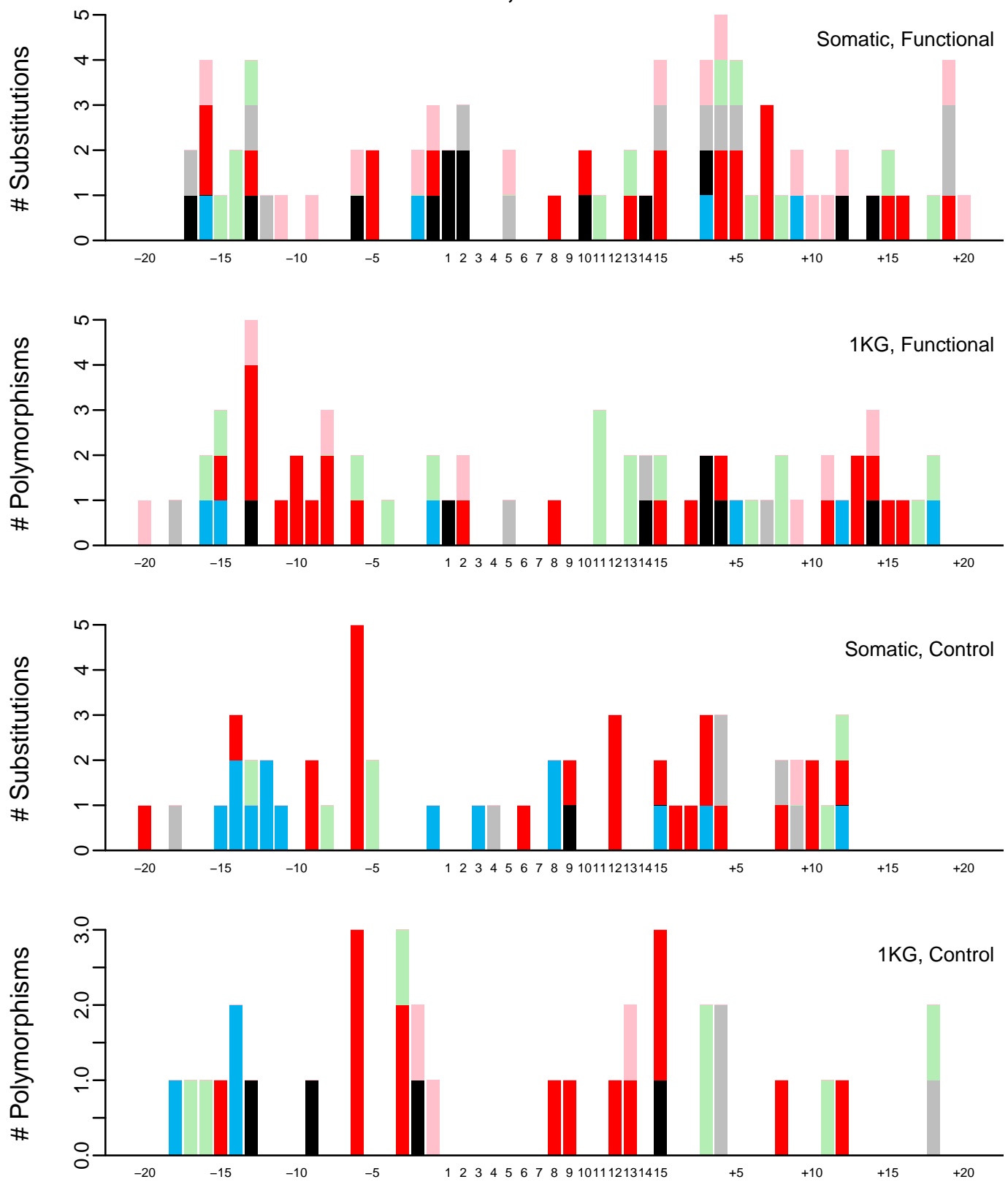
PAX5, MA0014.2
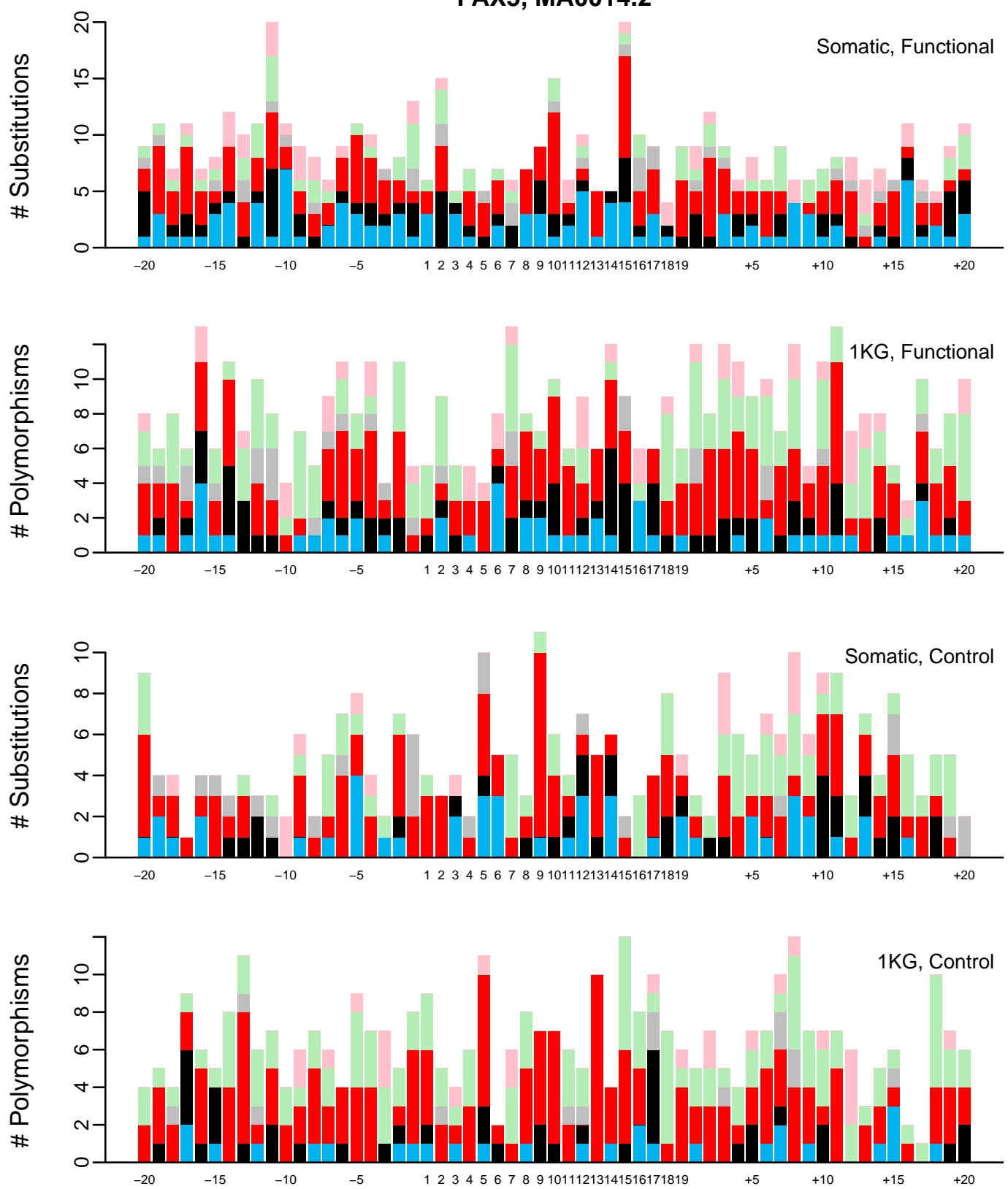
E2F1, MA0024.2
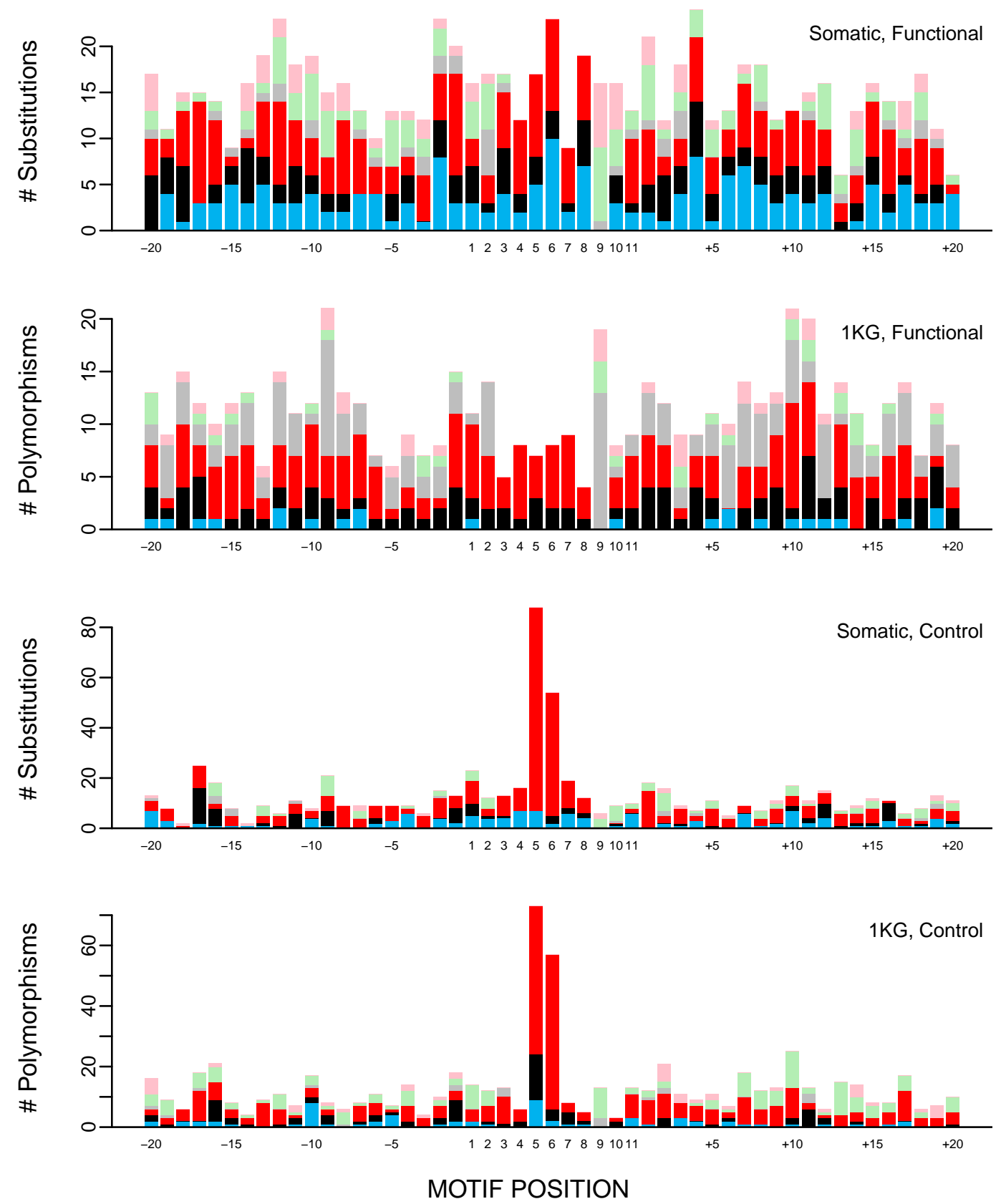
GATA1, MA0035.3
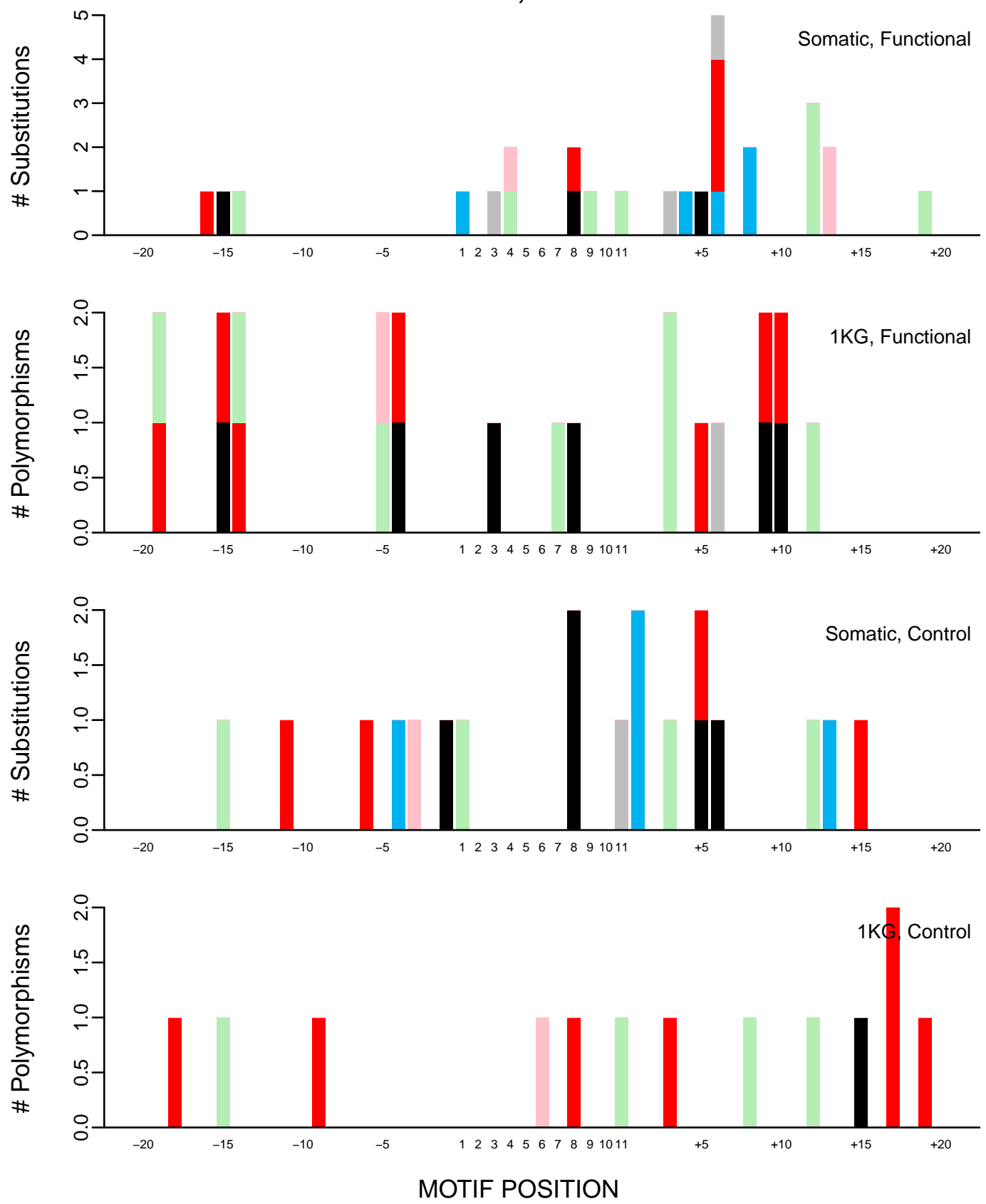

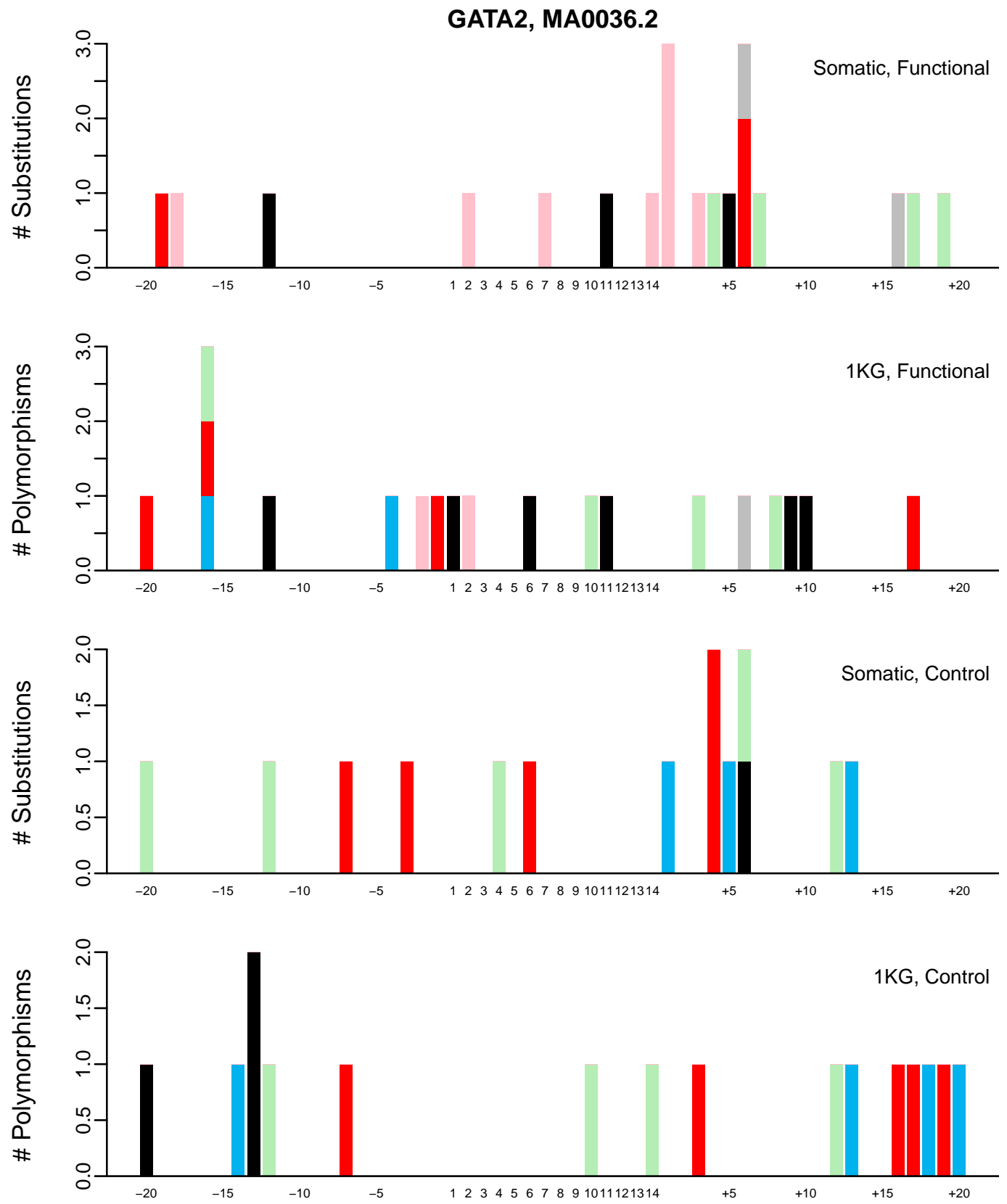

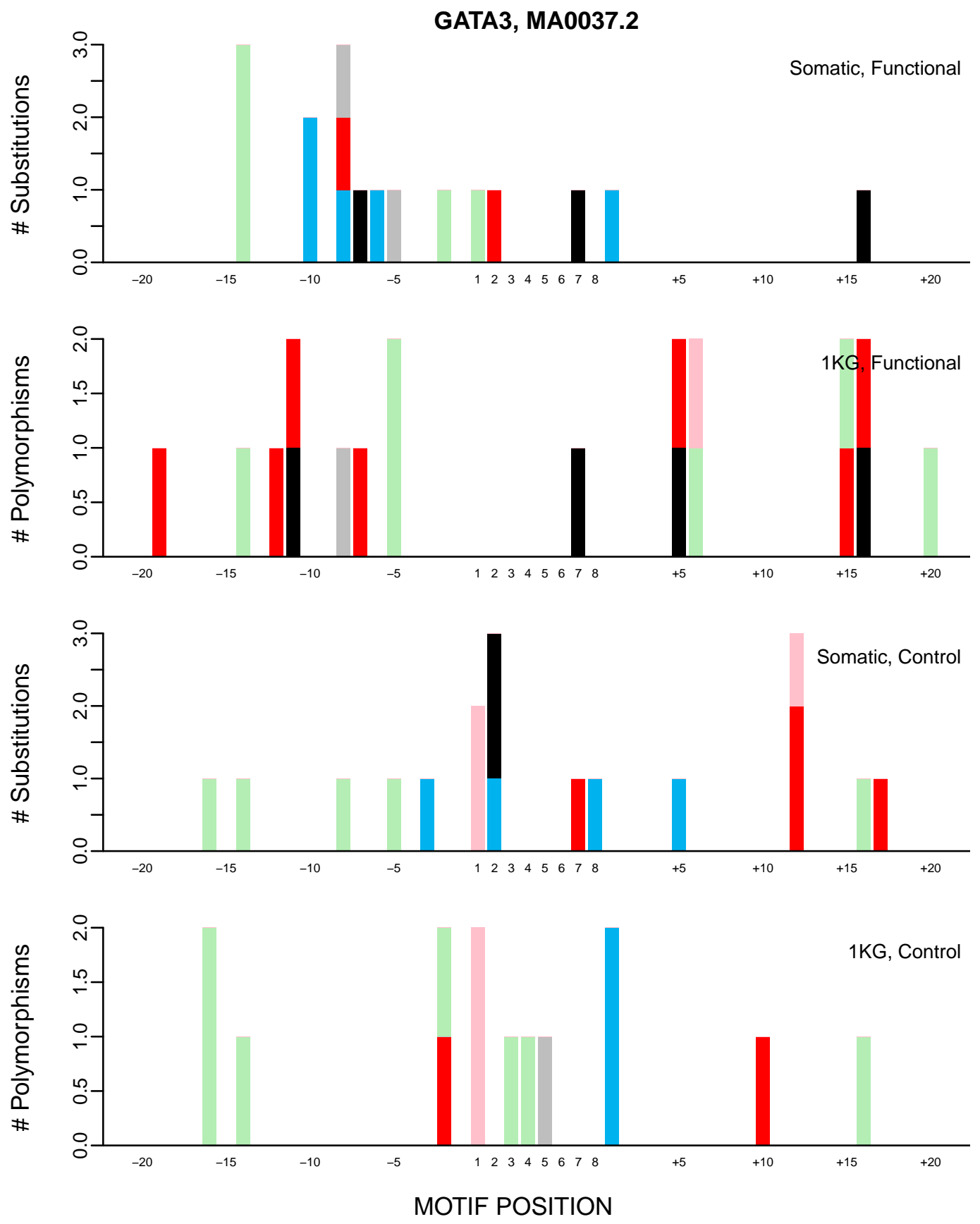
FOXA2, MA0047.2
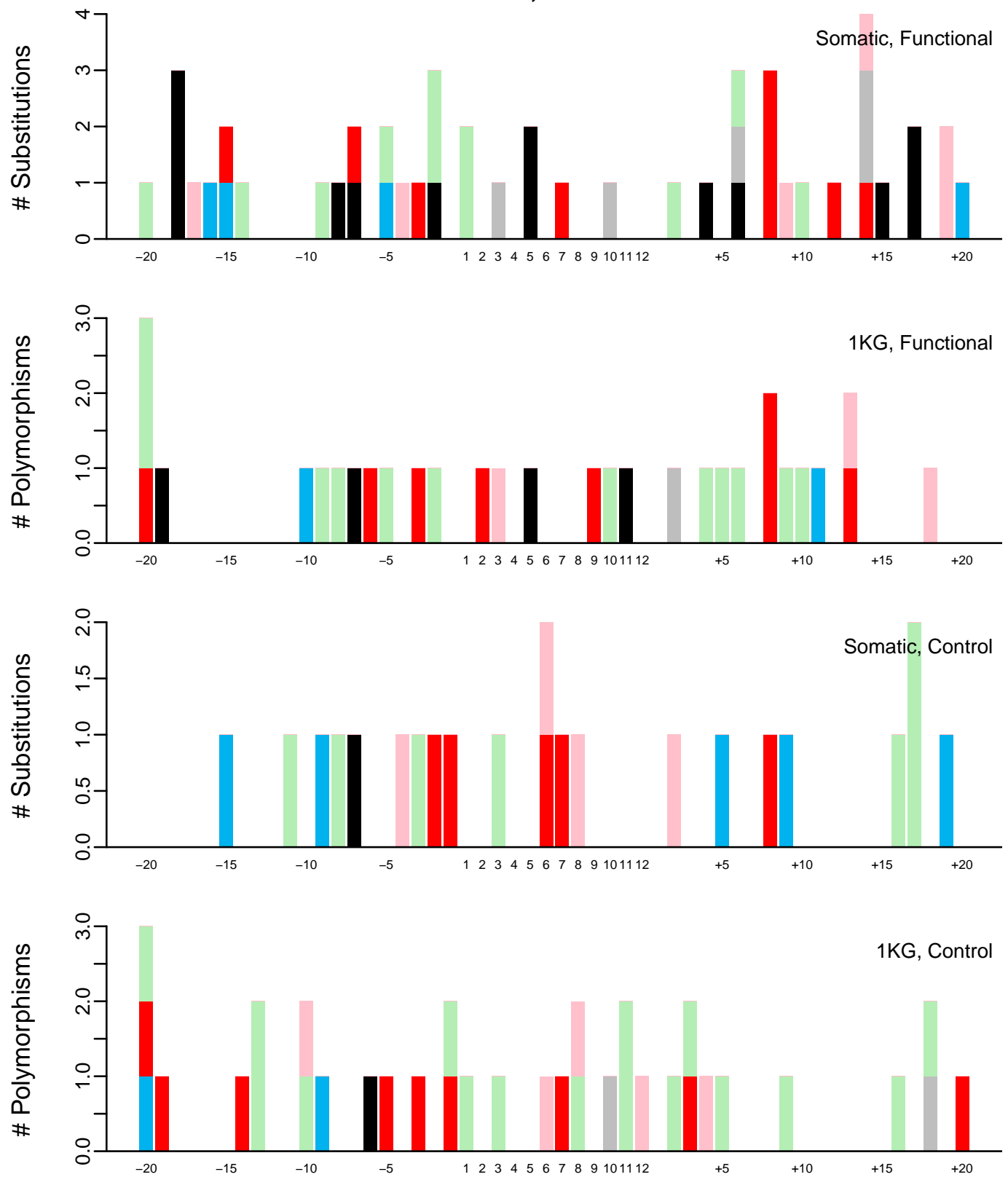
IRF1, MA0050.2
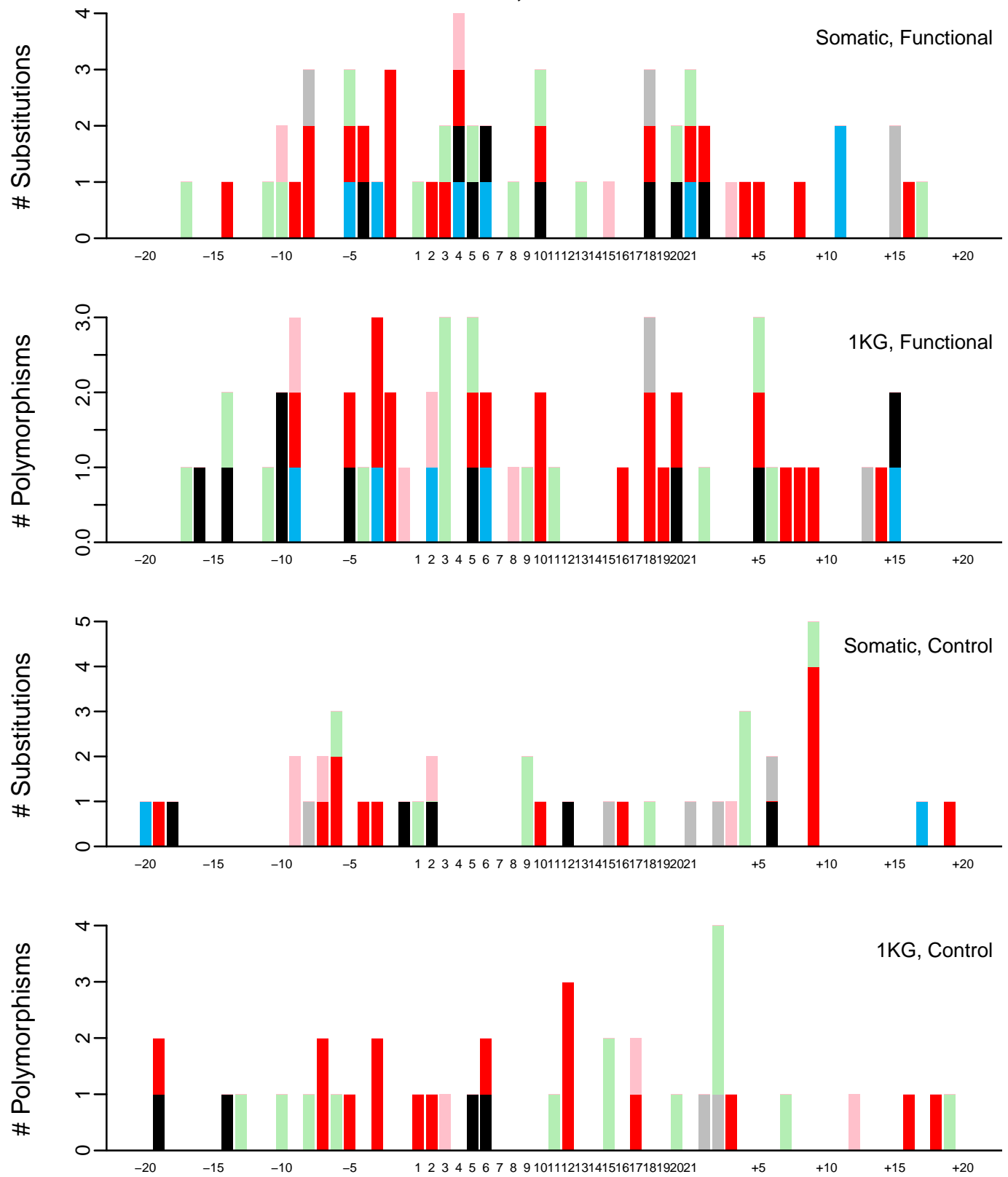

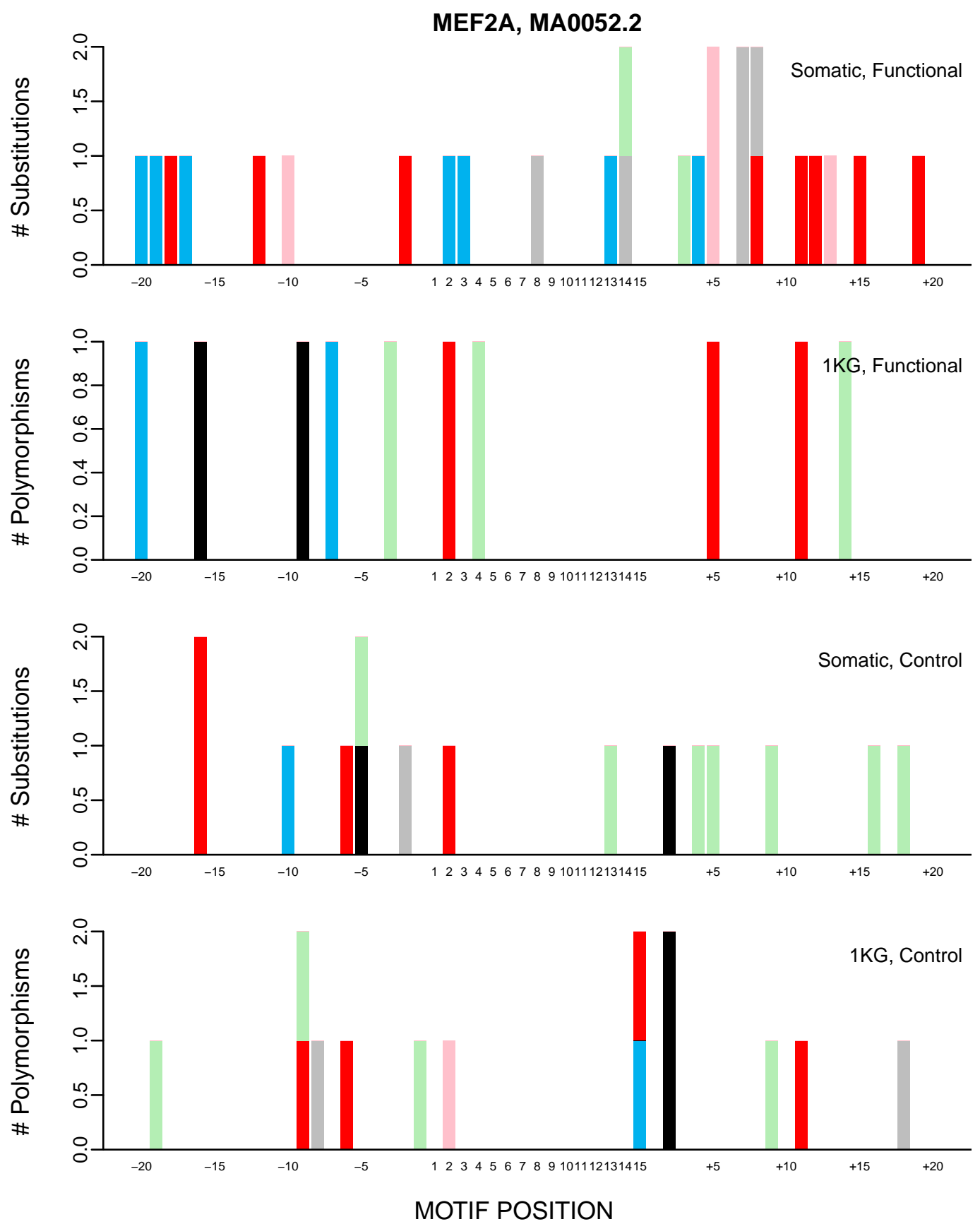
MAX, MA0058.2
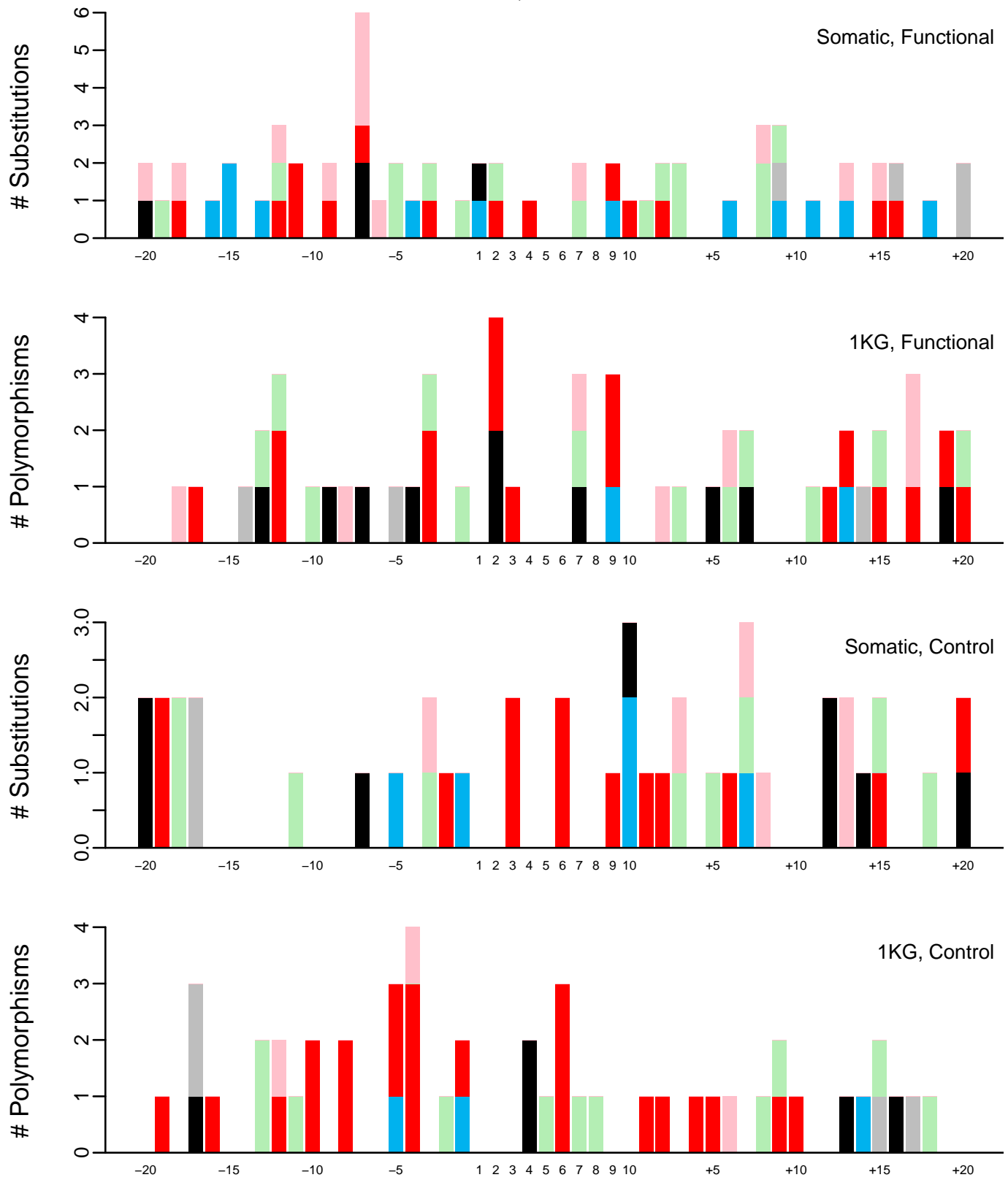


\section{NFYA, MA0060.2}
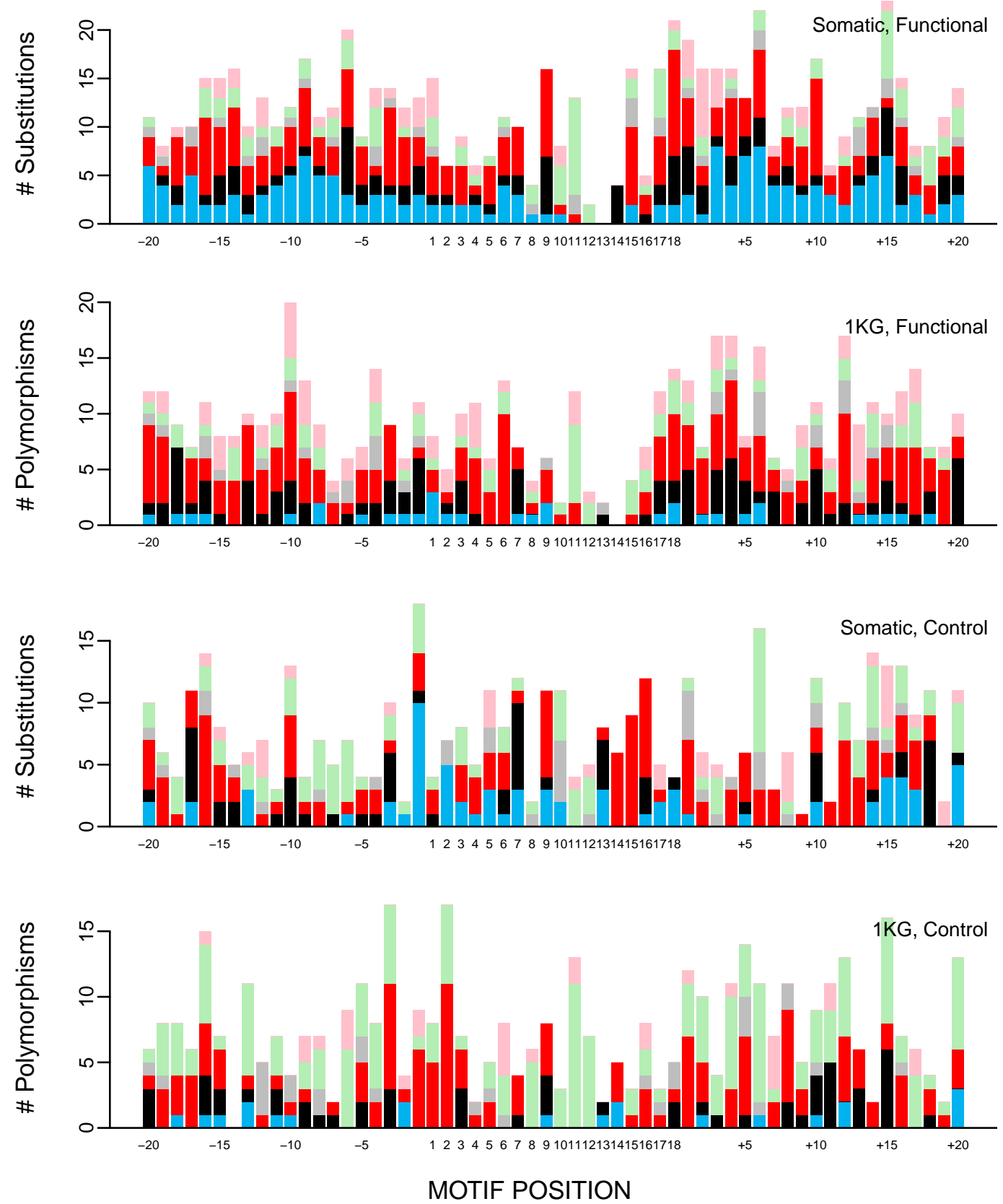
GABP, MA0062.2
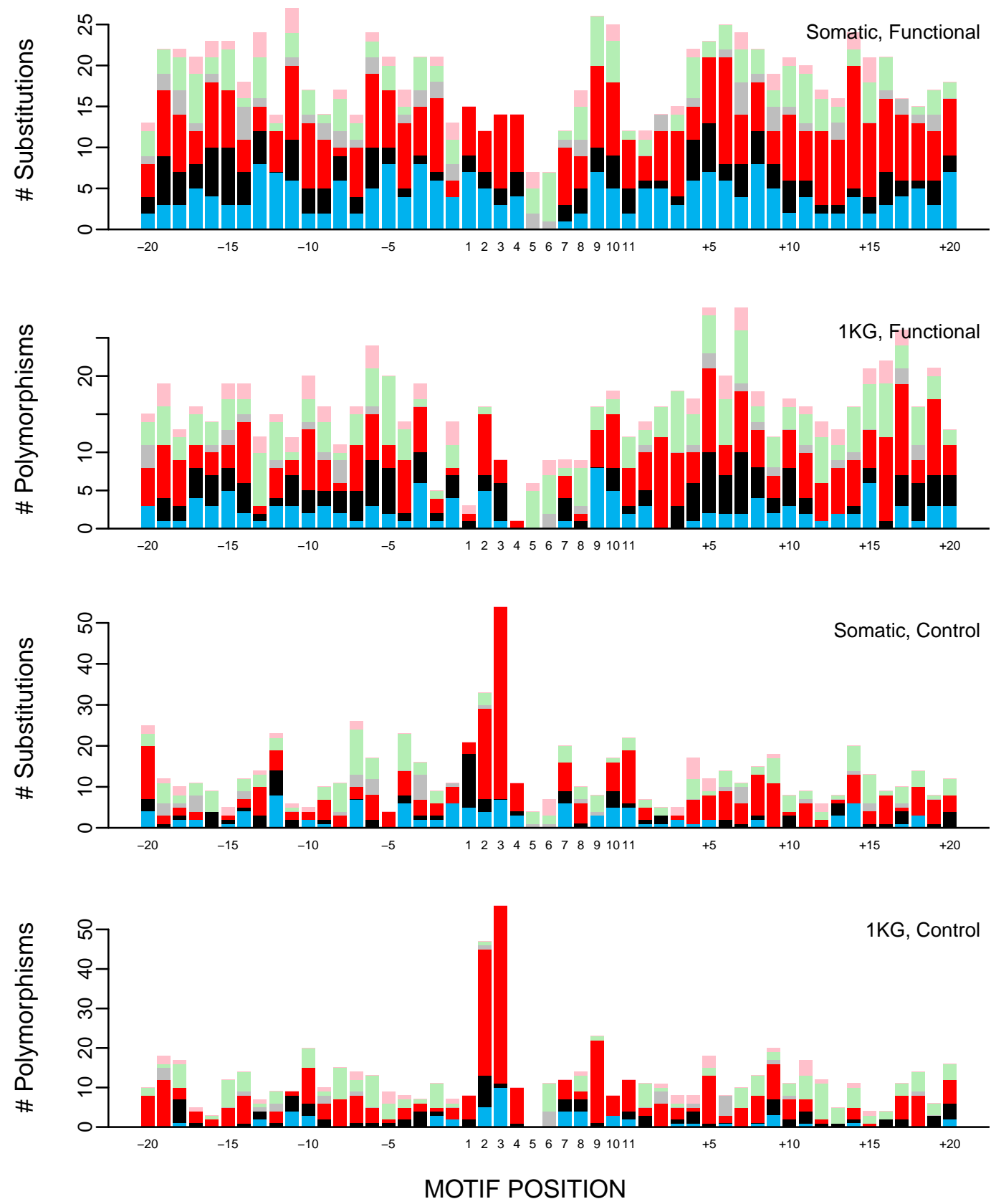


\section{ELK4, MA0076.2}
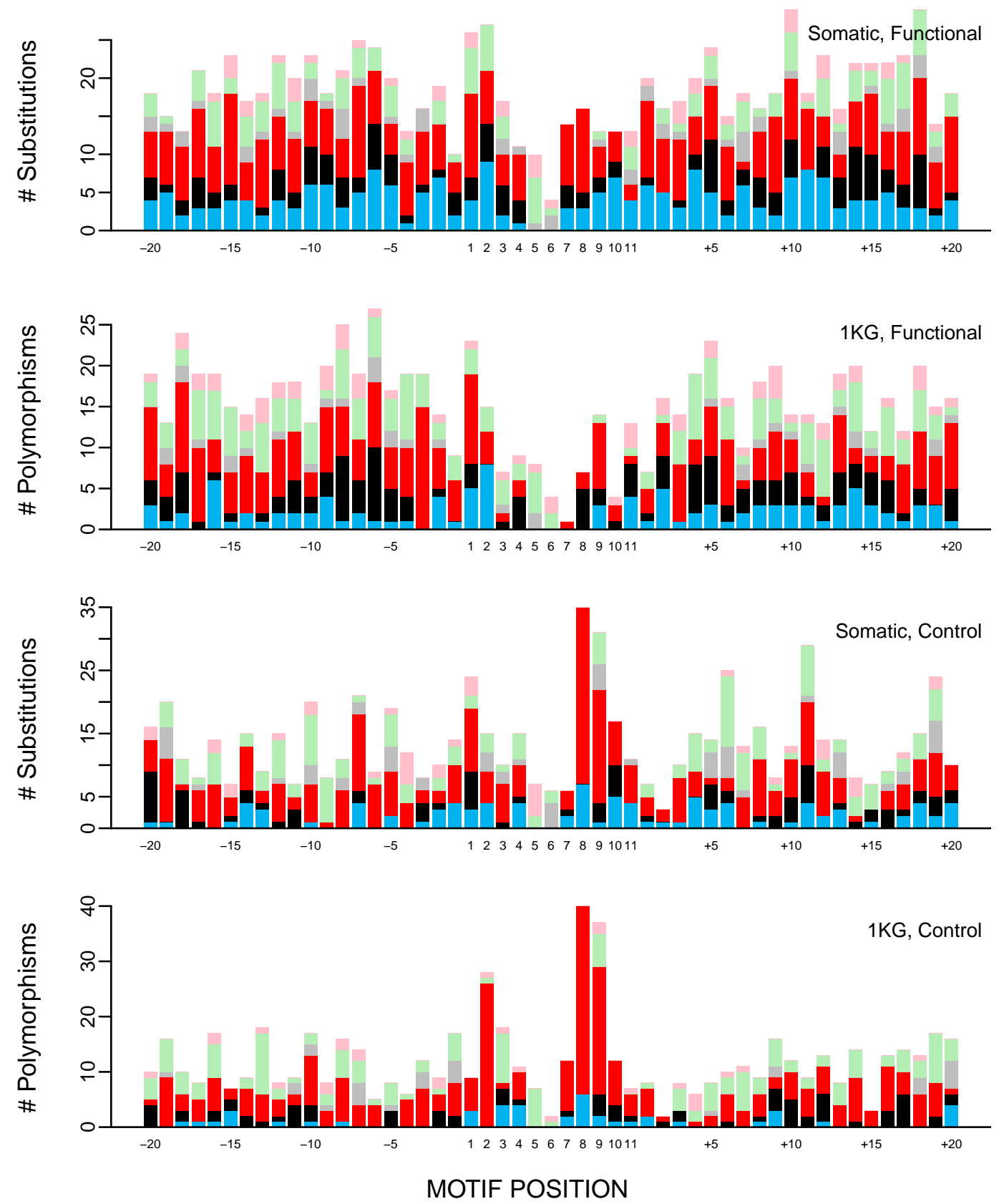
SP1, MA0079.3
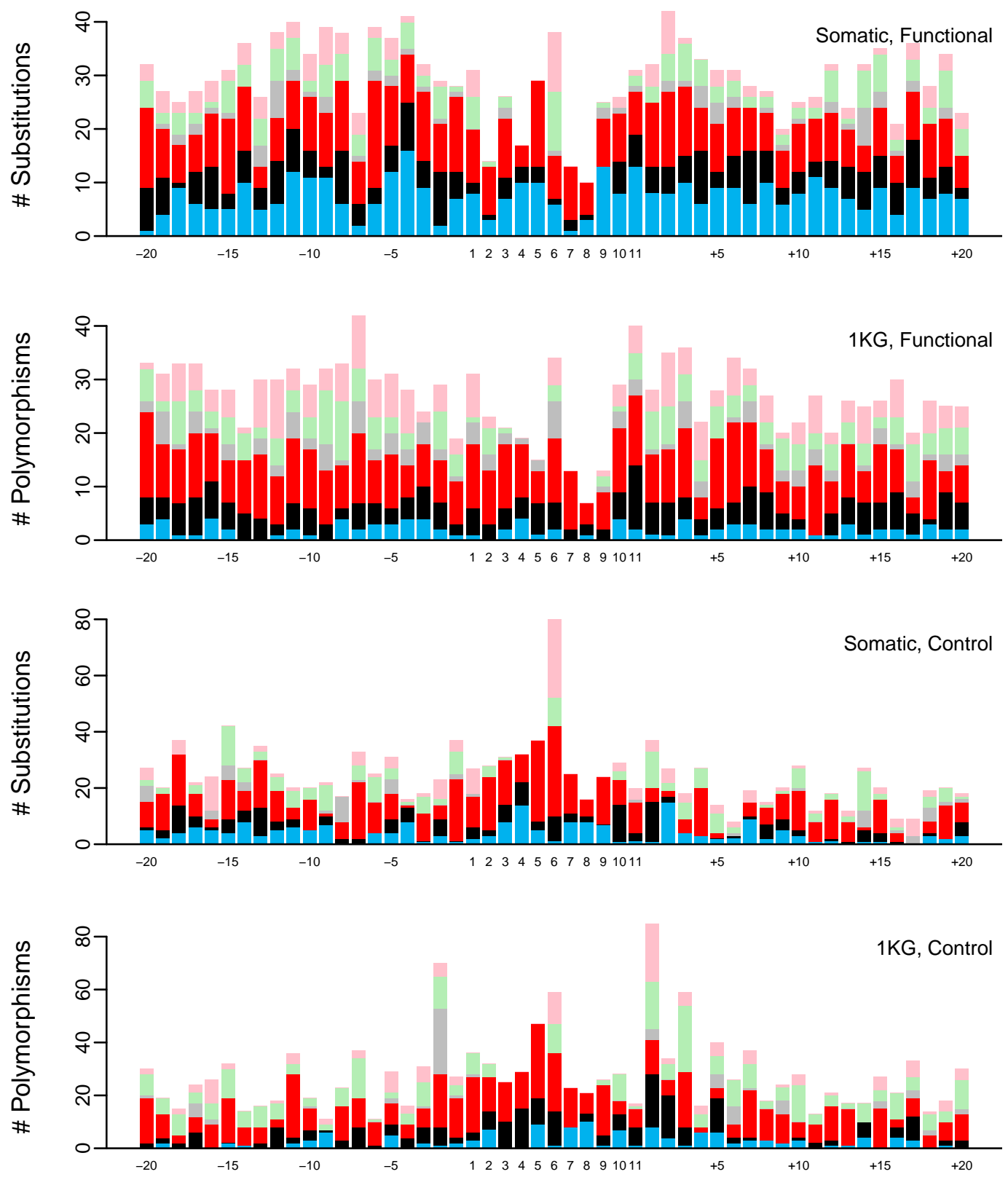
PU1, MA0080.3
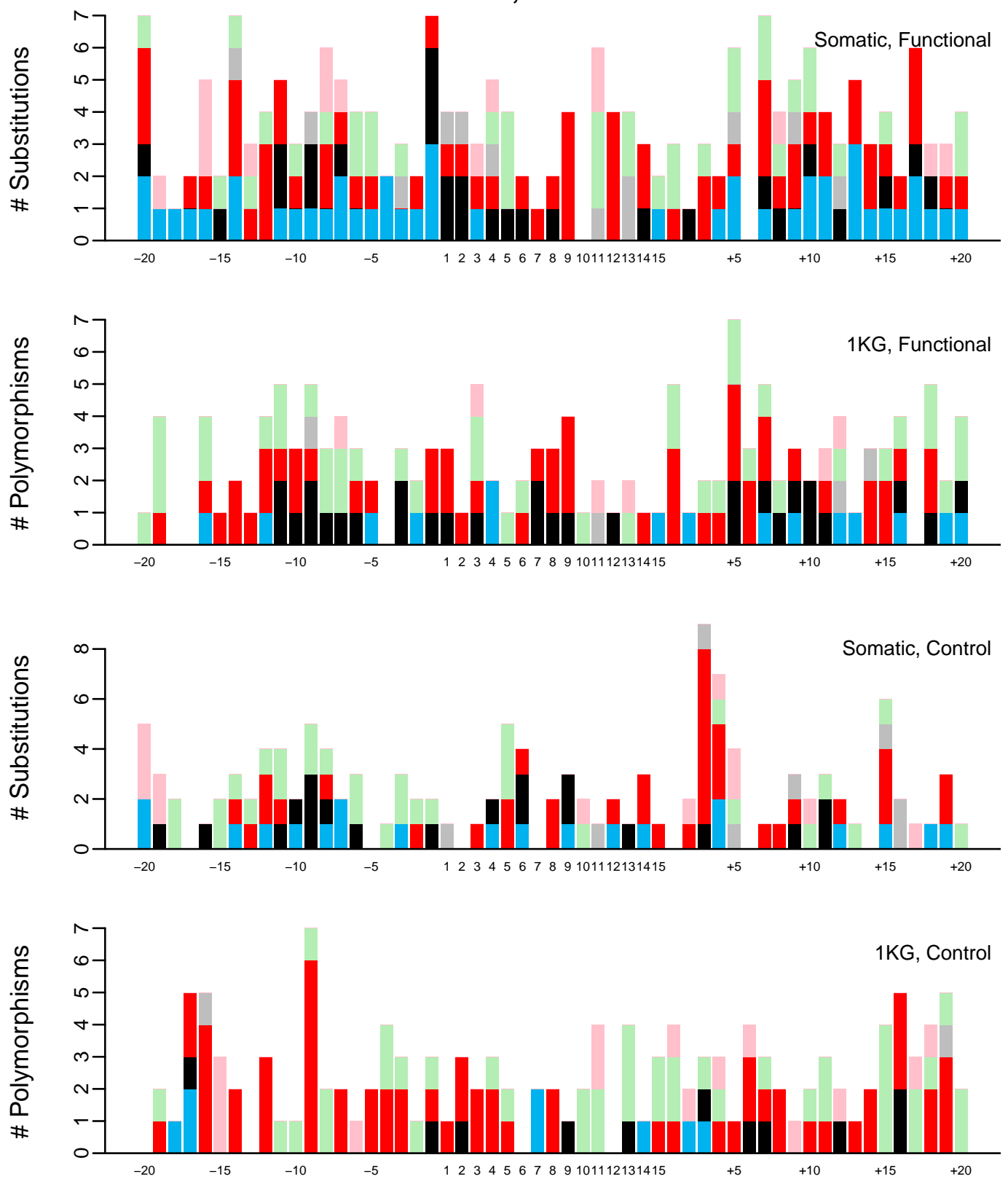
SRF, MA0083.2
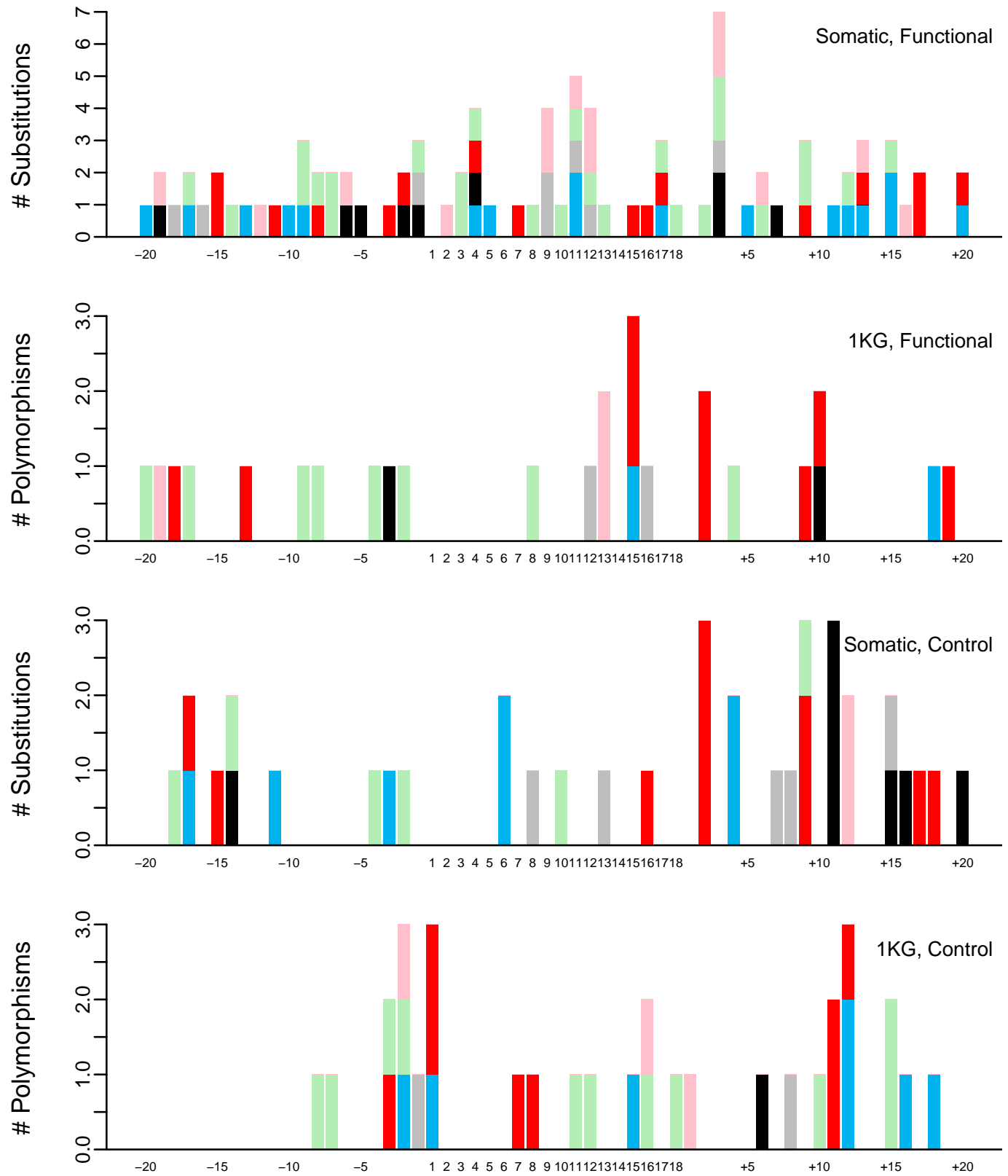
USF1, MA0093.2
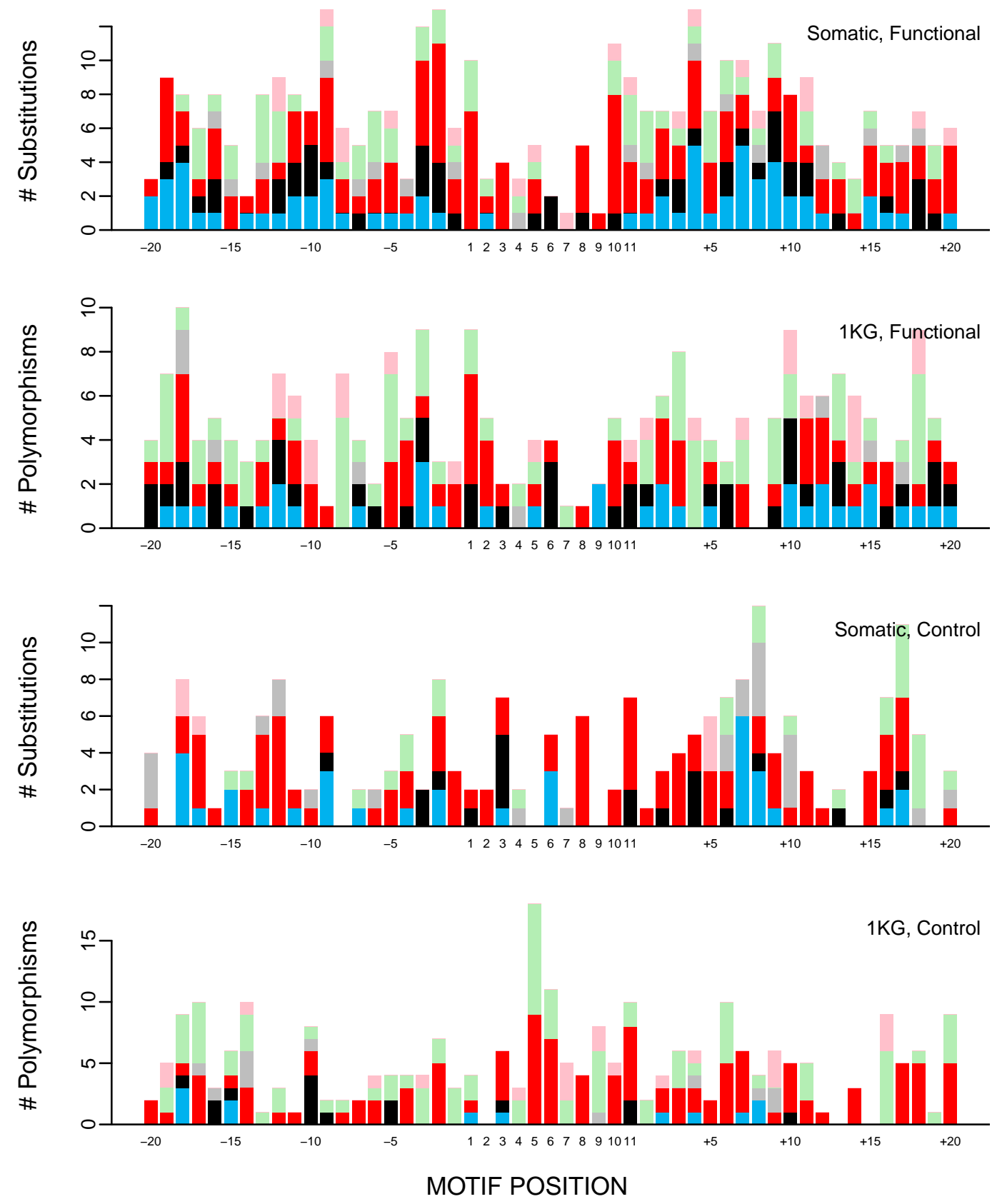


\section{YY1, MA0095.2}
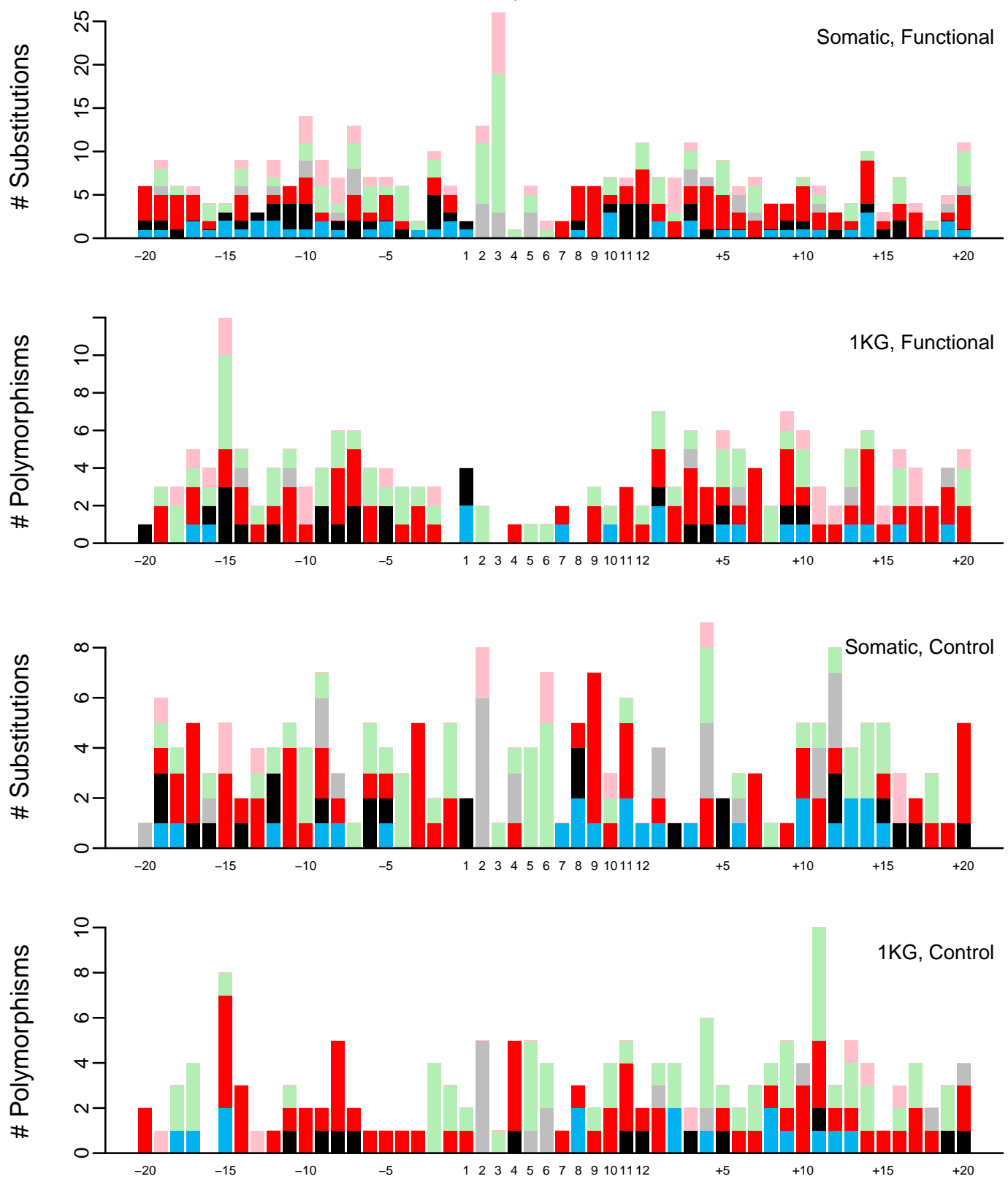


\section{ETS1, MA0098.2}
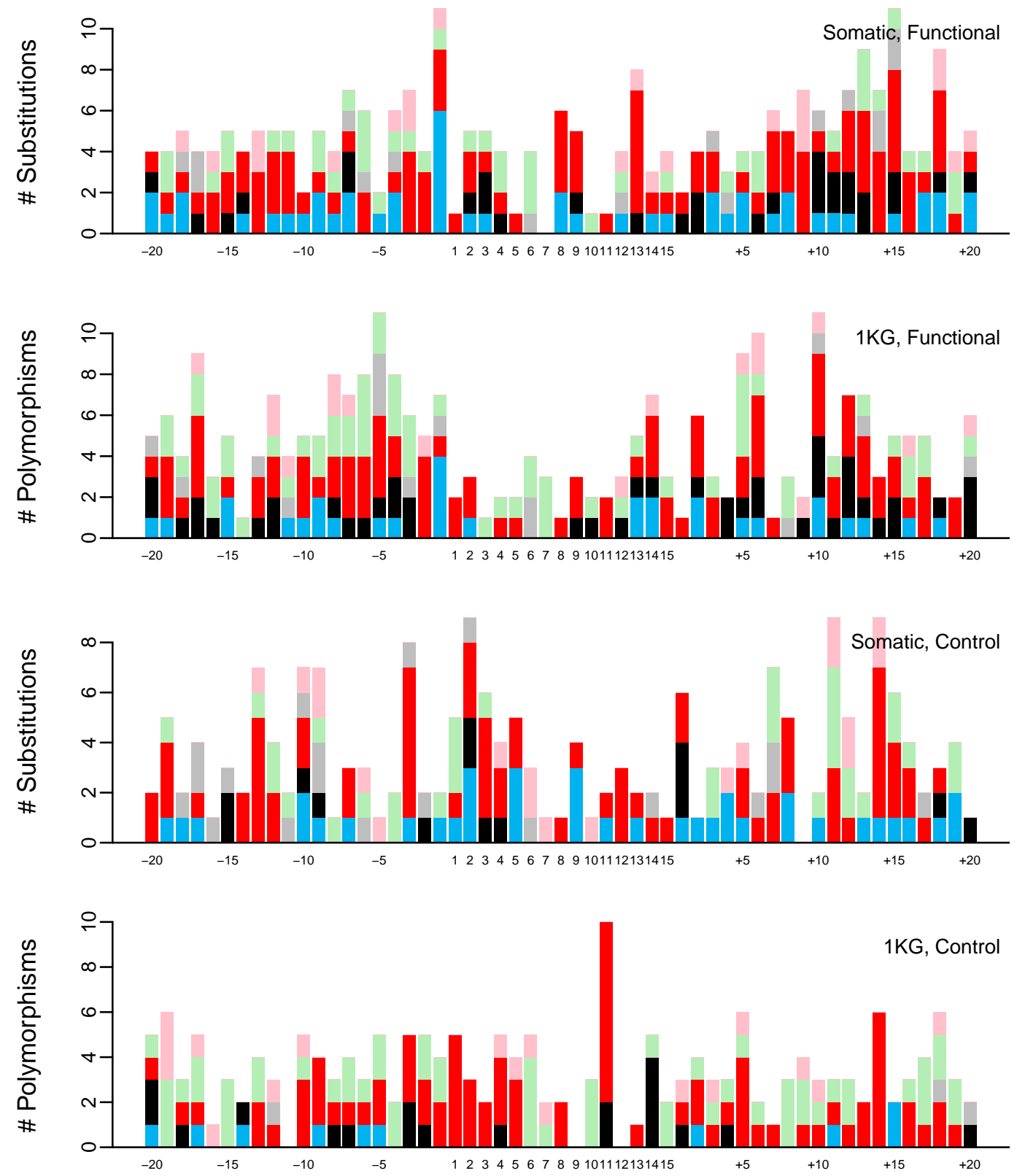
CEBPA, MA0102.3
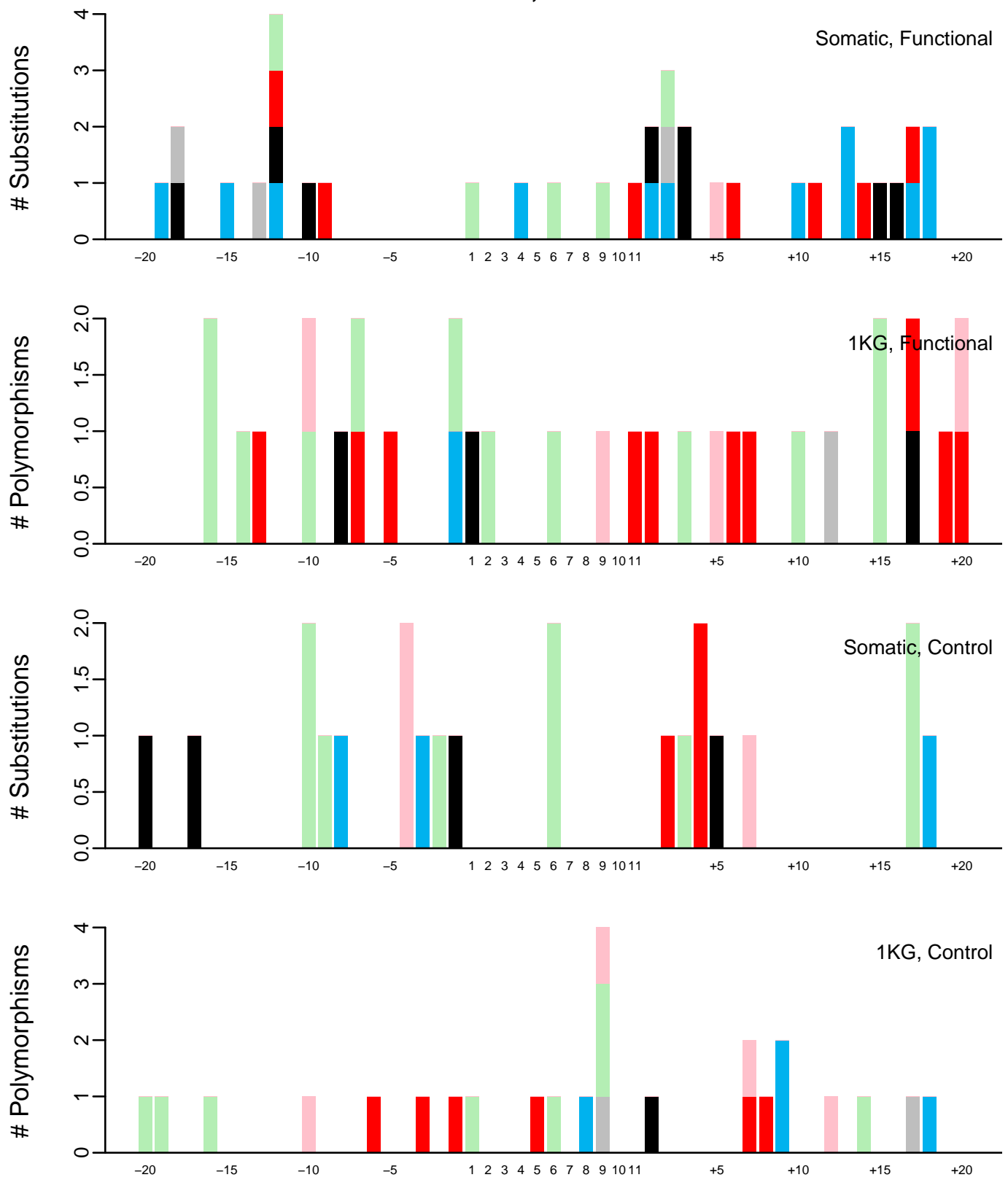


\section{ZEB1, MA0103.2}
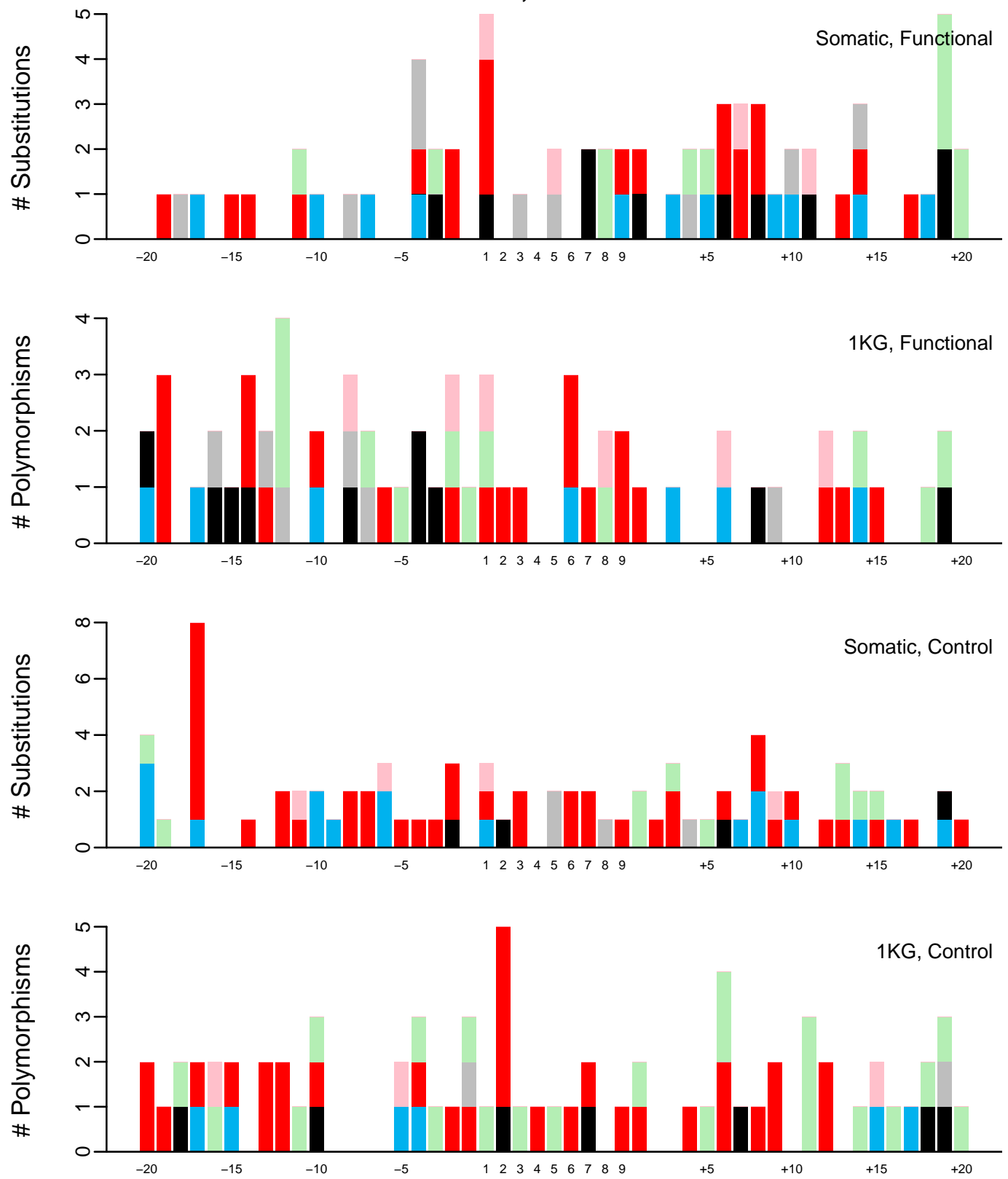
NFKB, MA0105.3
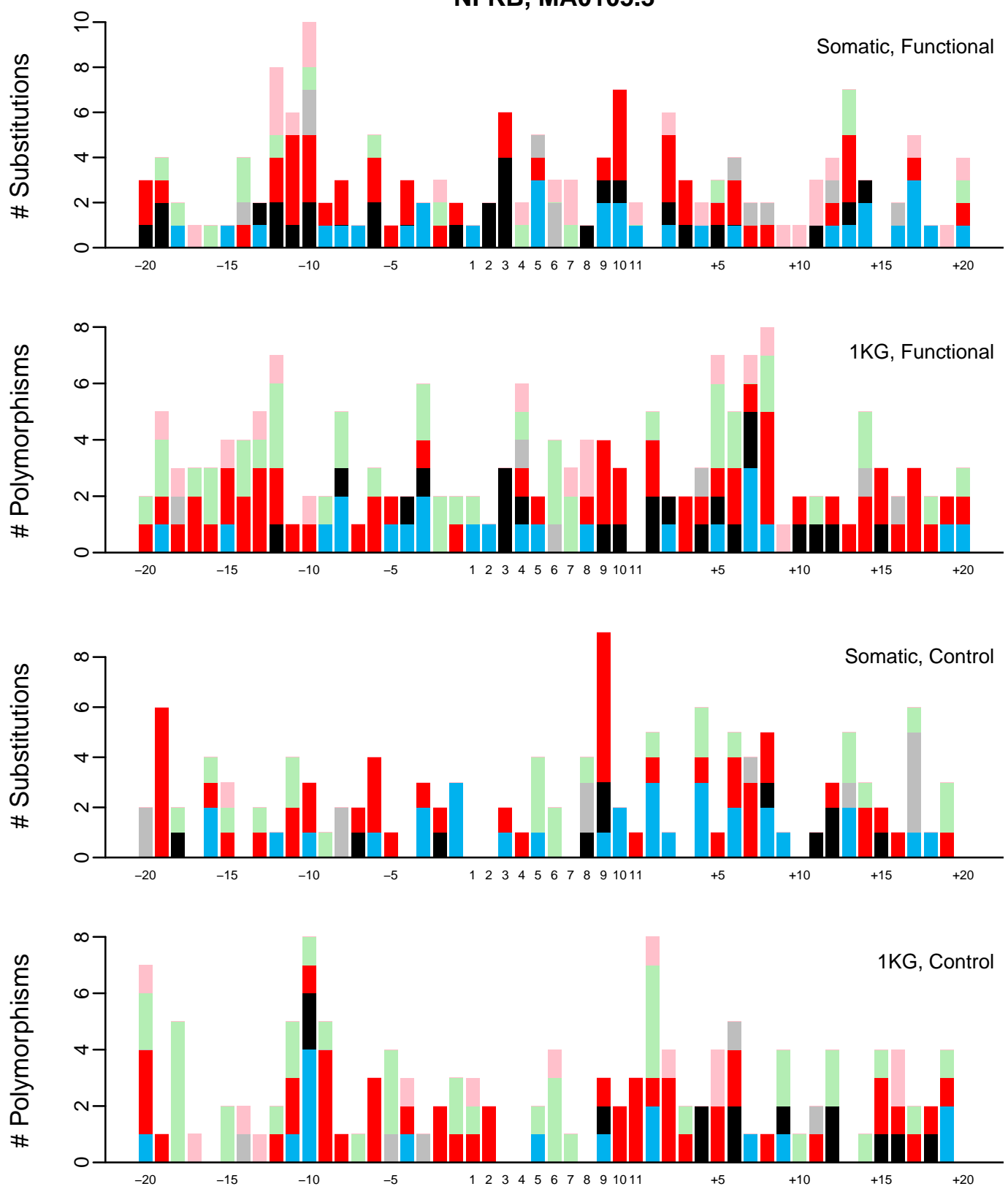
TP53, MA0106.2
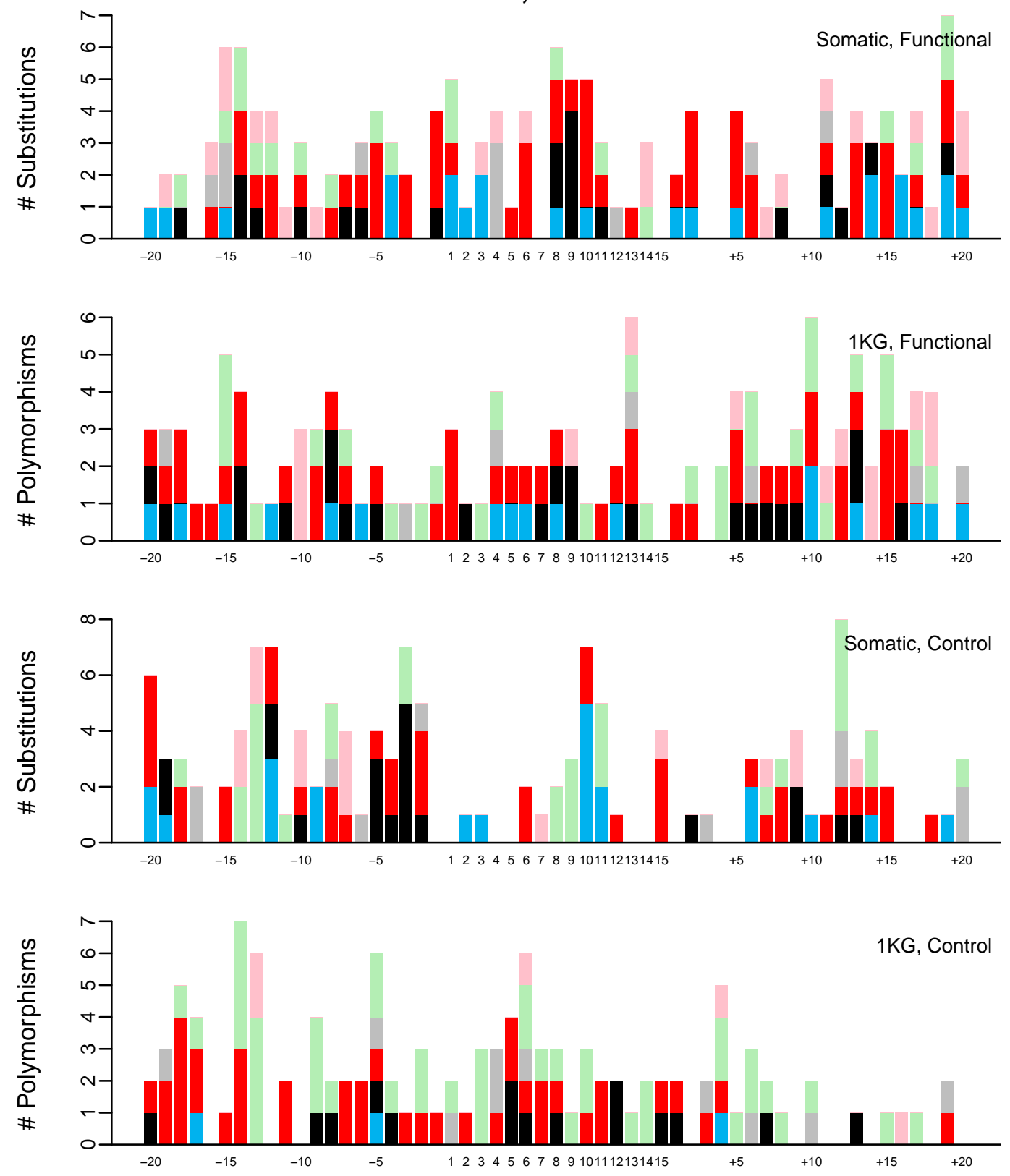
HNF4A, MA0114.2
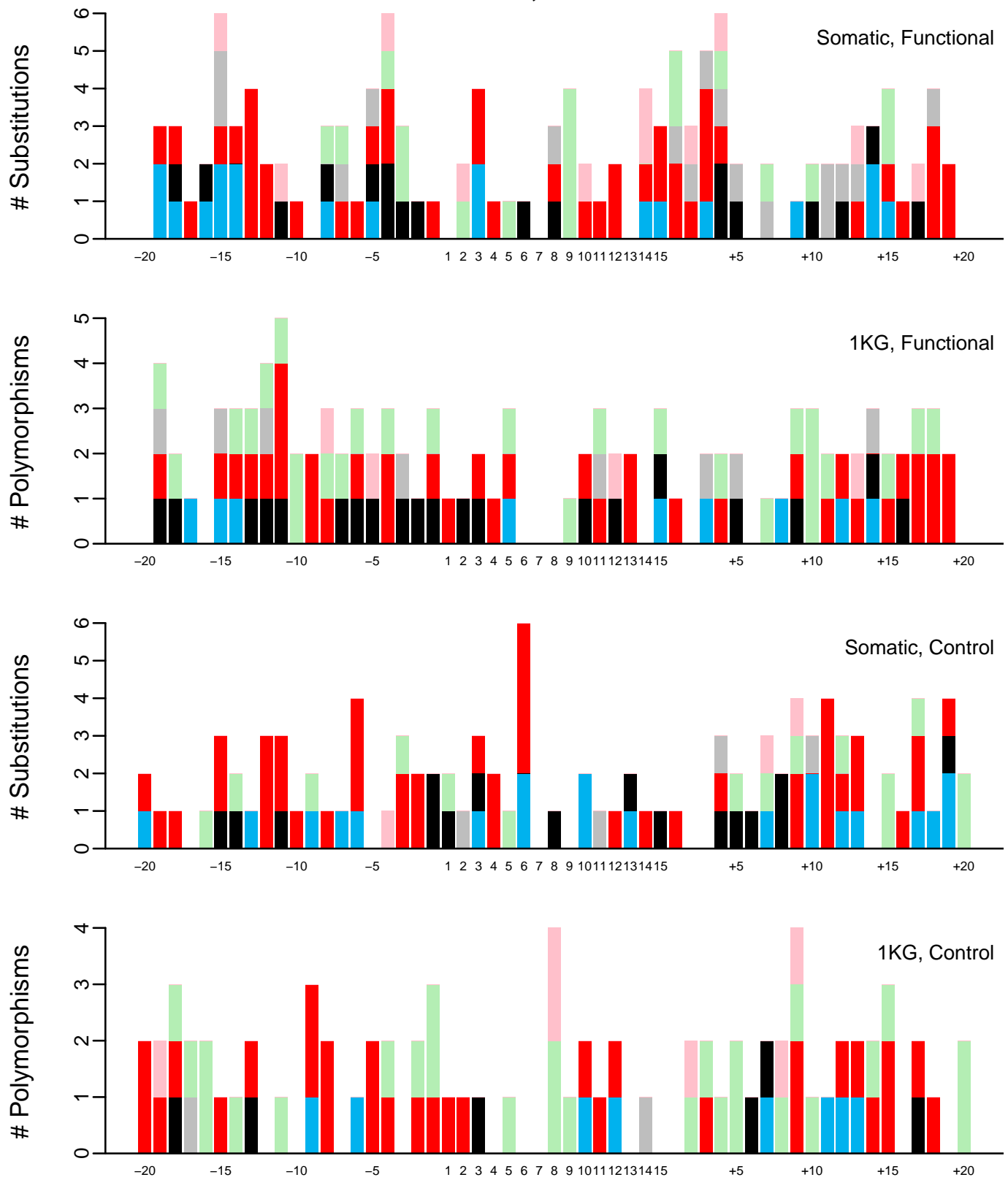


\section{STAT1, MA0137.3}
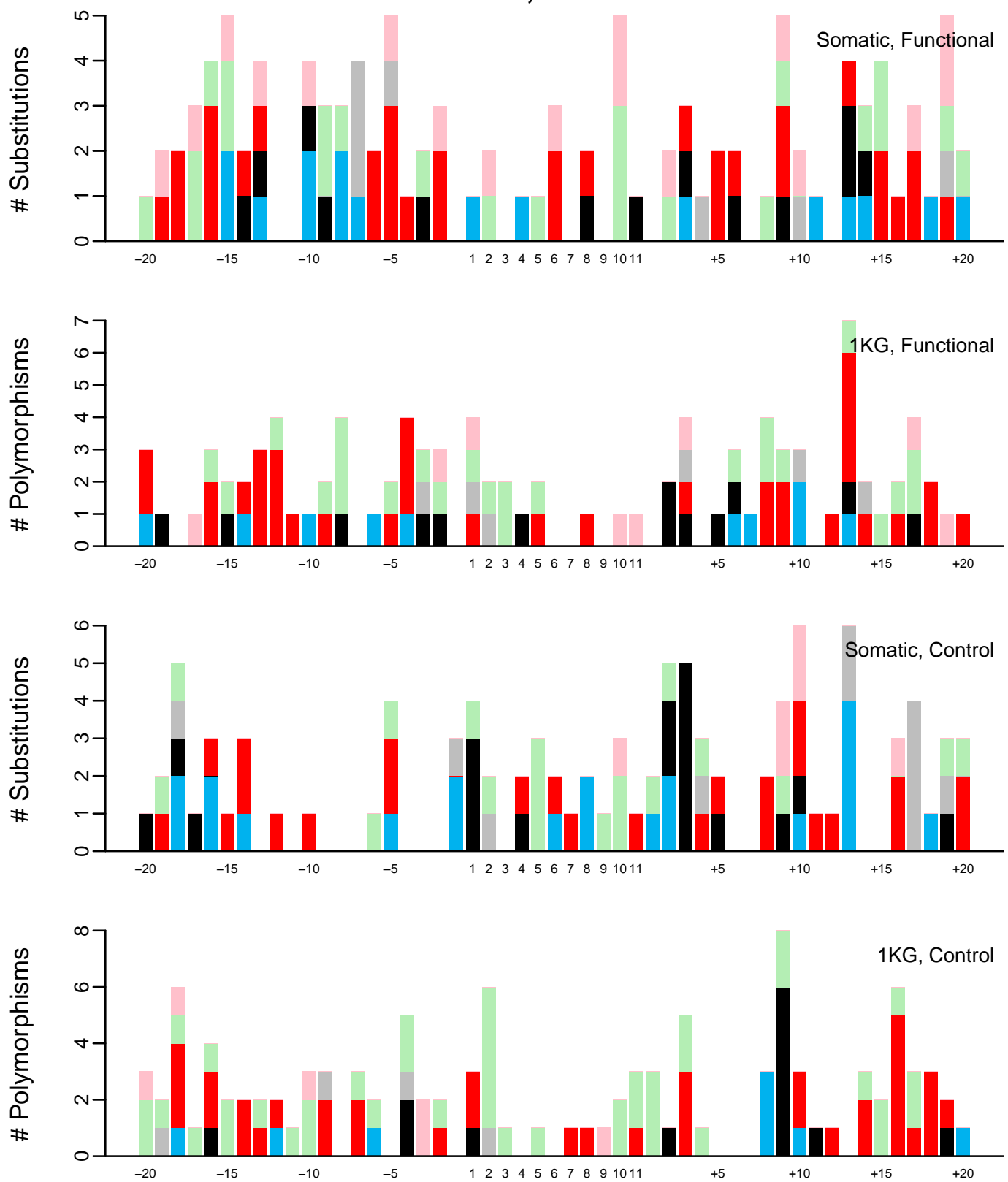


\section{NRSF, MA0138.2}
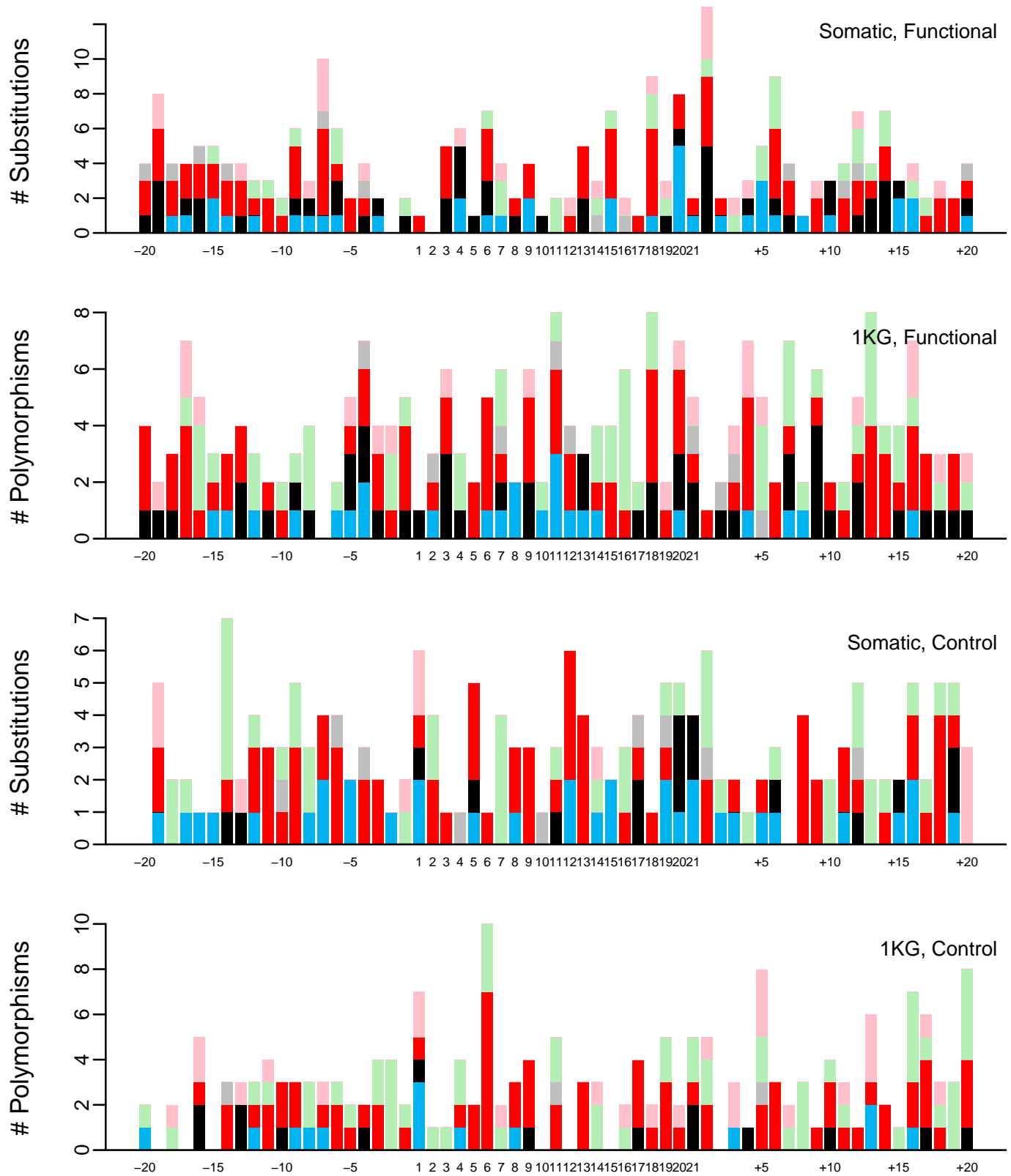
CTCF, MA0139.1
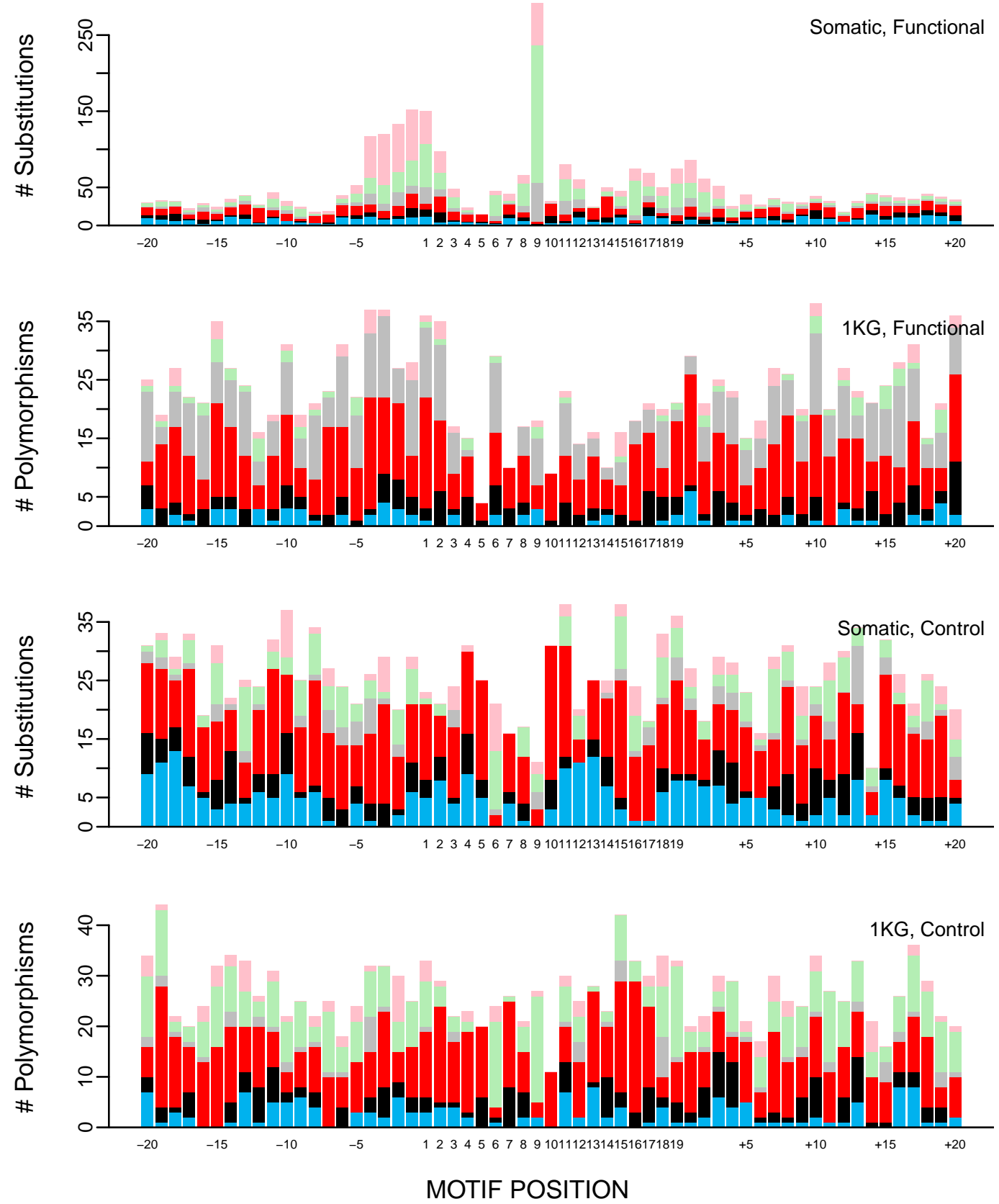
TAL1::GATA1, MA0140.2
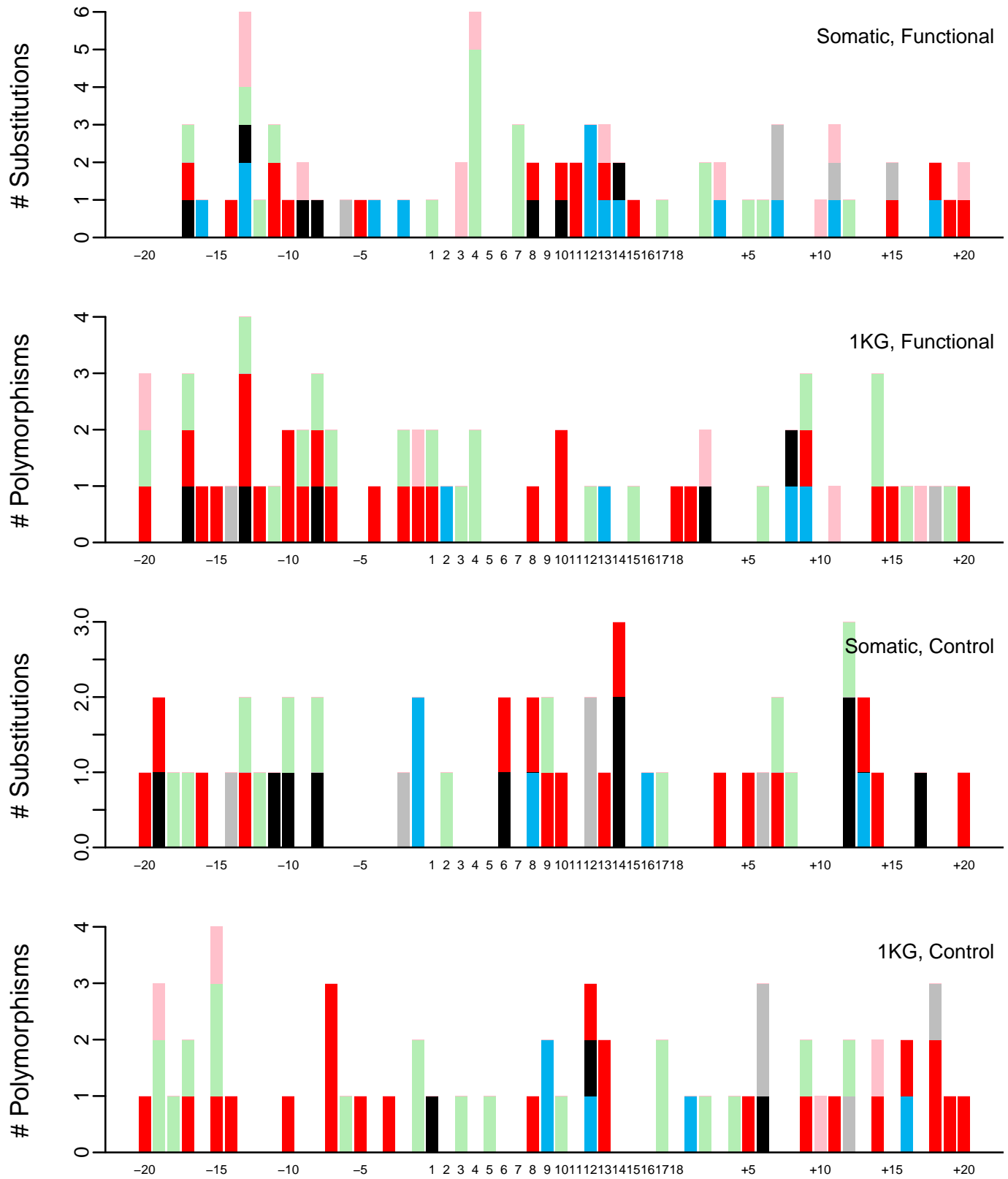
STAT3, MA0144.2
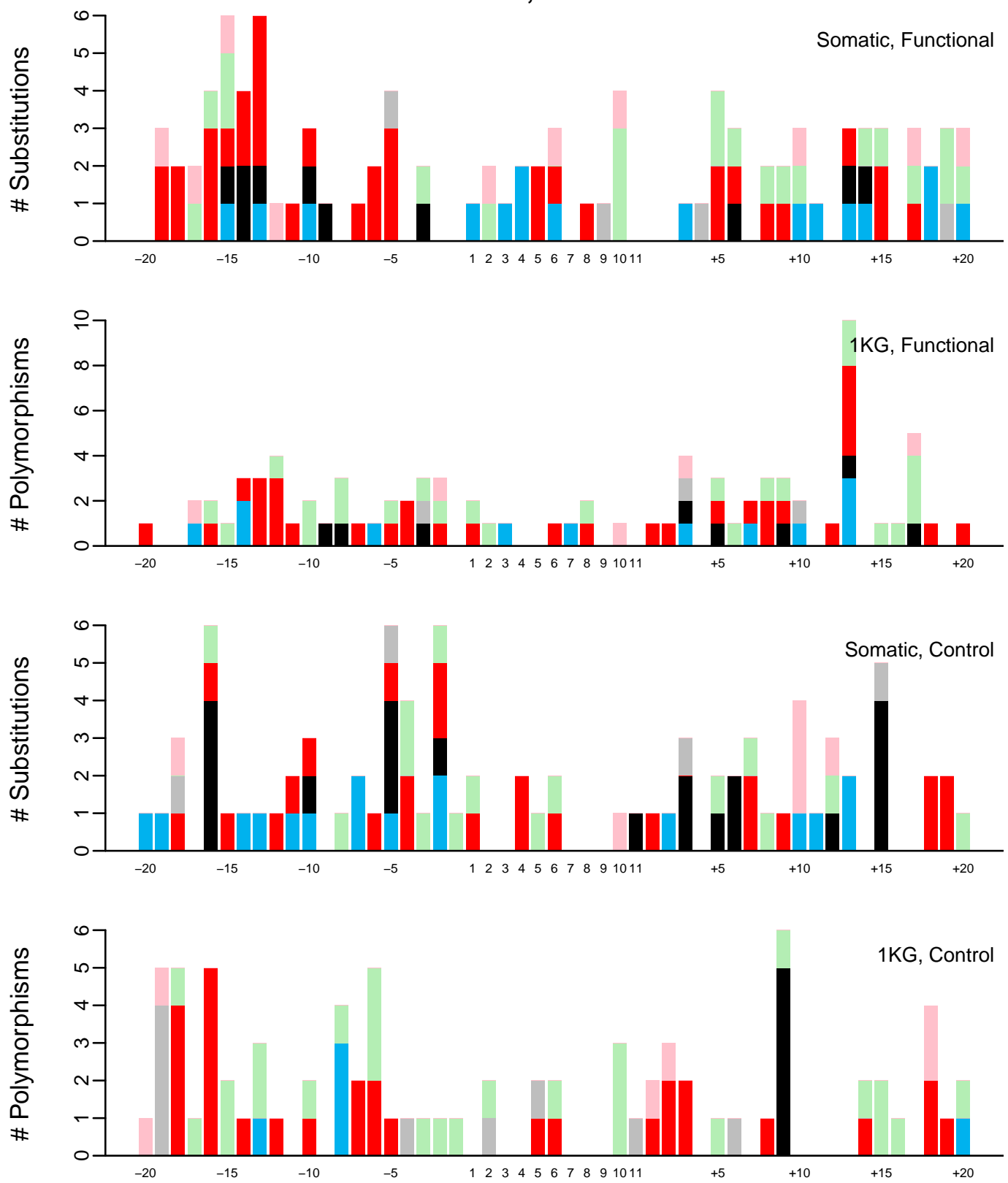
CMYC, MA0147.2
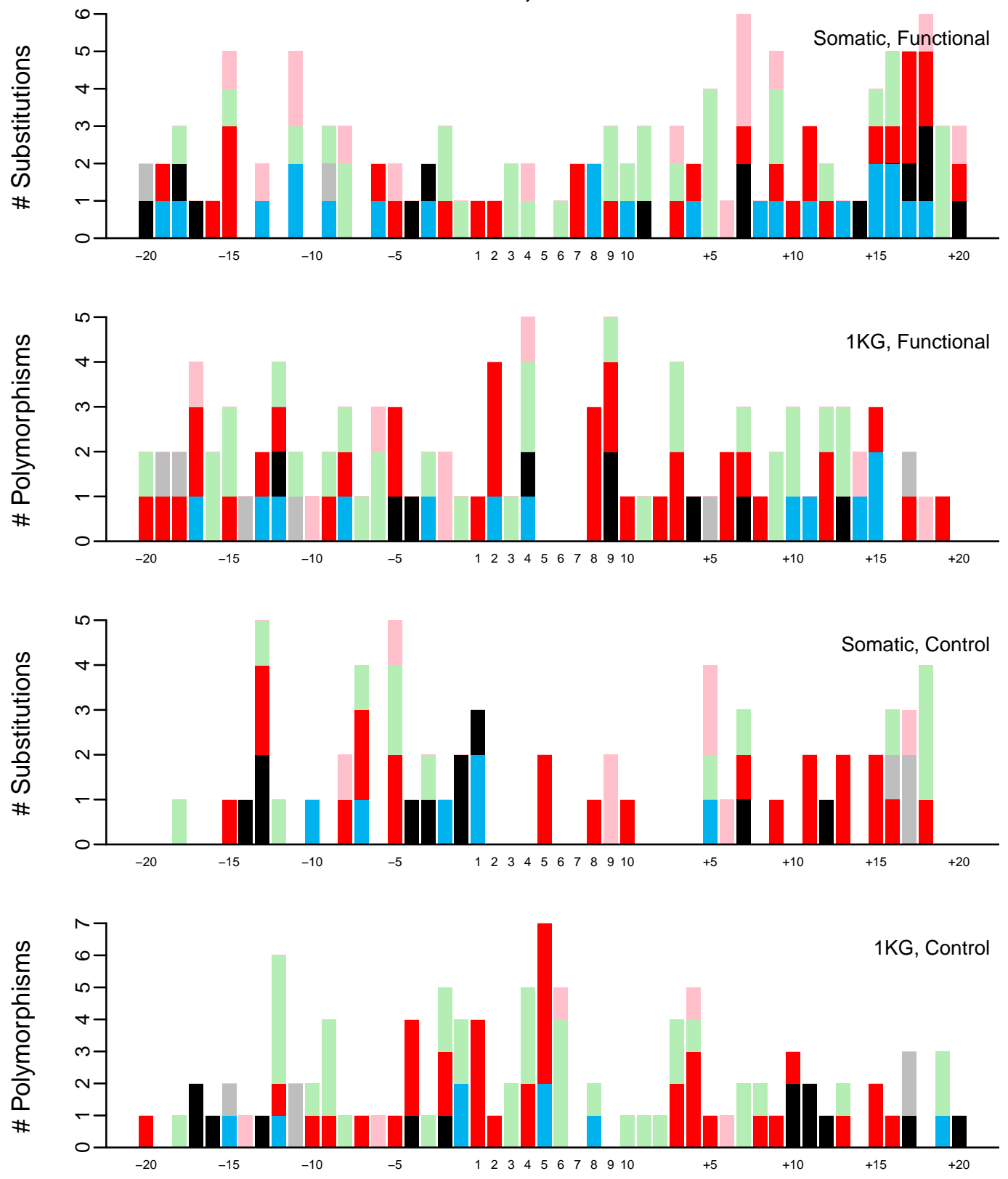
FOXA1, MA0148.3
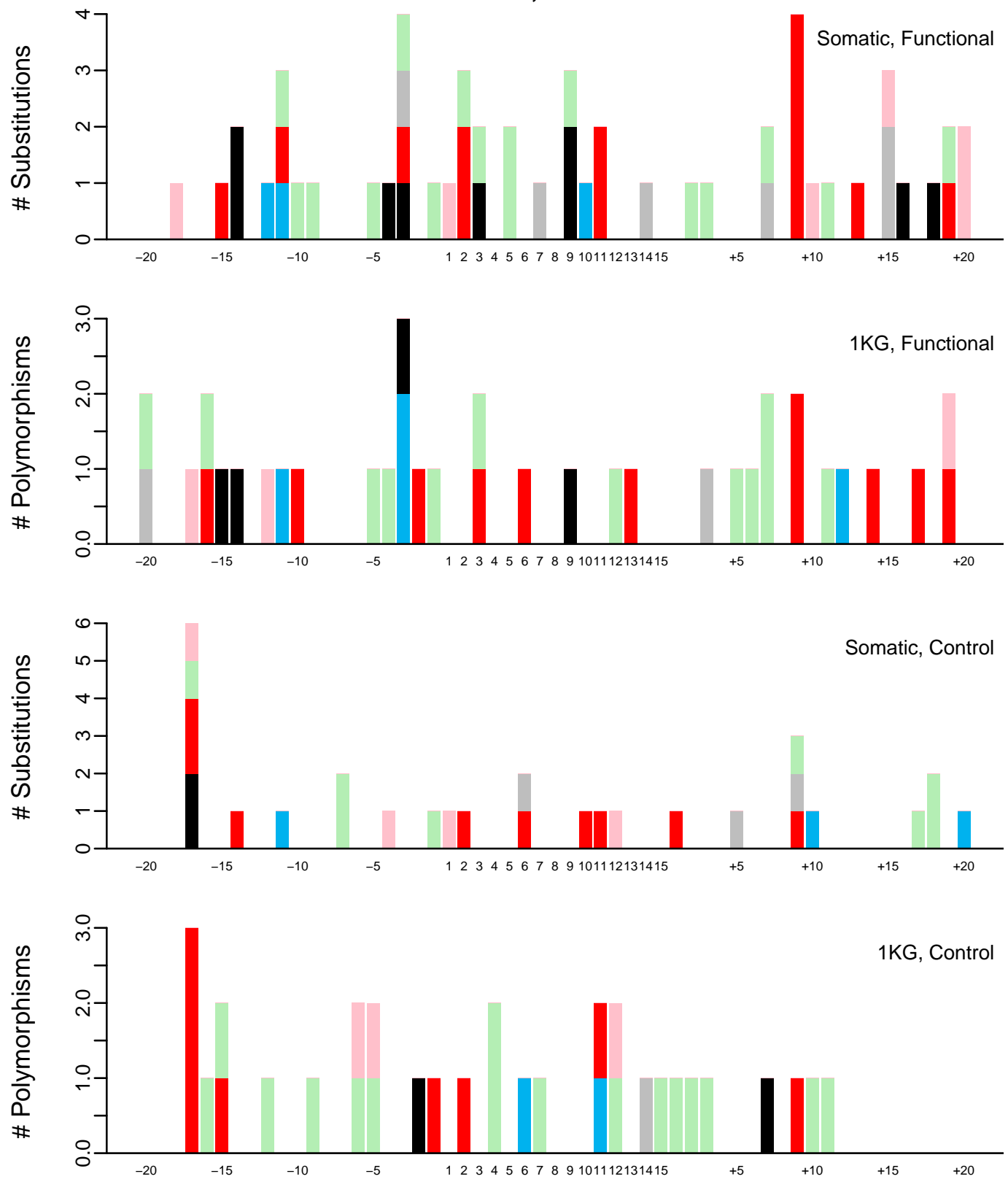
EBF1, MA0154.2
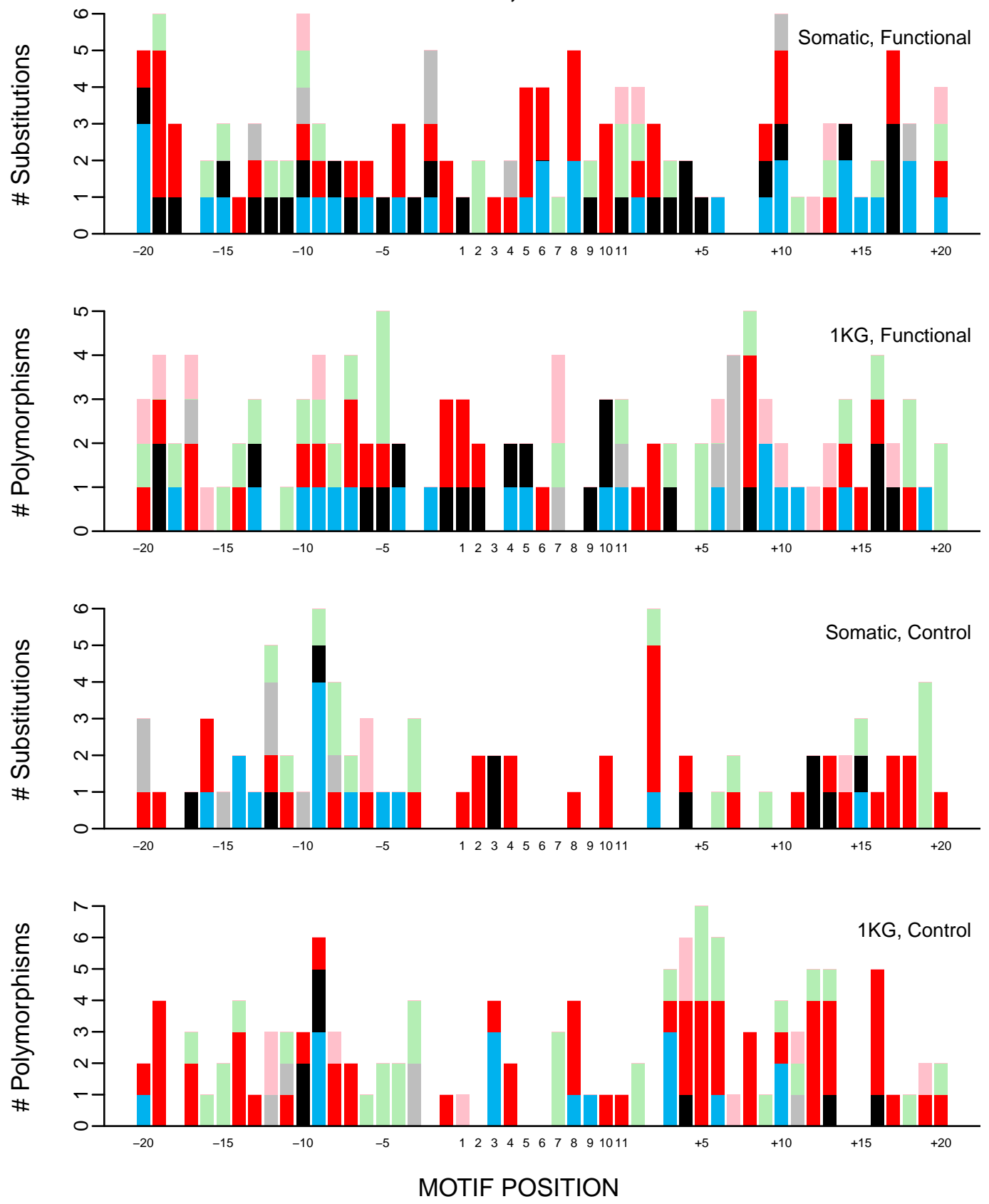
EGR1, MA0162.2
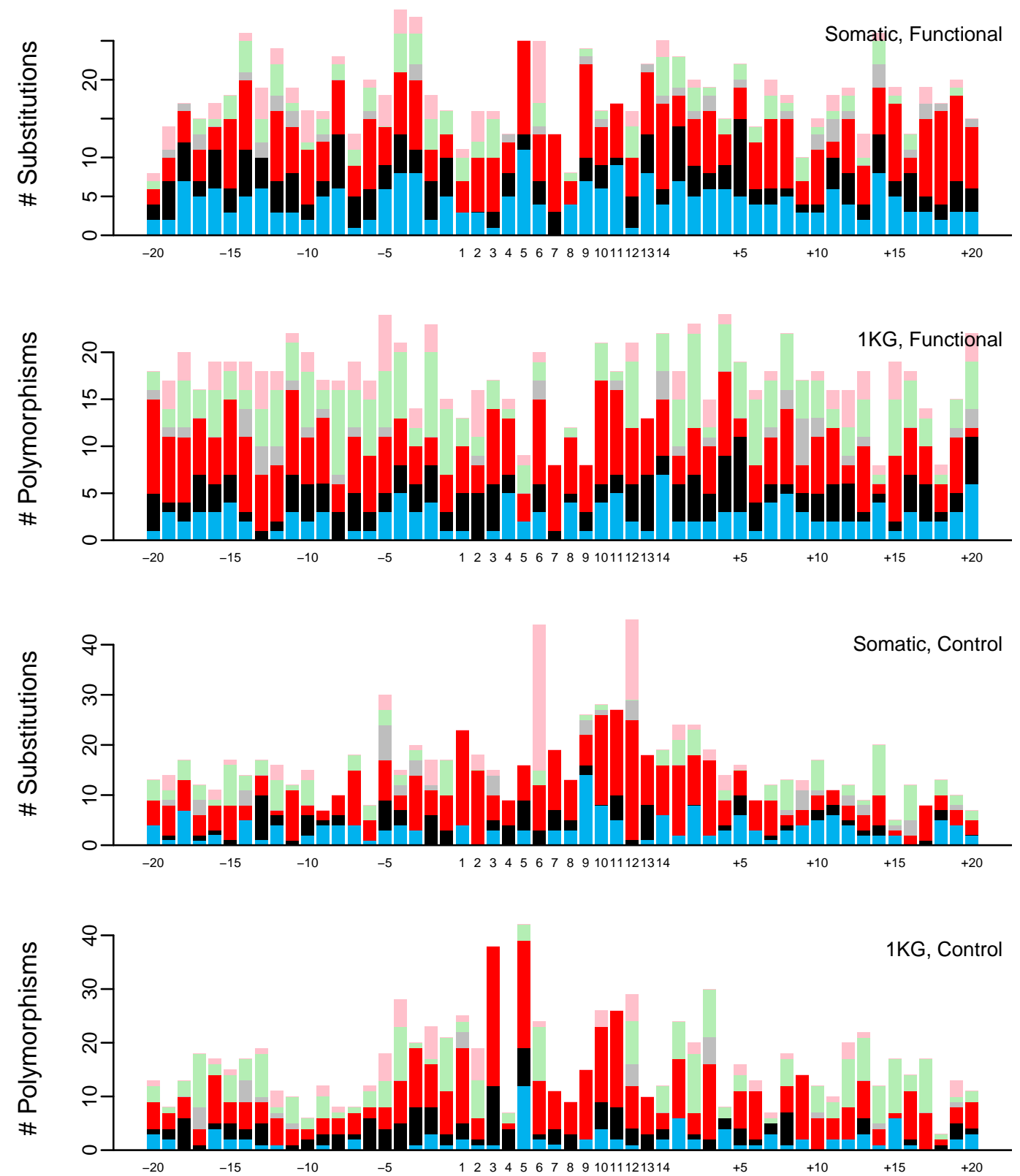
PAX5, MA0239.1
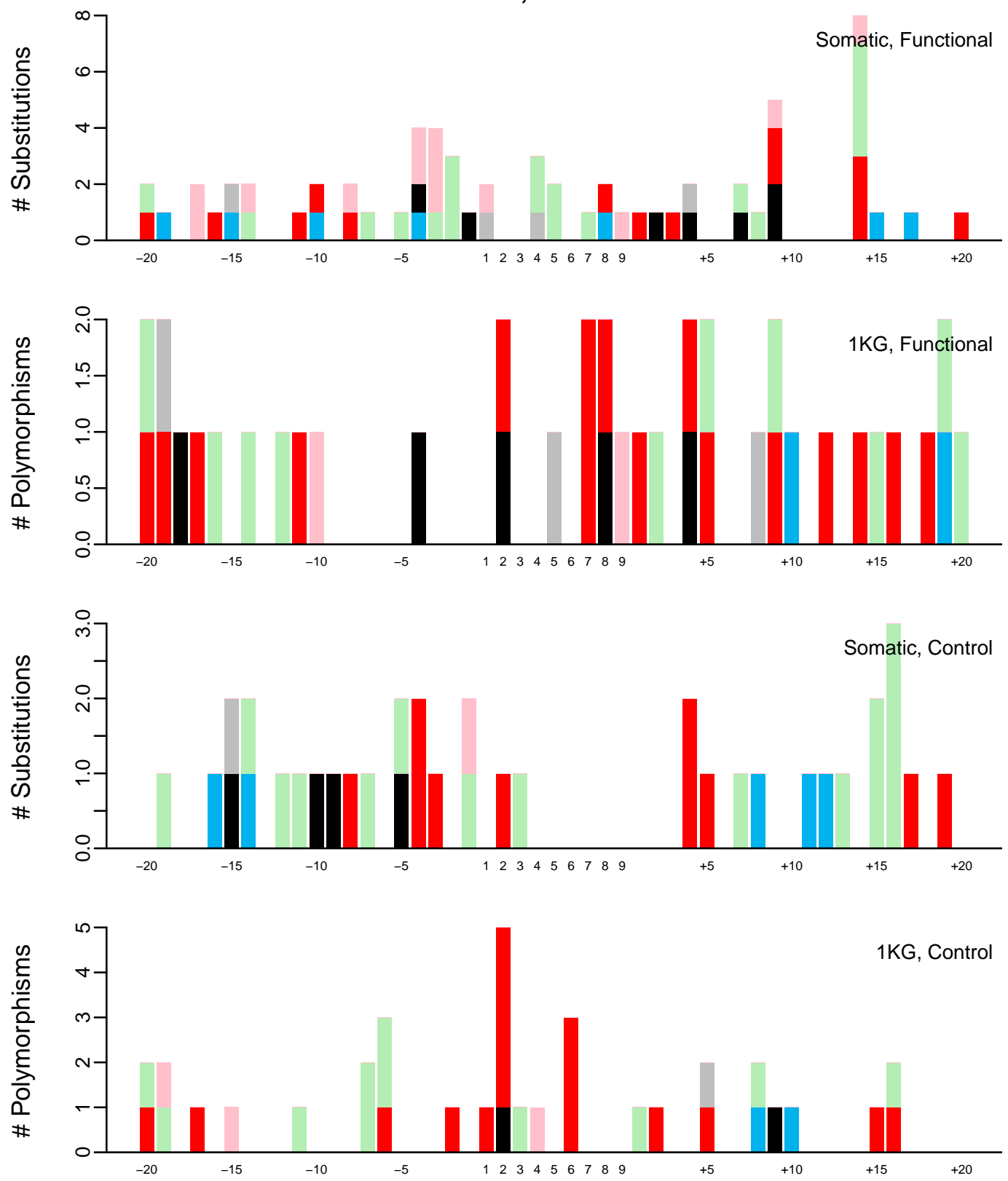
ESR2, MA0258.2
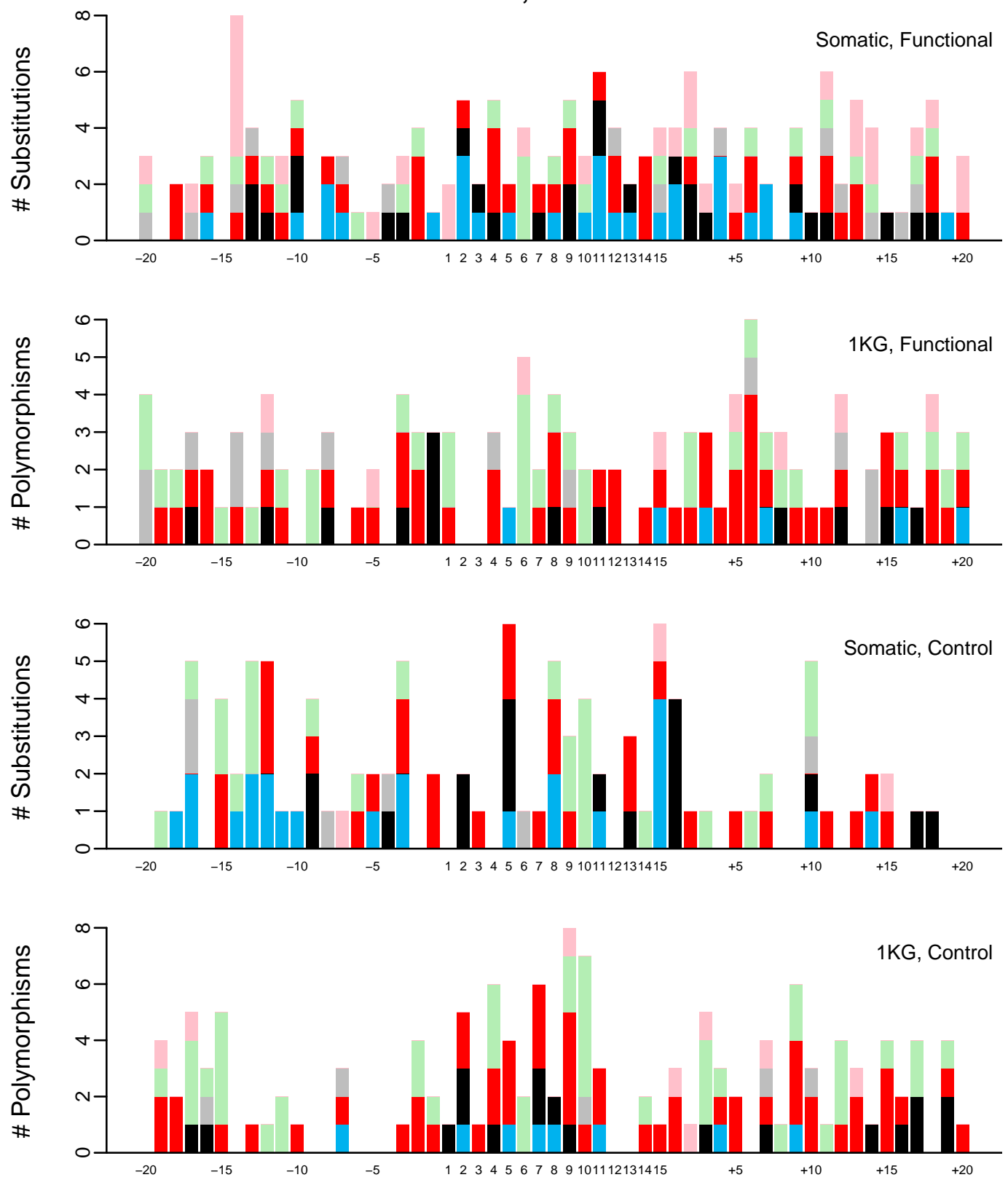
USF1, MA0281.1
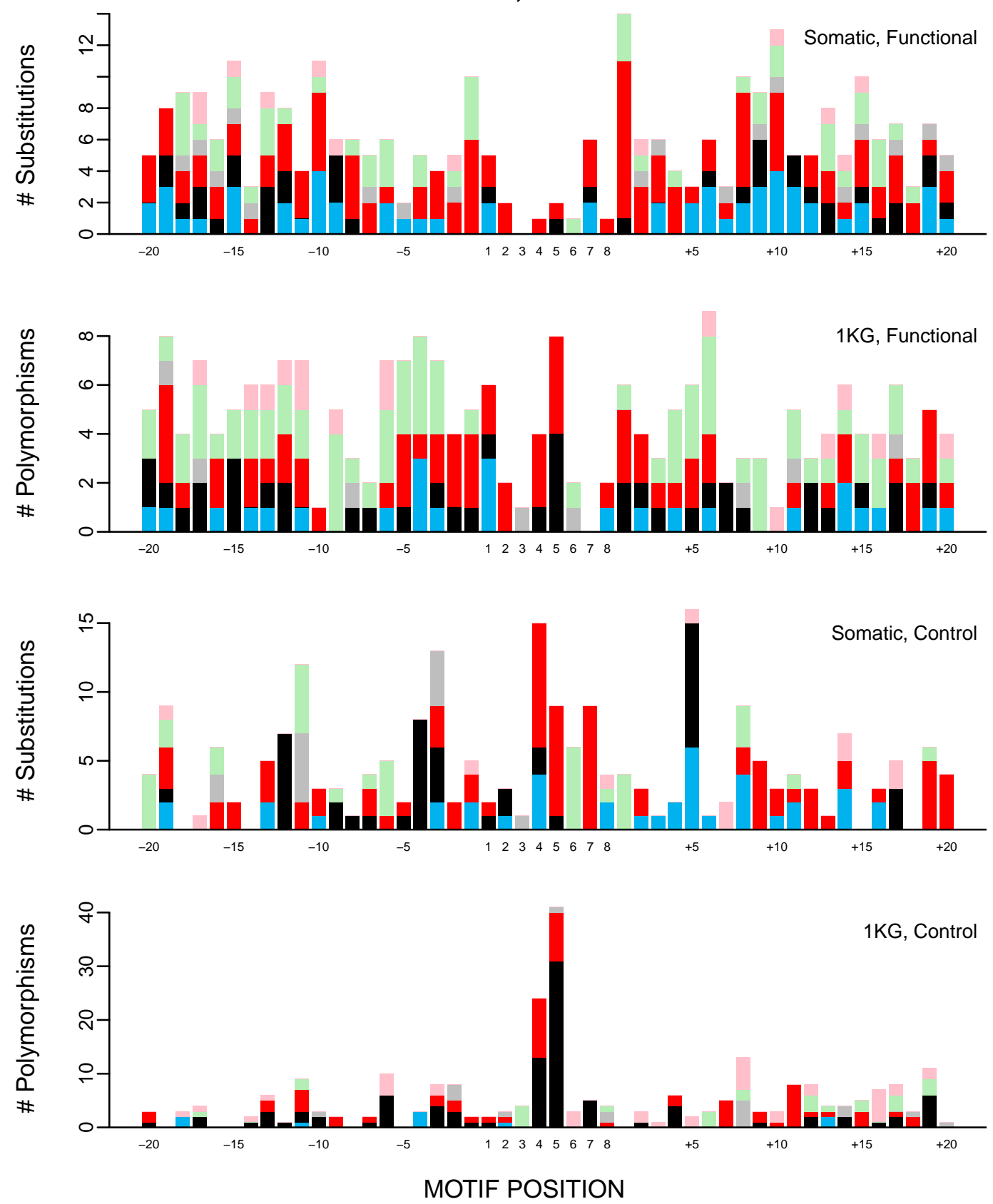


\section{CJUN, MA0303.1}
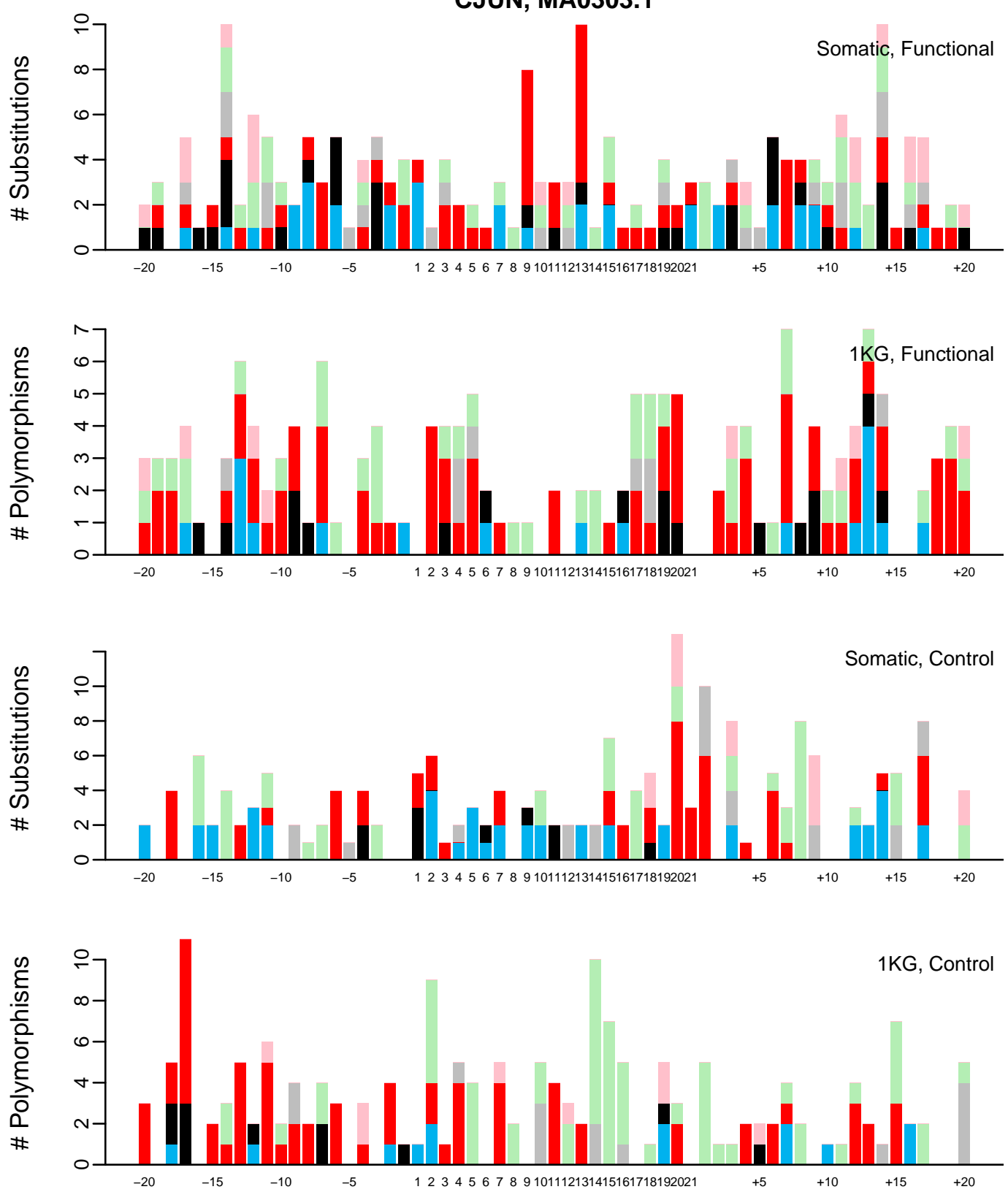


\section{PBX3, MA0318.1}
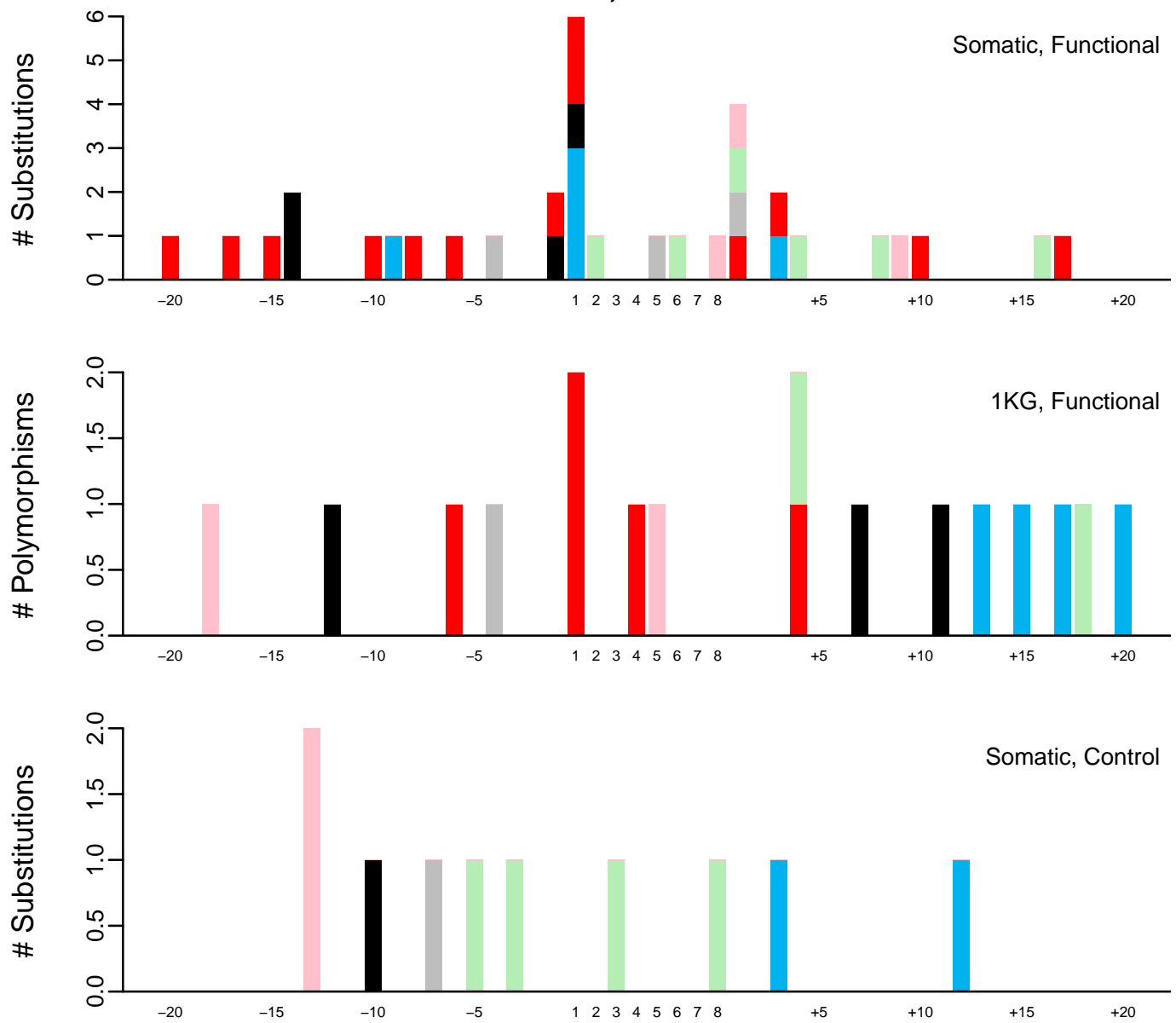

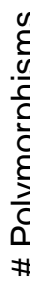

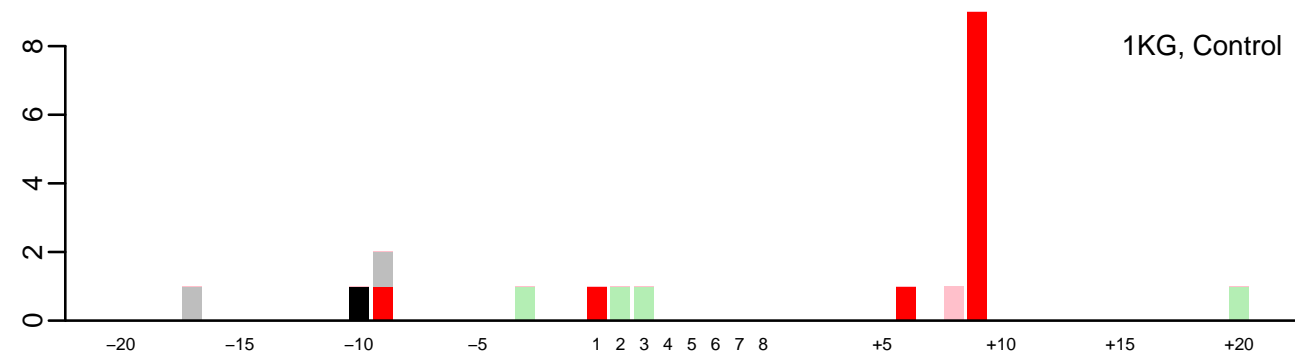



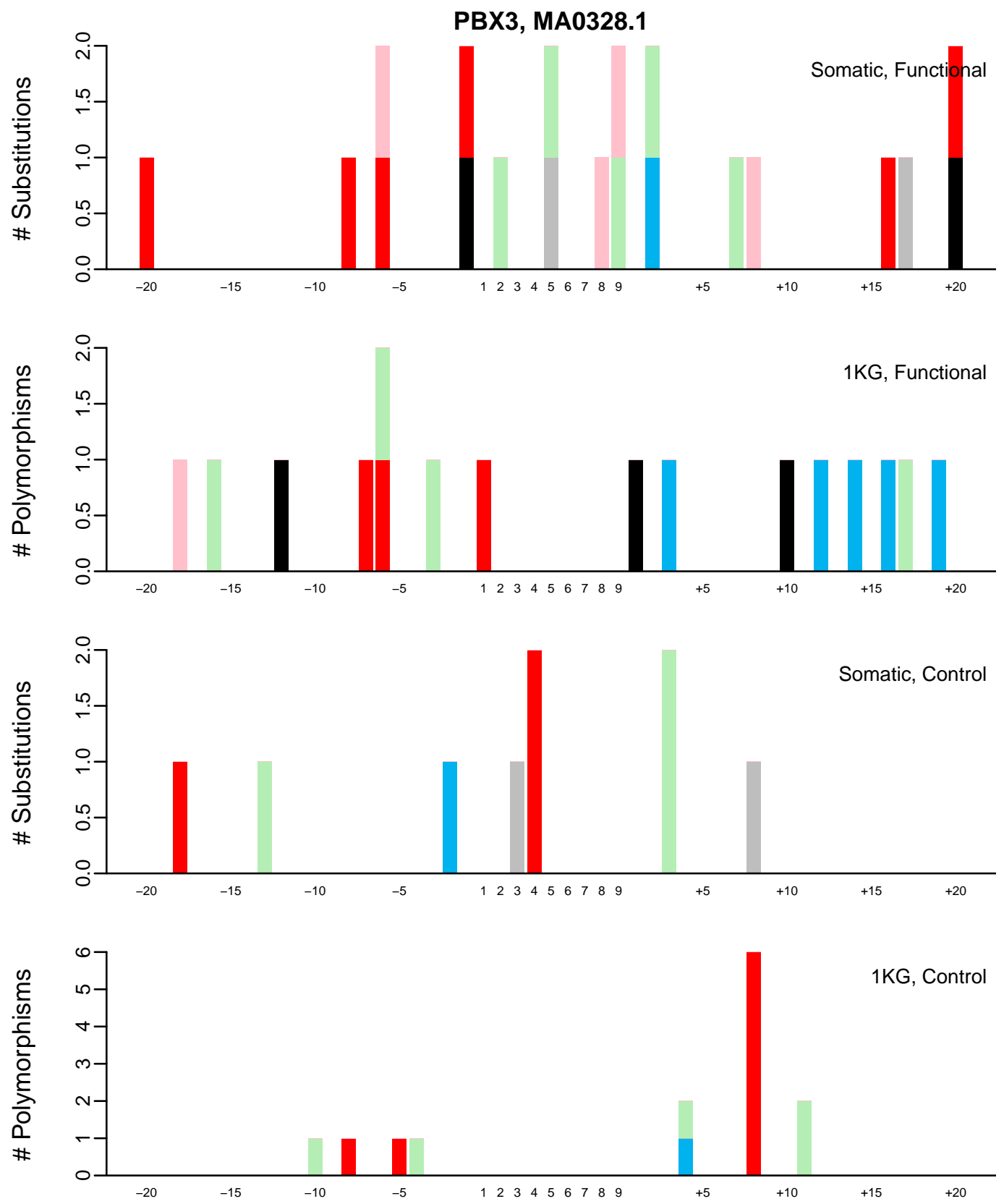
SRF, MA0331.1
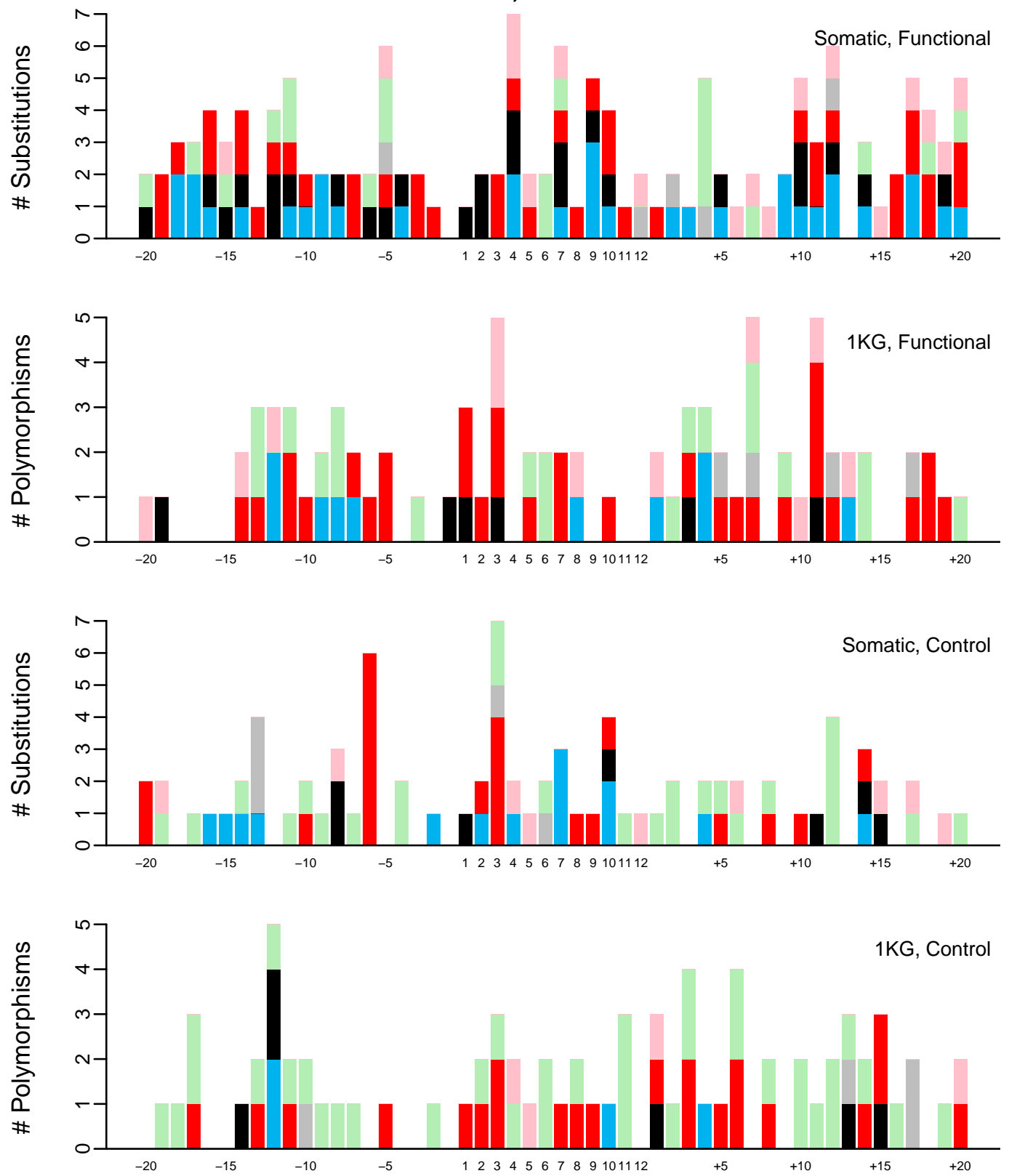
EGR1, MA0337.1
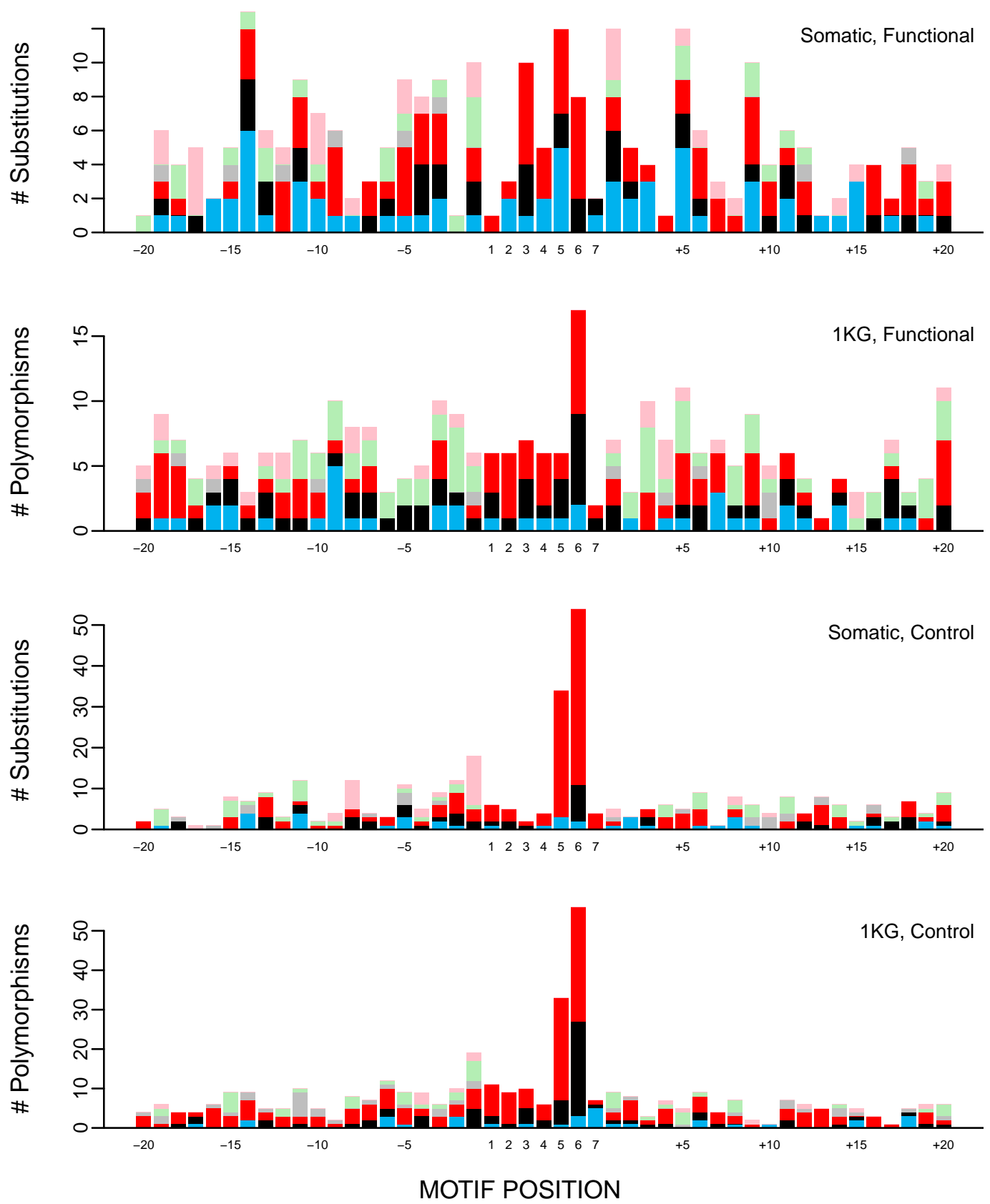

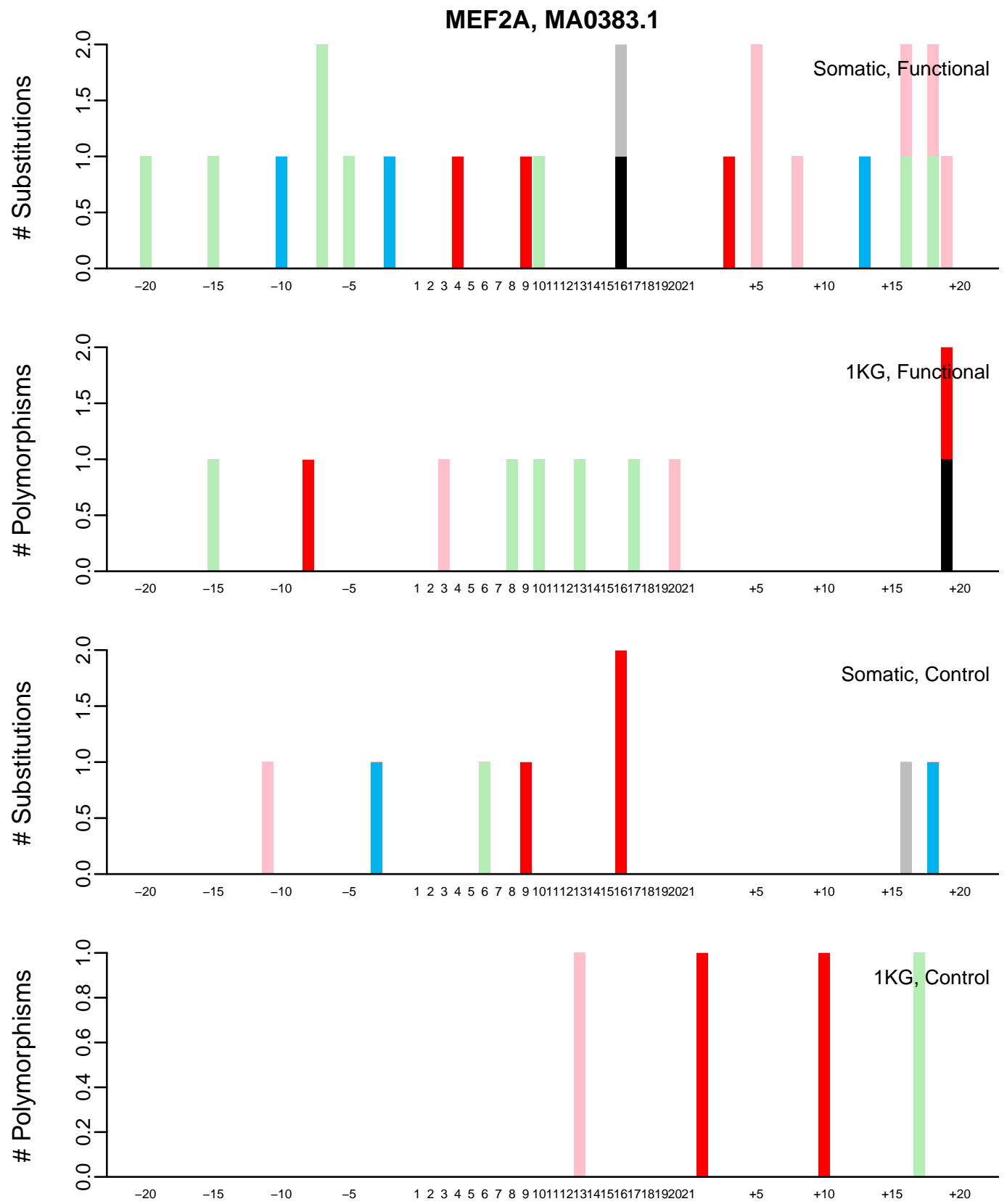
SREBP1, MA0409.1
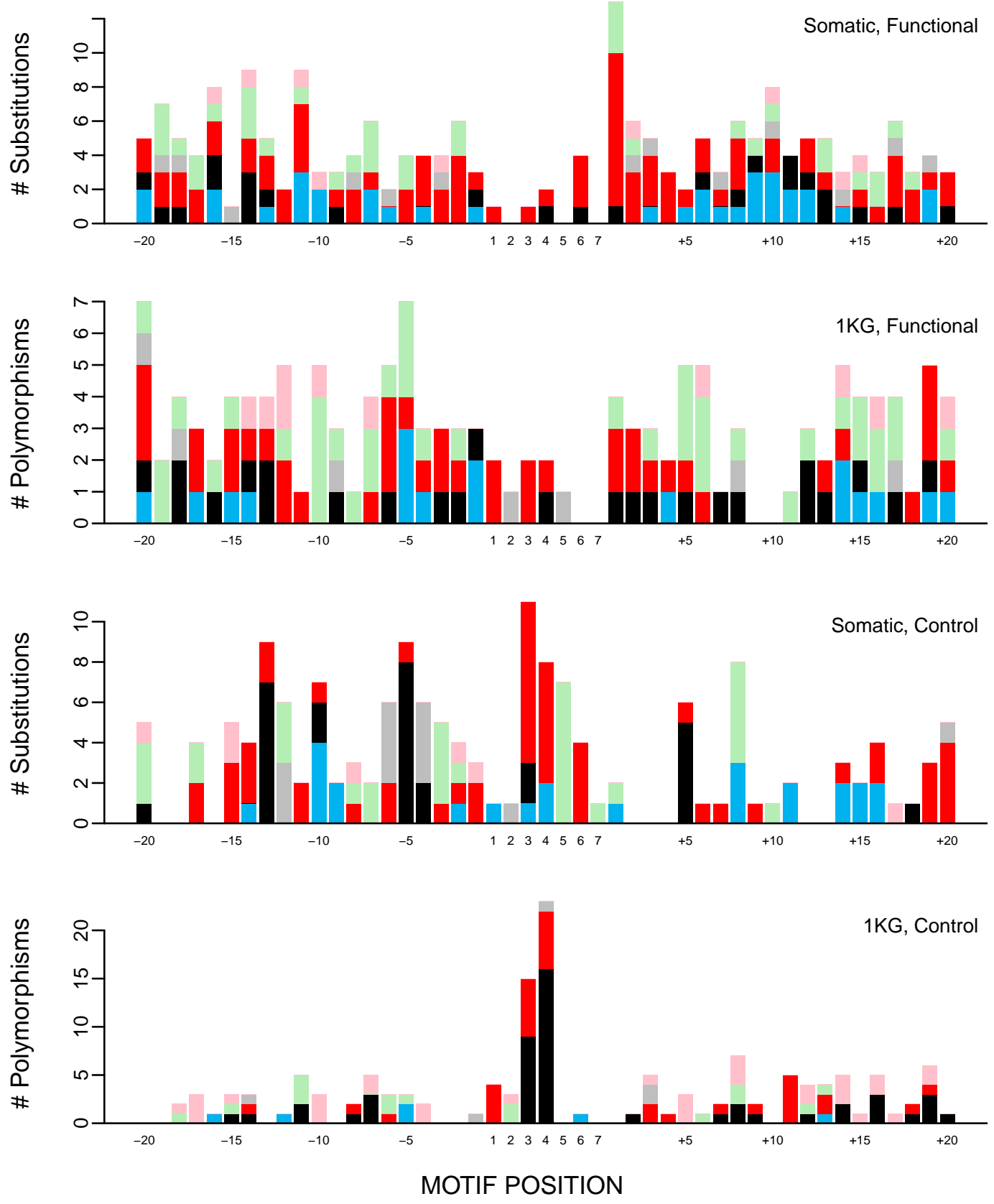
EGR1, MA0423.1
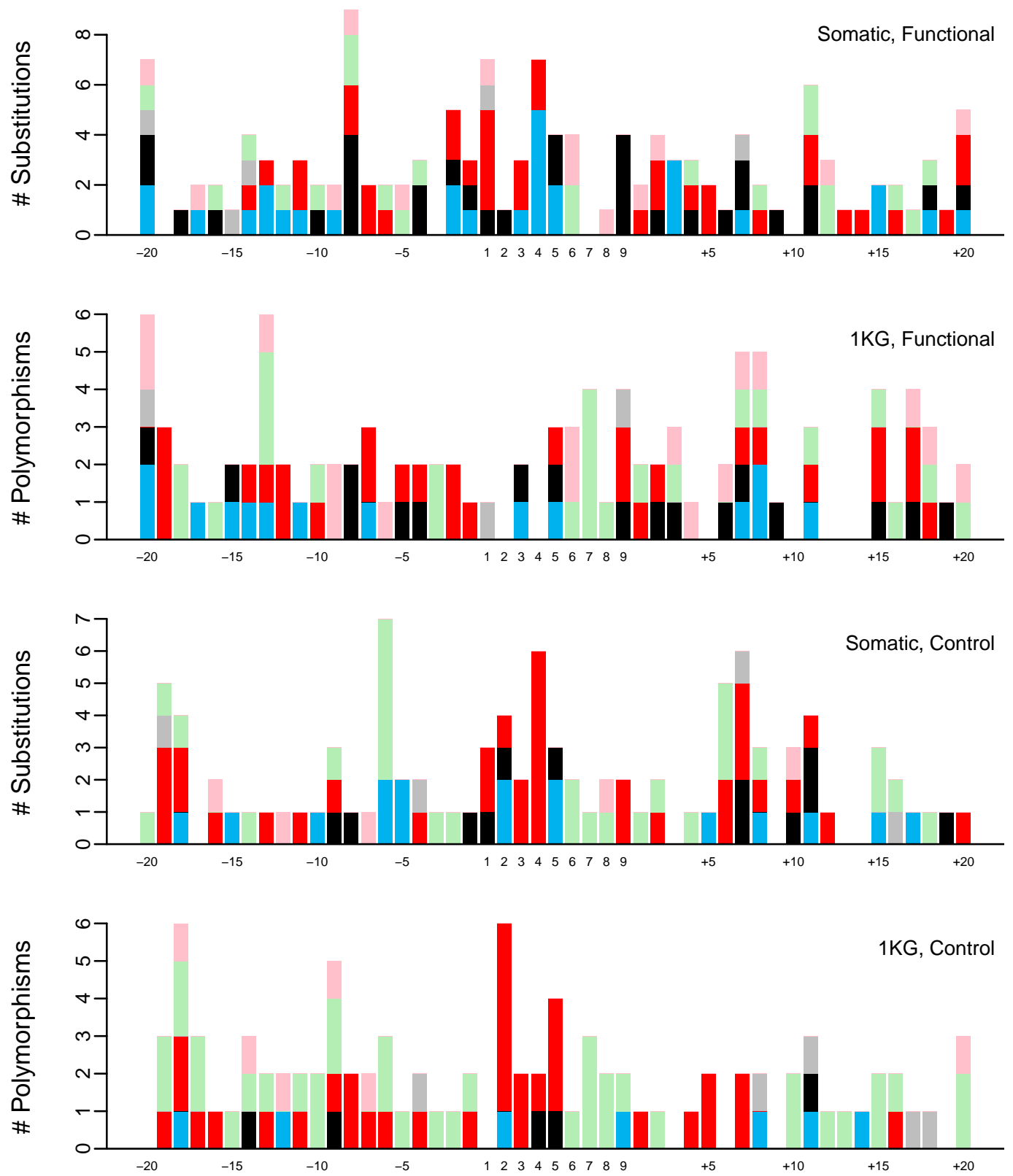

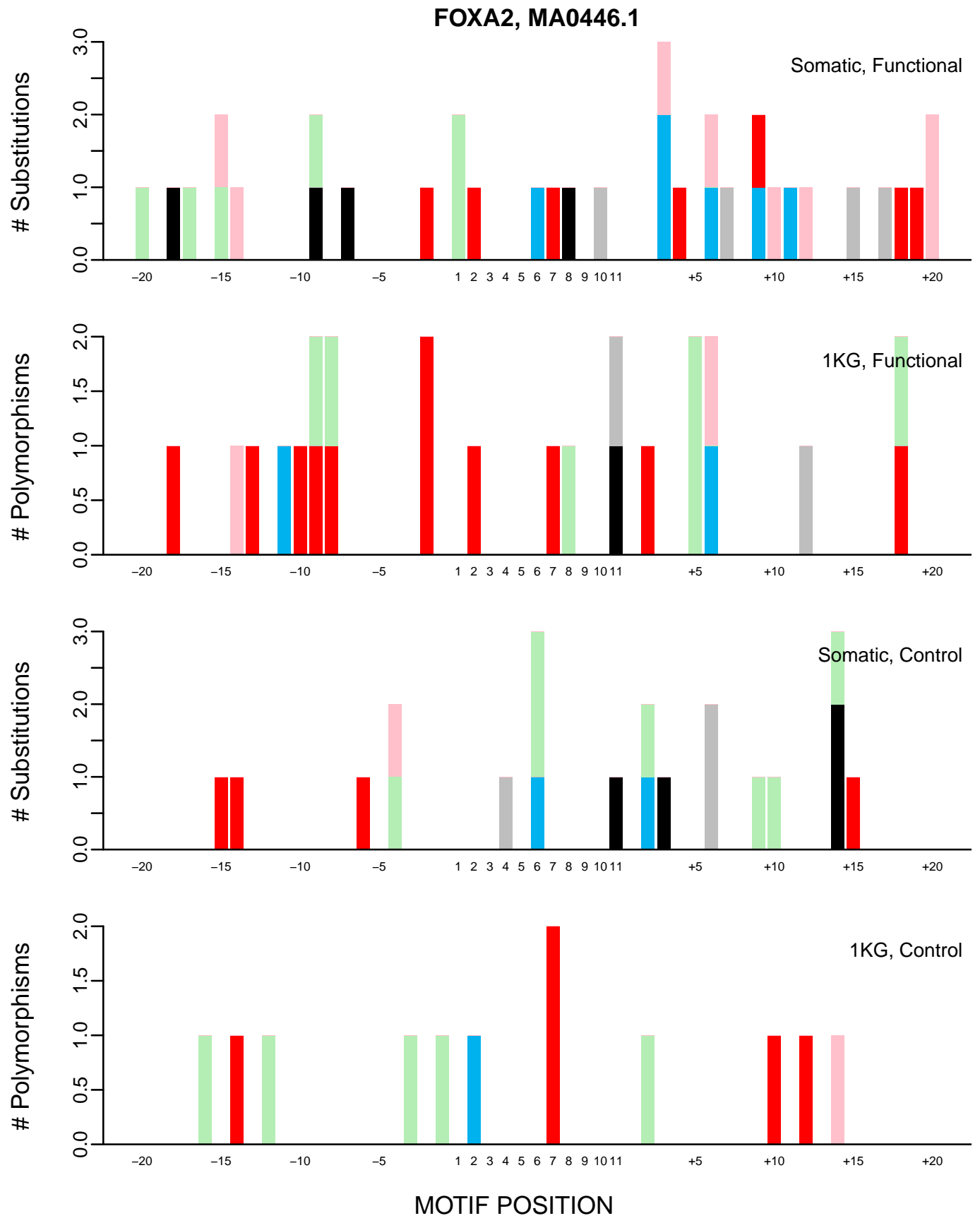
BATF::JUN, MA0462.1
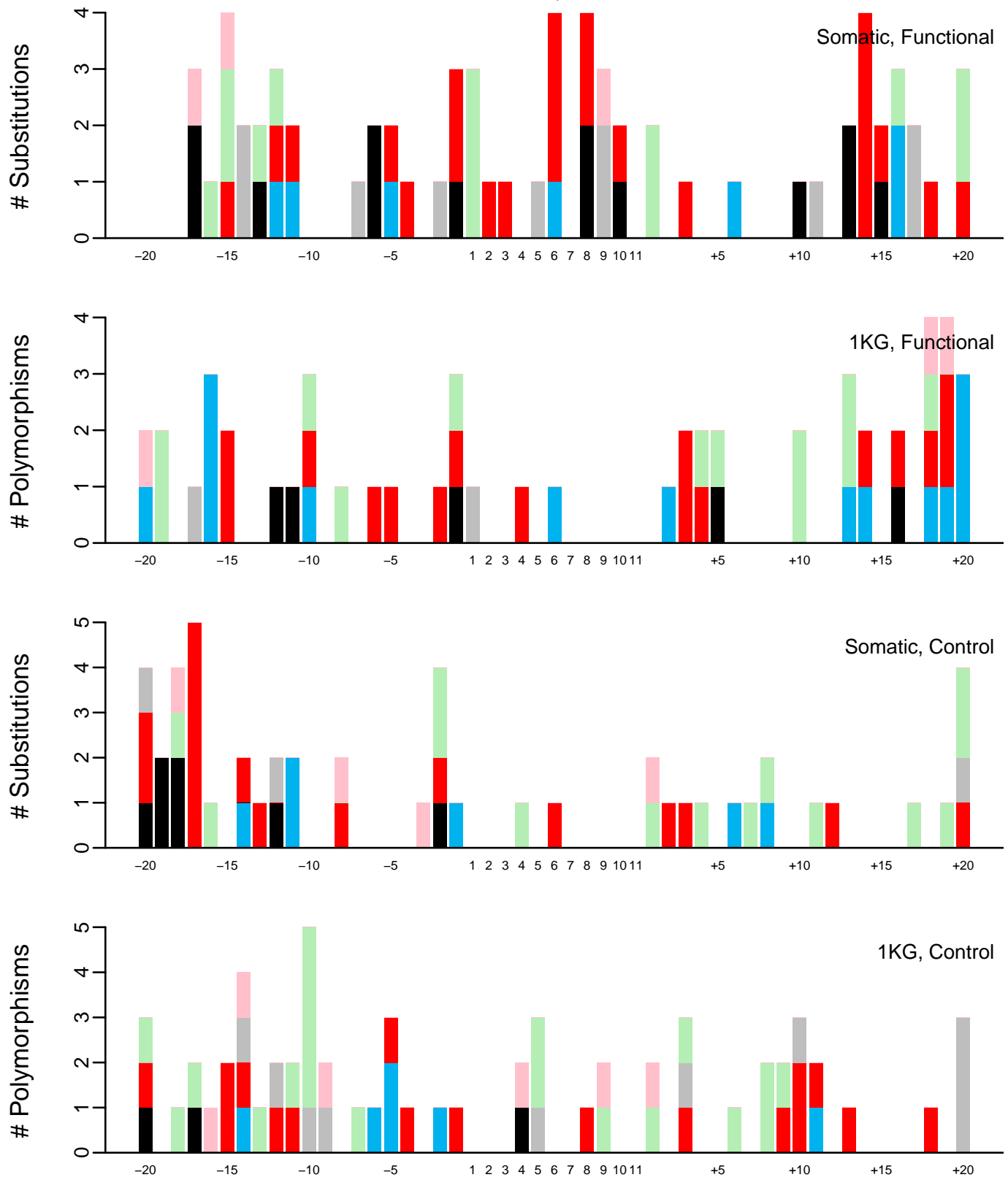
BHLHE40, MA0464.1
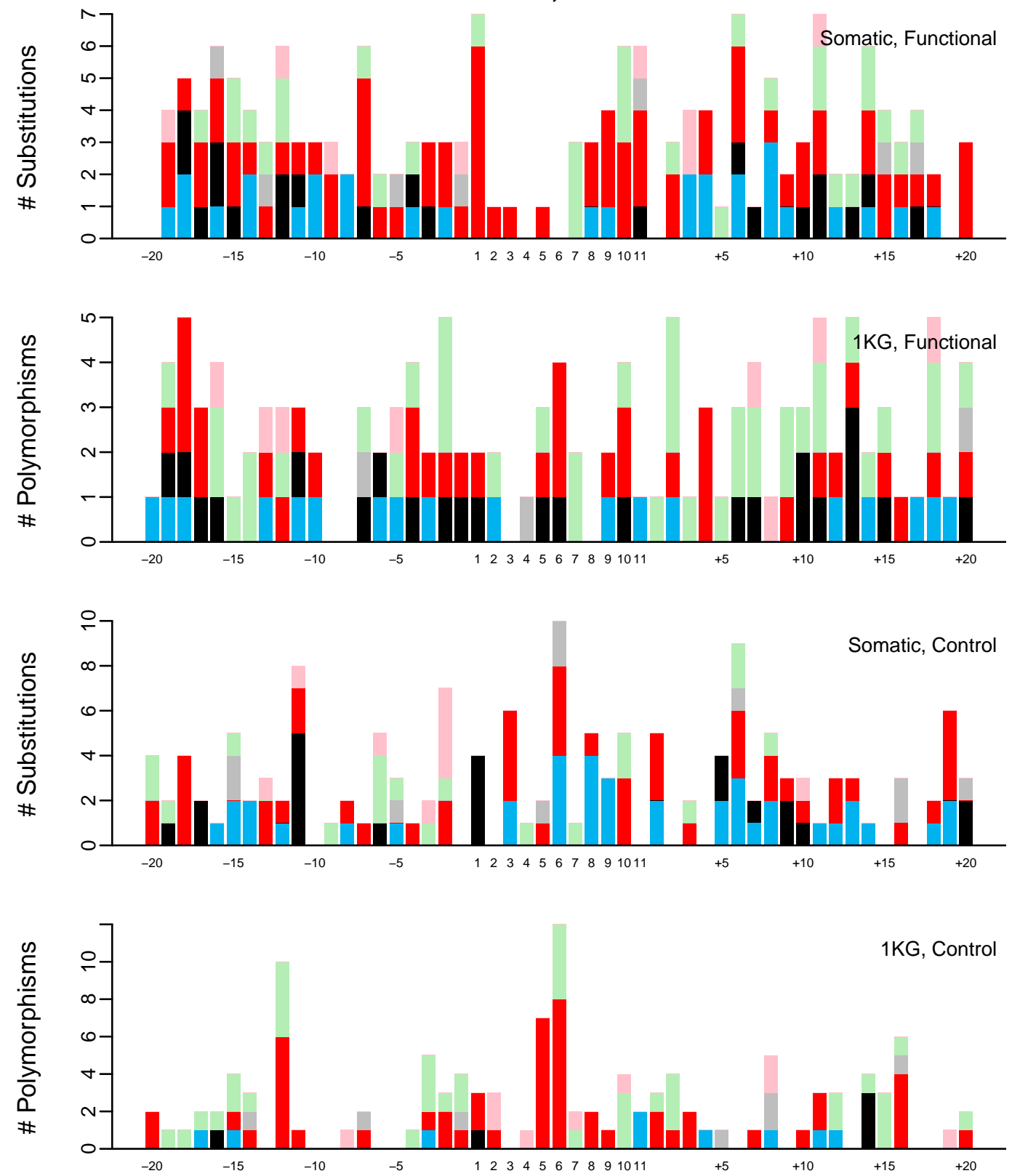
CDX2, MA0465.1
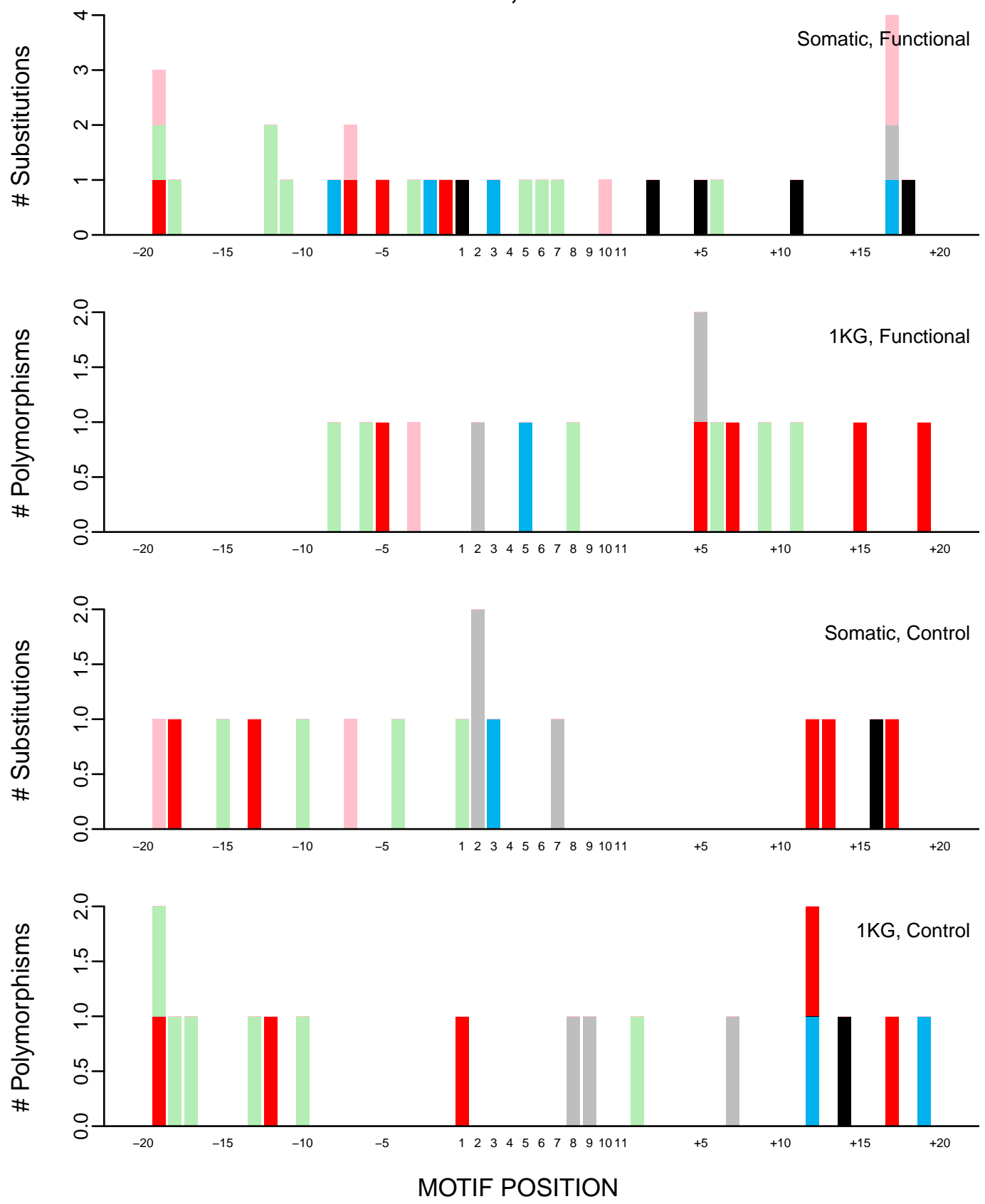


\section{CEBPB, MA0466.1}
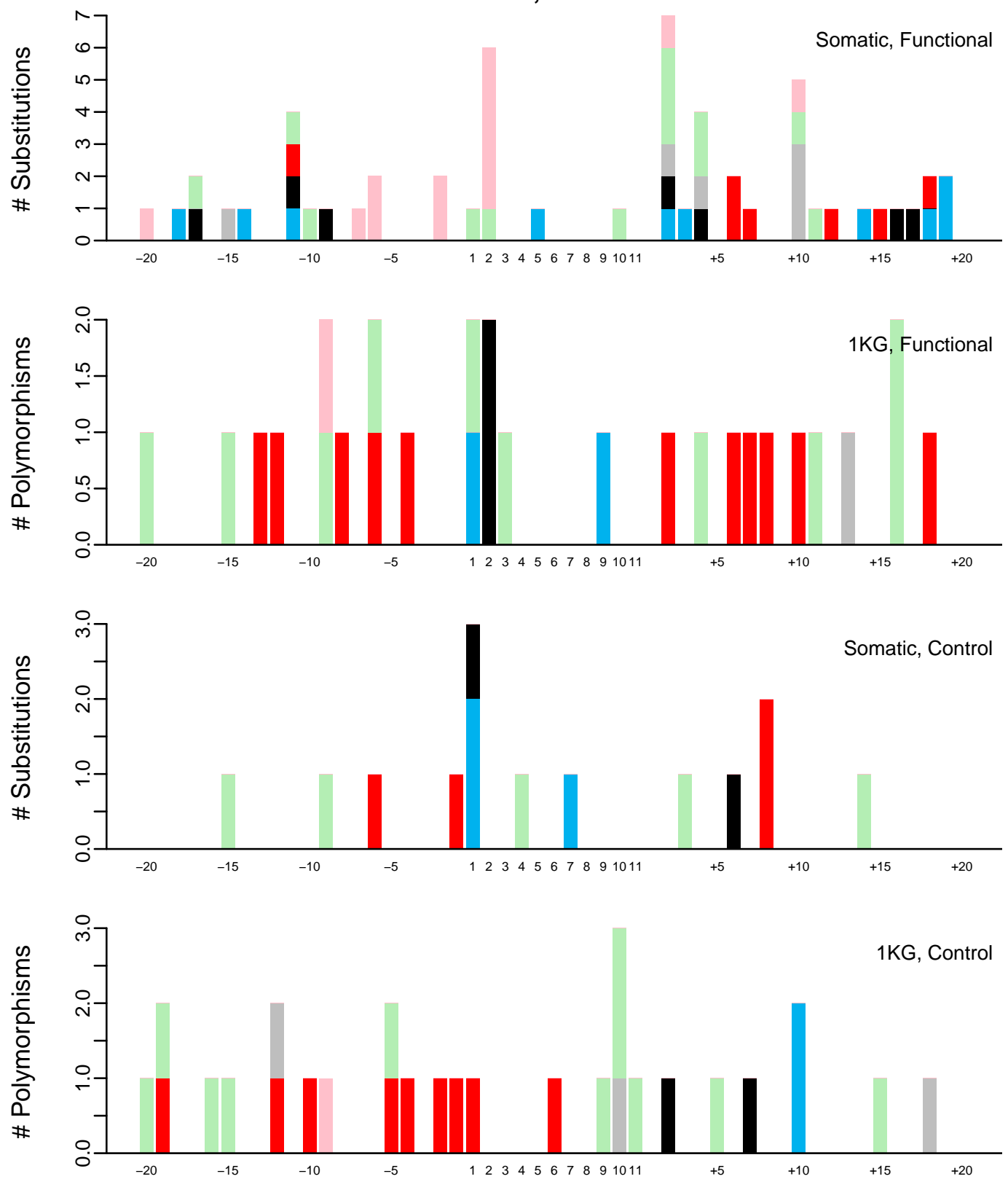

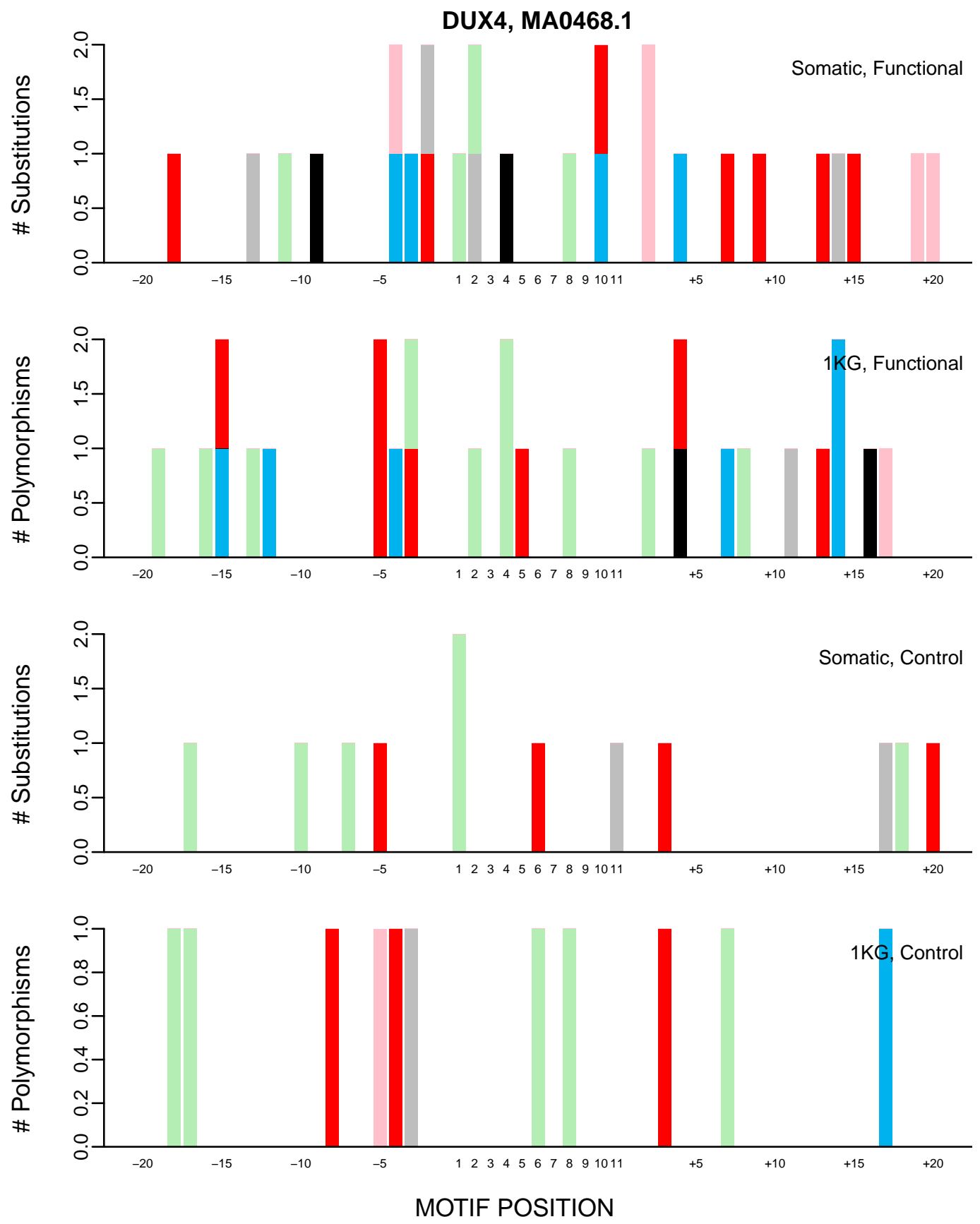
E2F4, MA0470.1
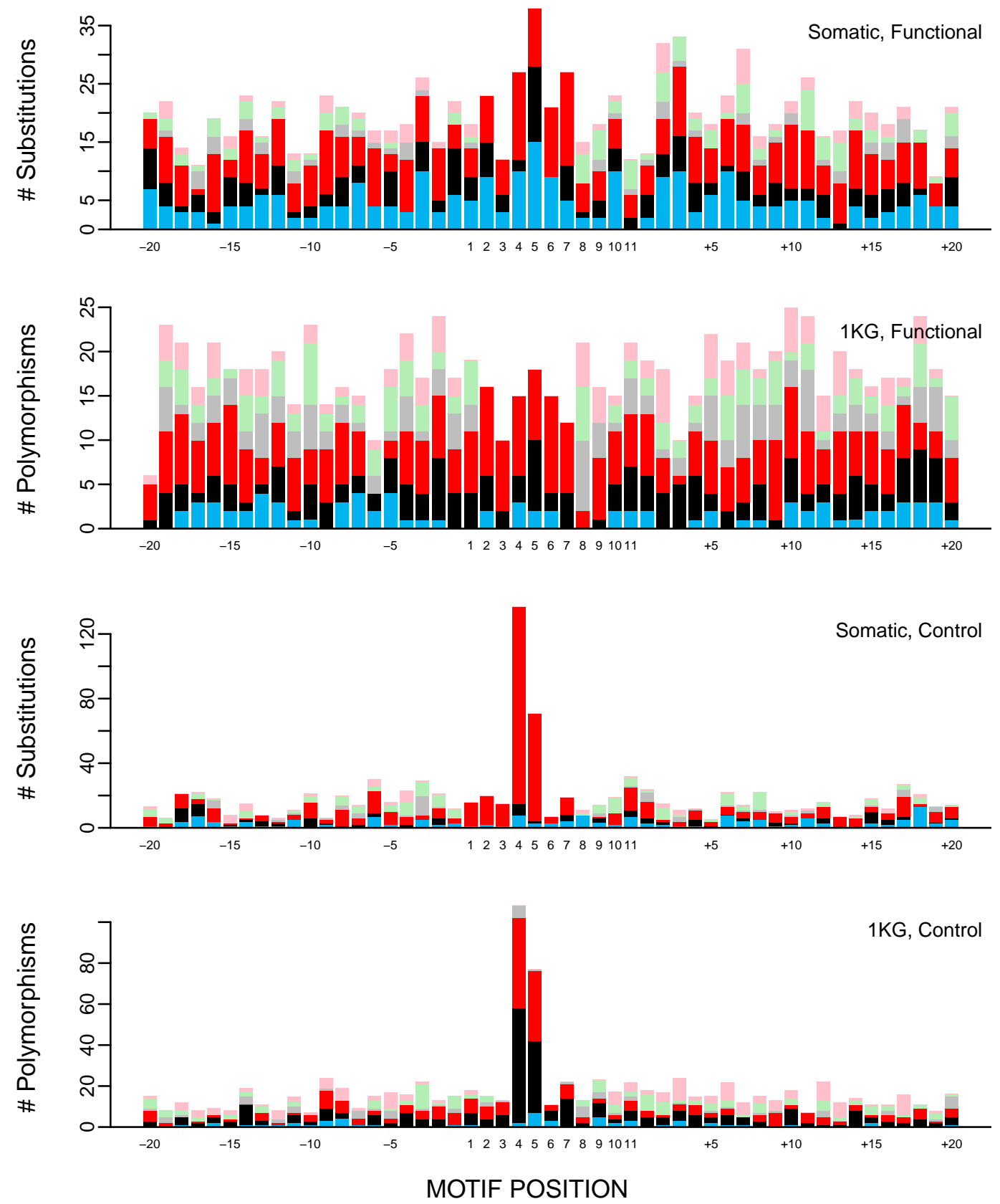
E2F6, MA0471.1
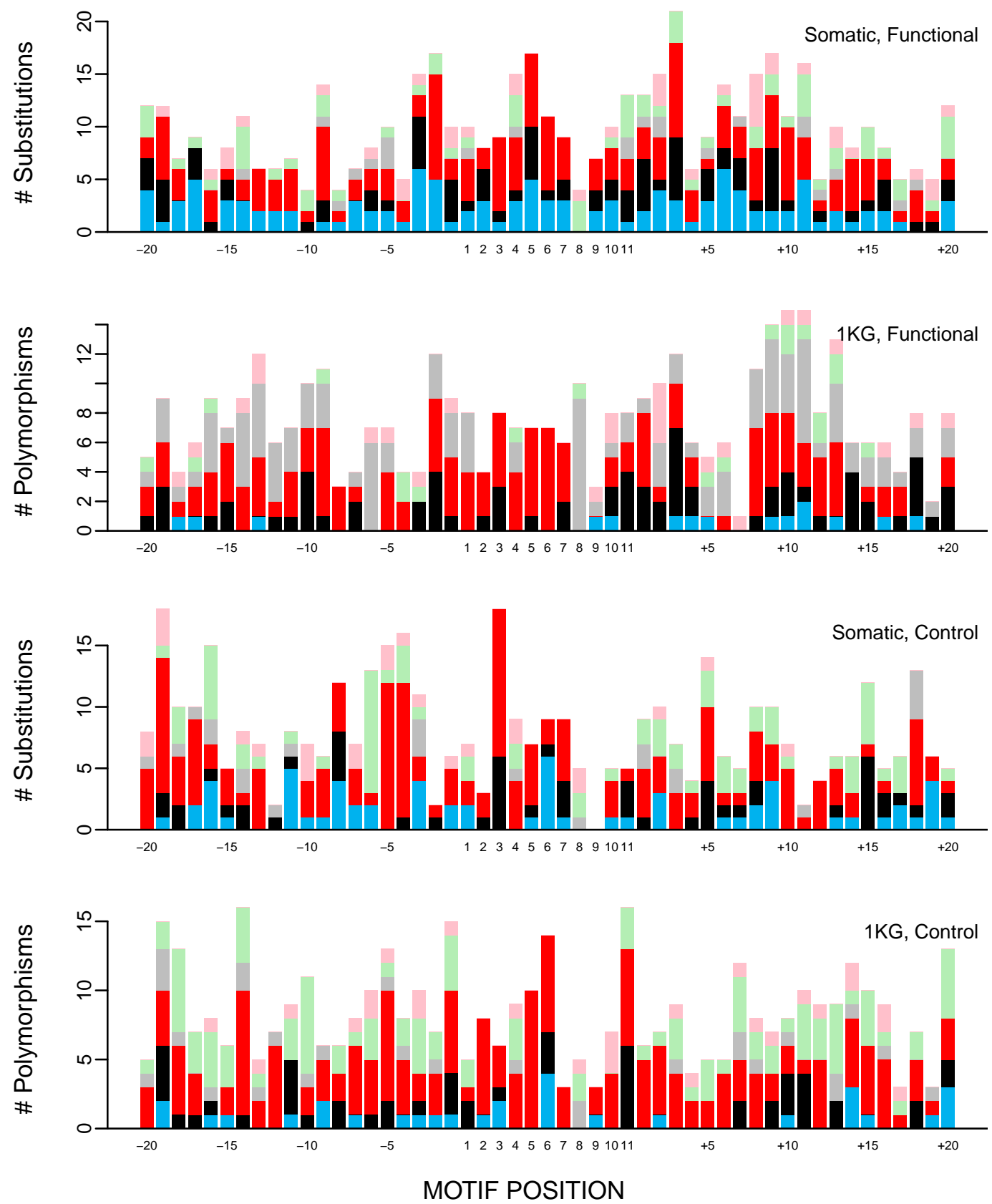


\section{ELF1, MA0473.1}
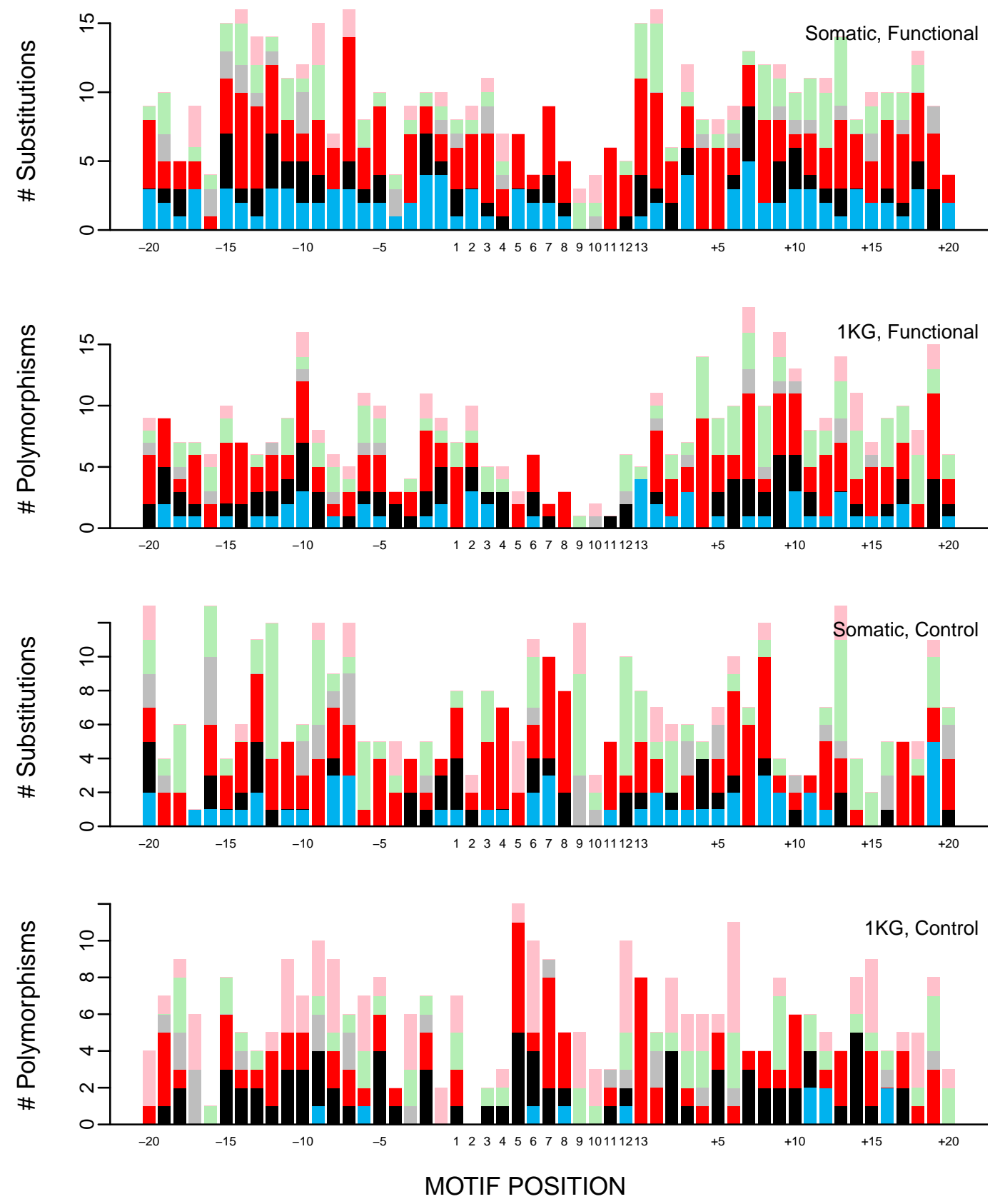
FLI1, MA0475.1
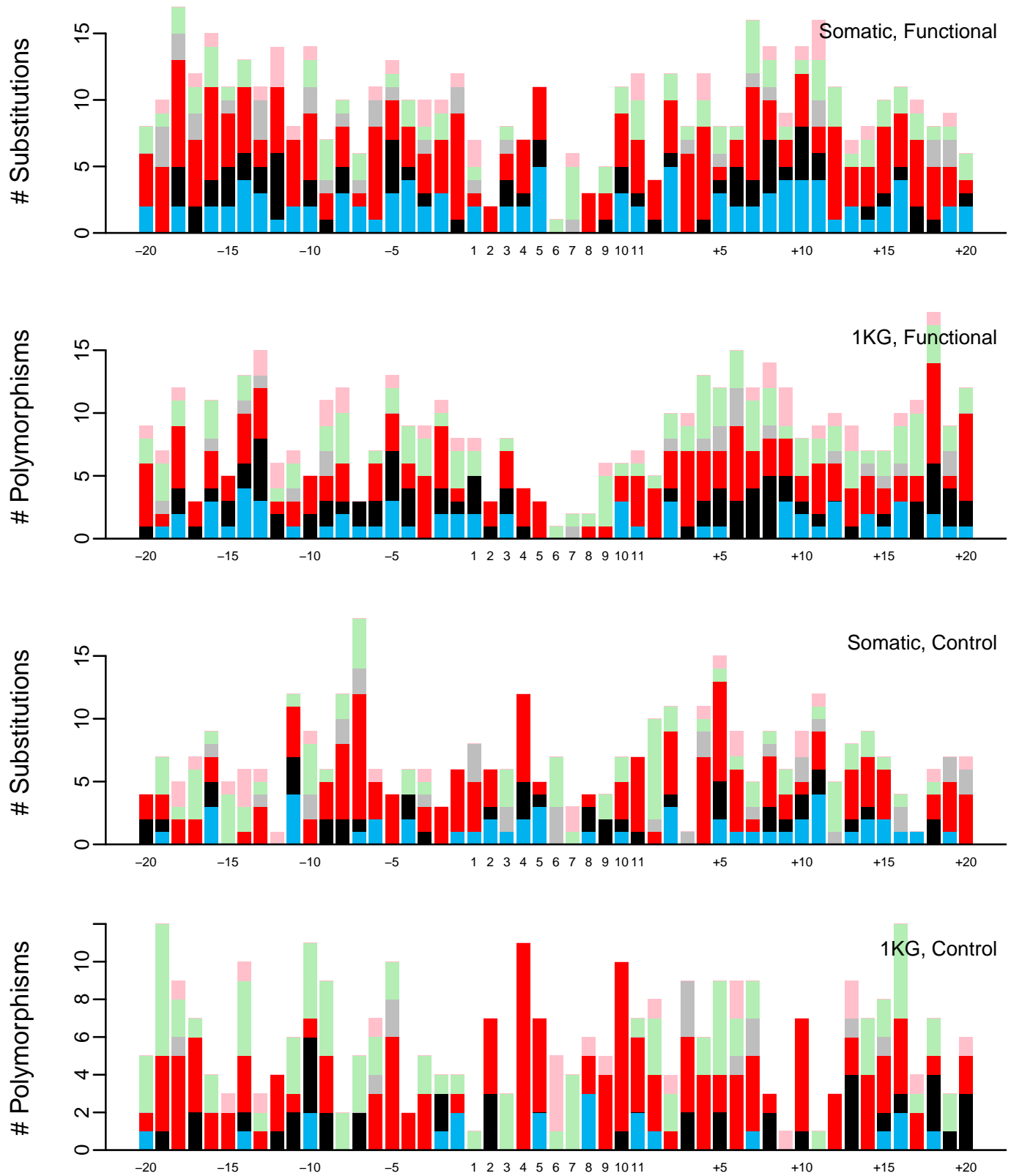
CFOS, MA0476.1
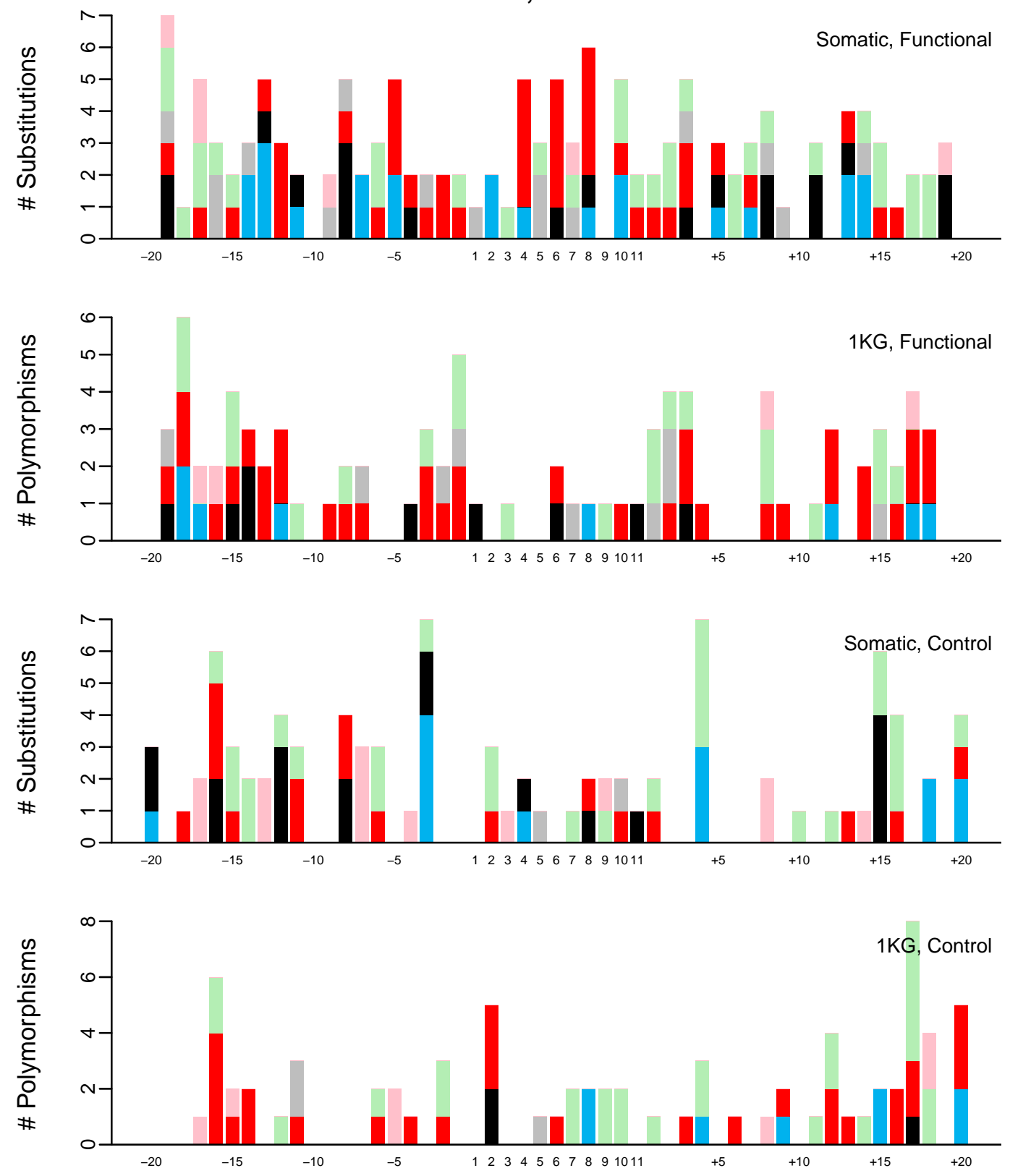
FOSL1, MA0477.1
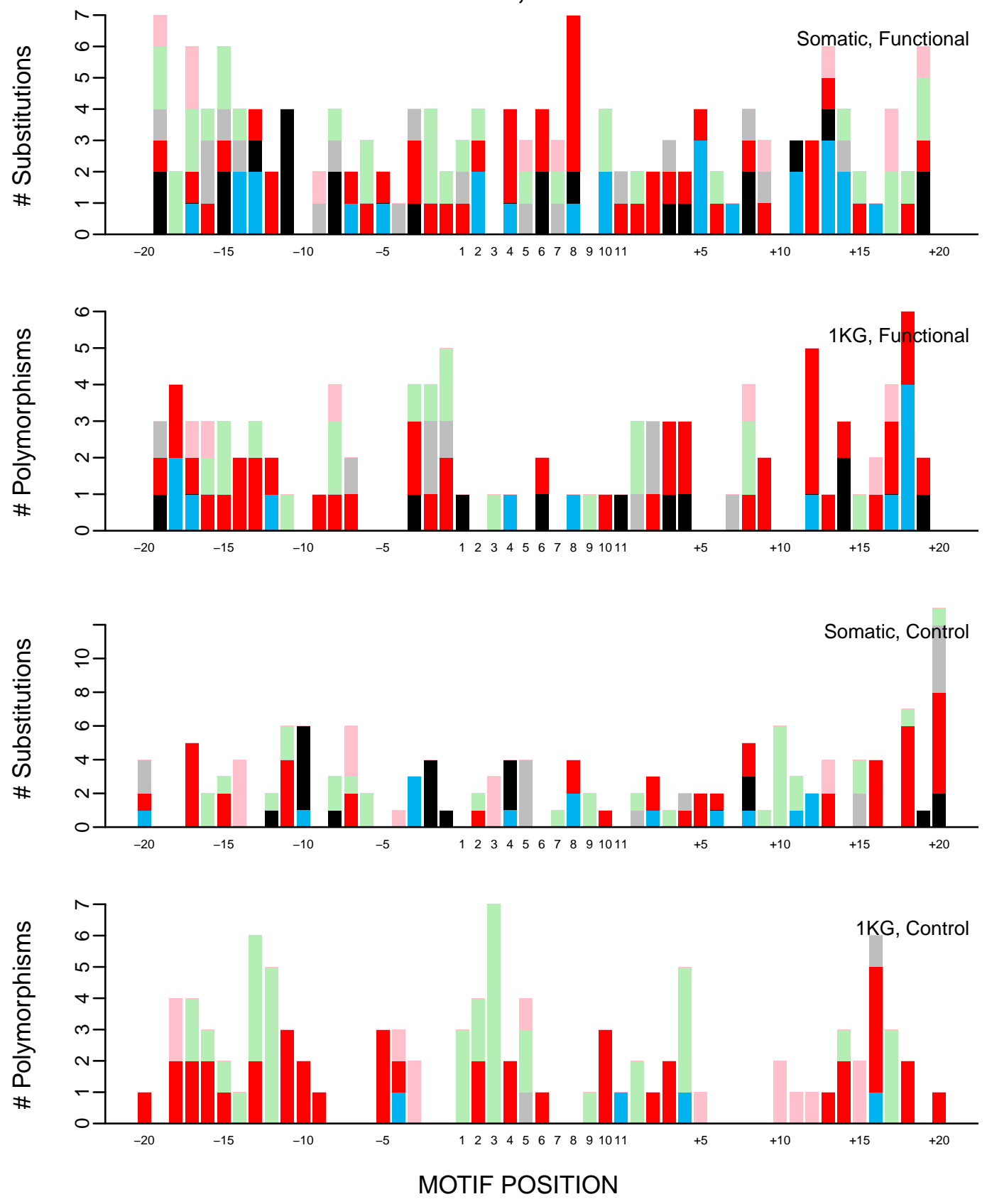
FOSL2, MA0478.1
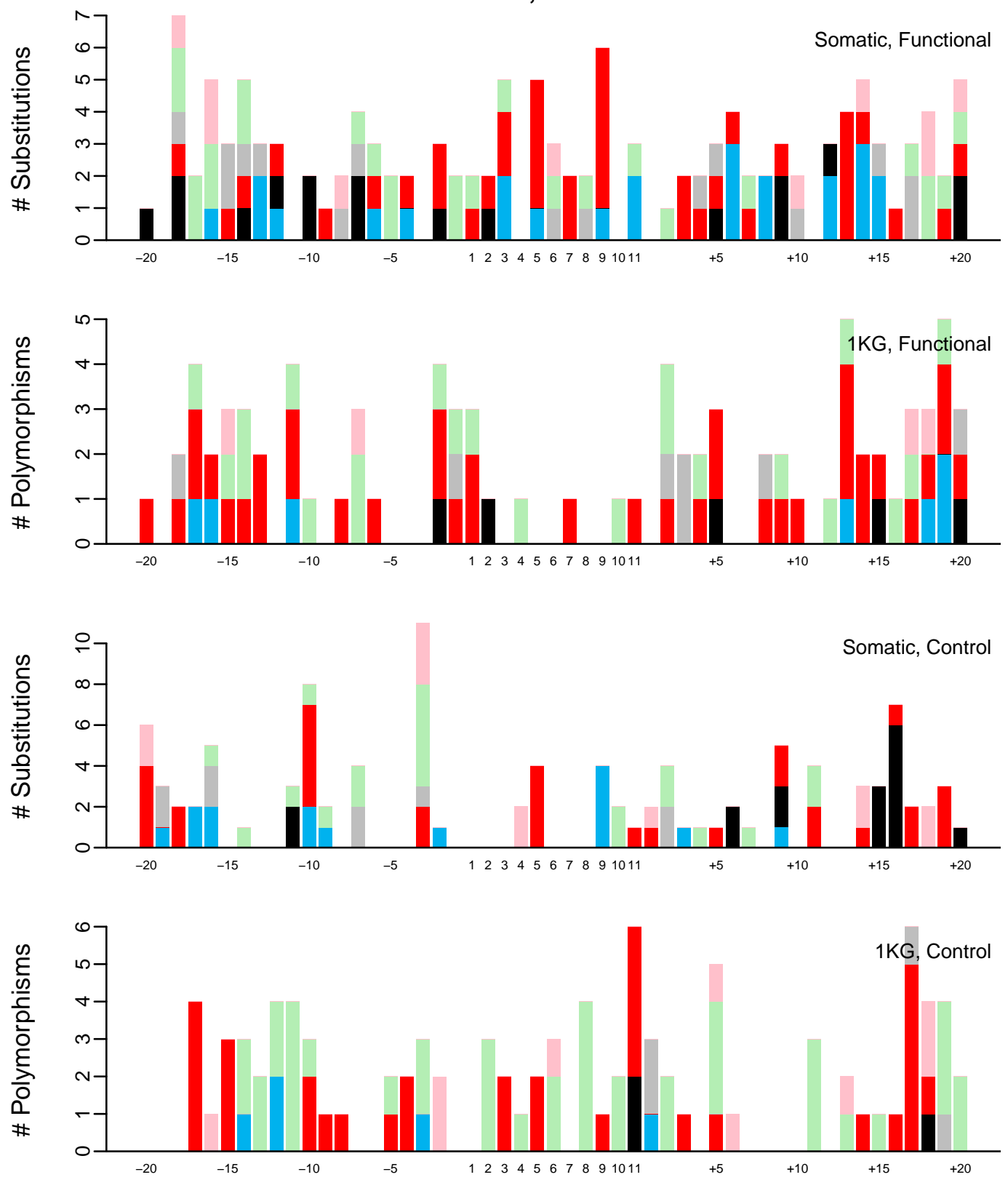
FOXH1, MA0479.1
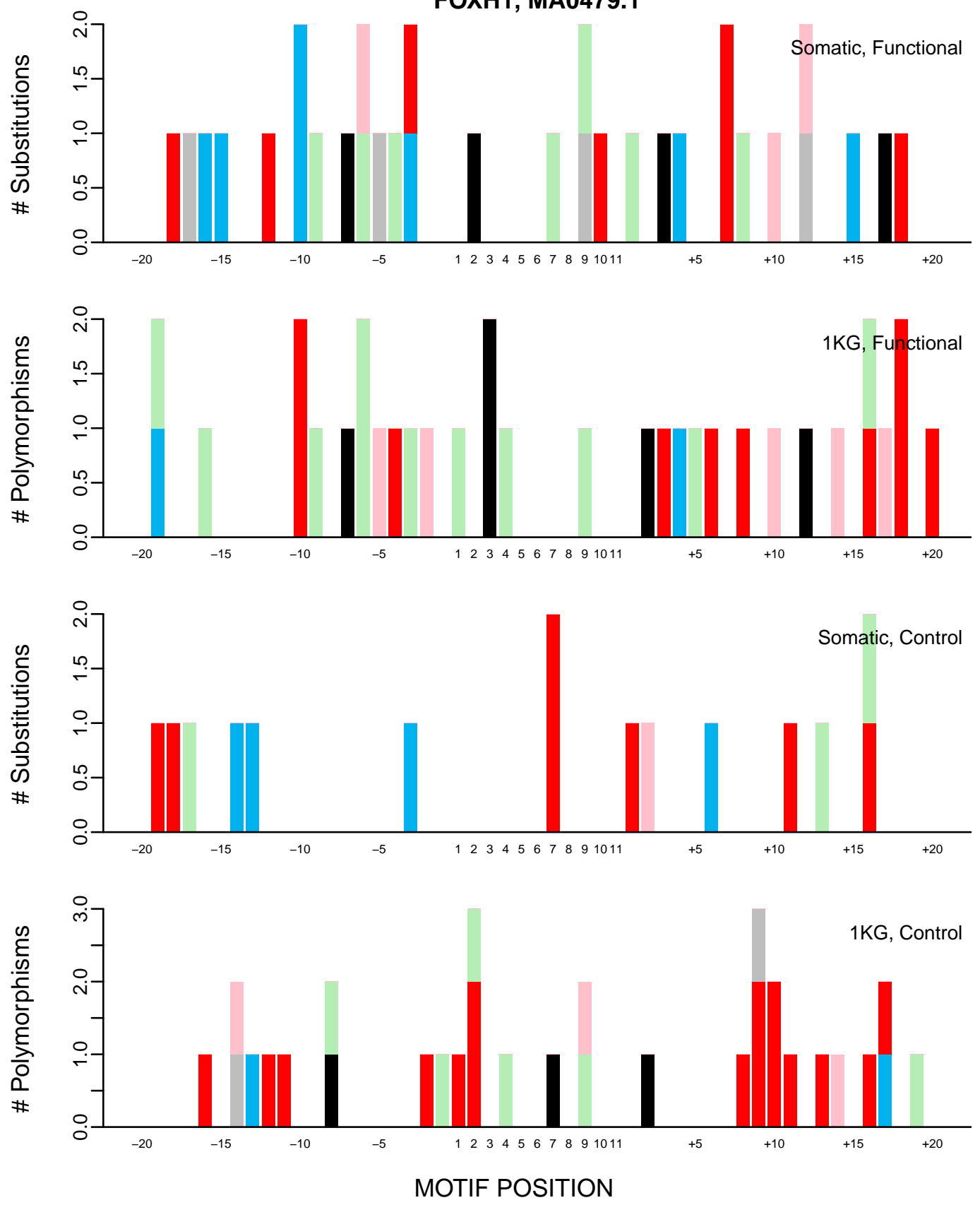

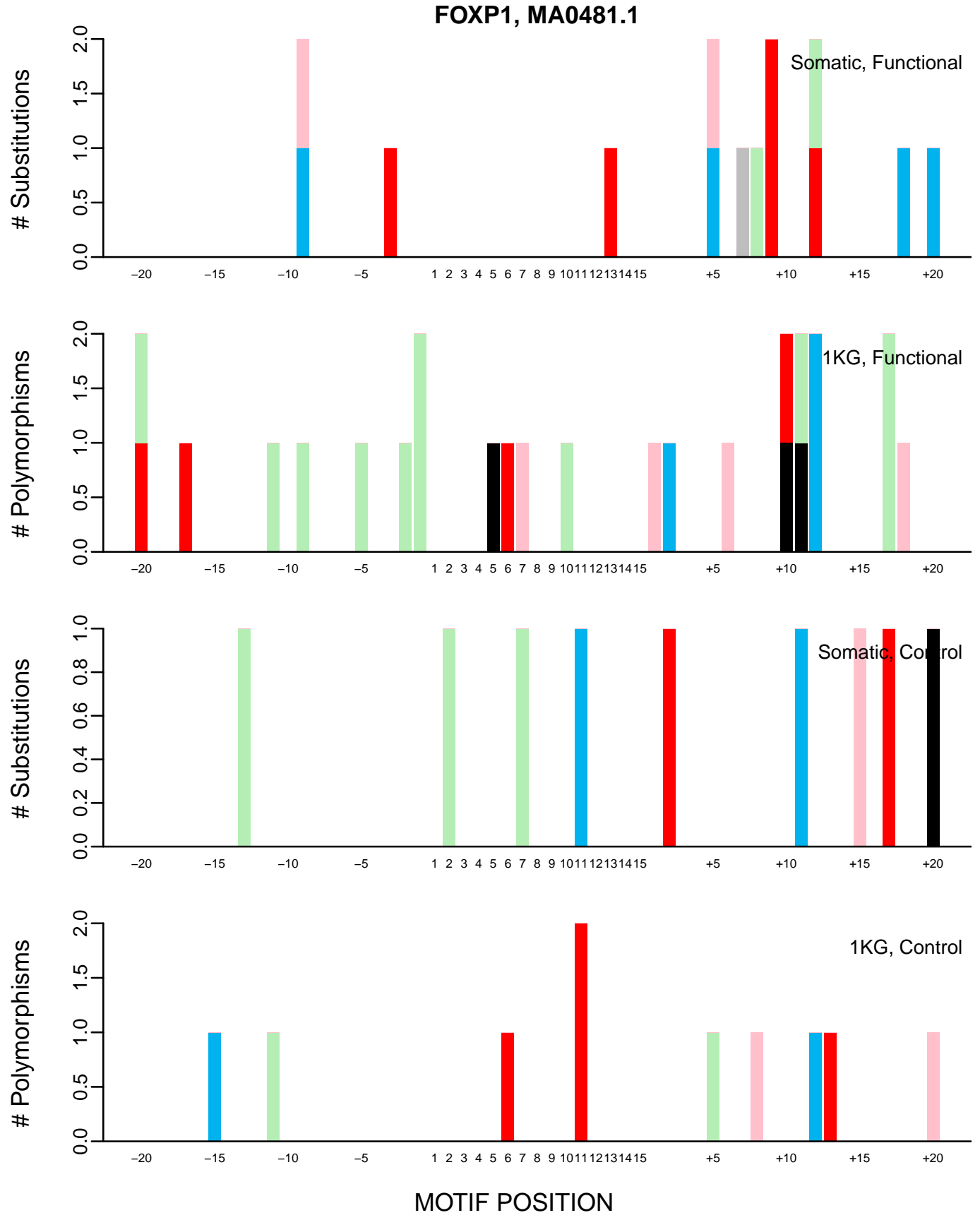
HNF4G, MA0484.1
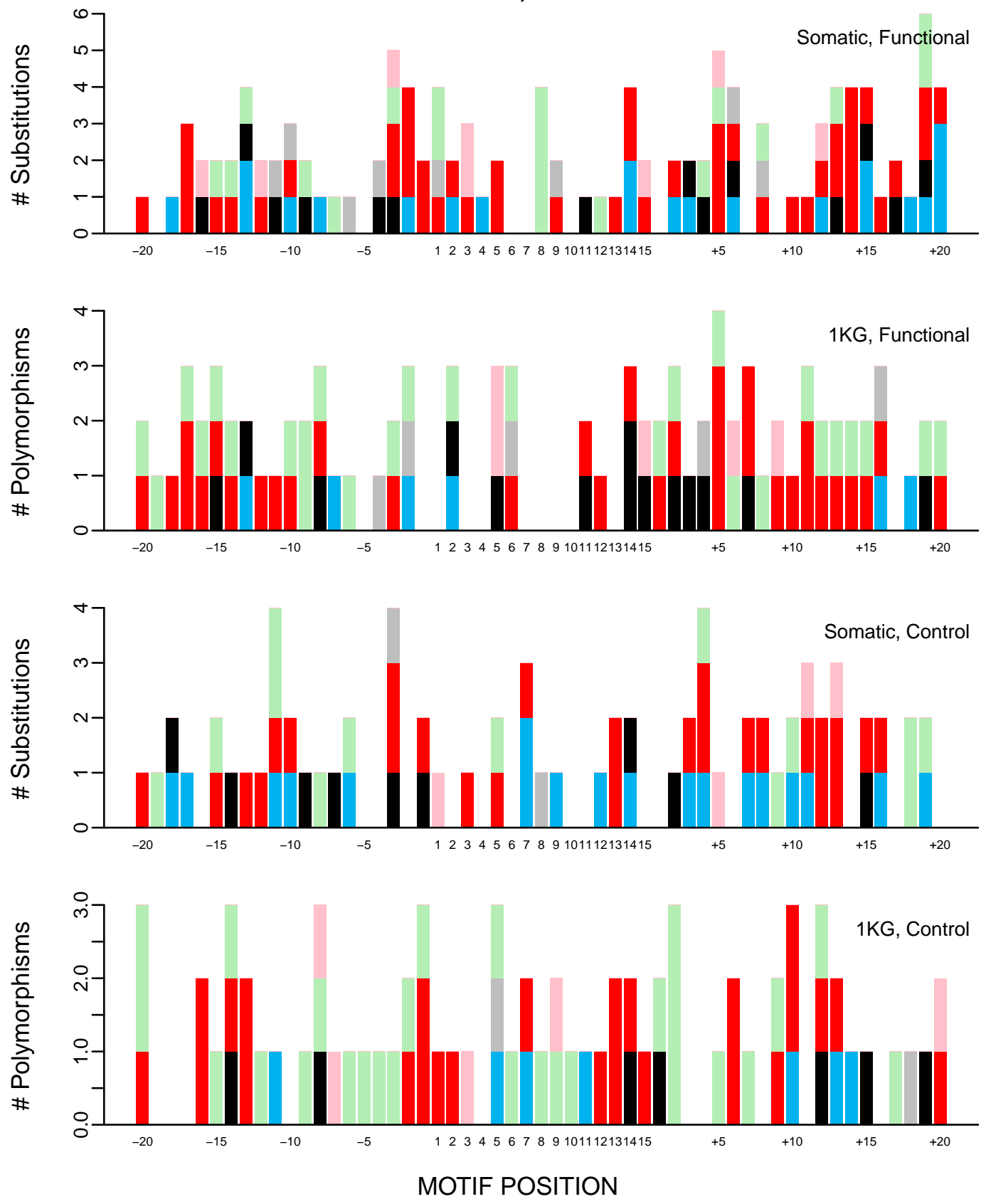
HSF1, MA0486.1
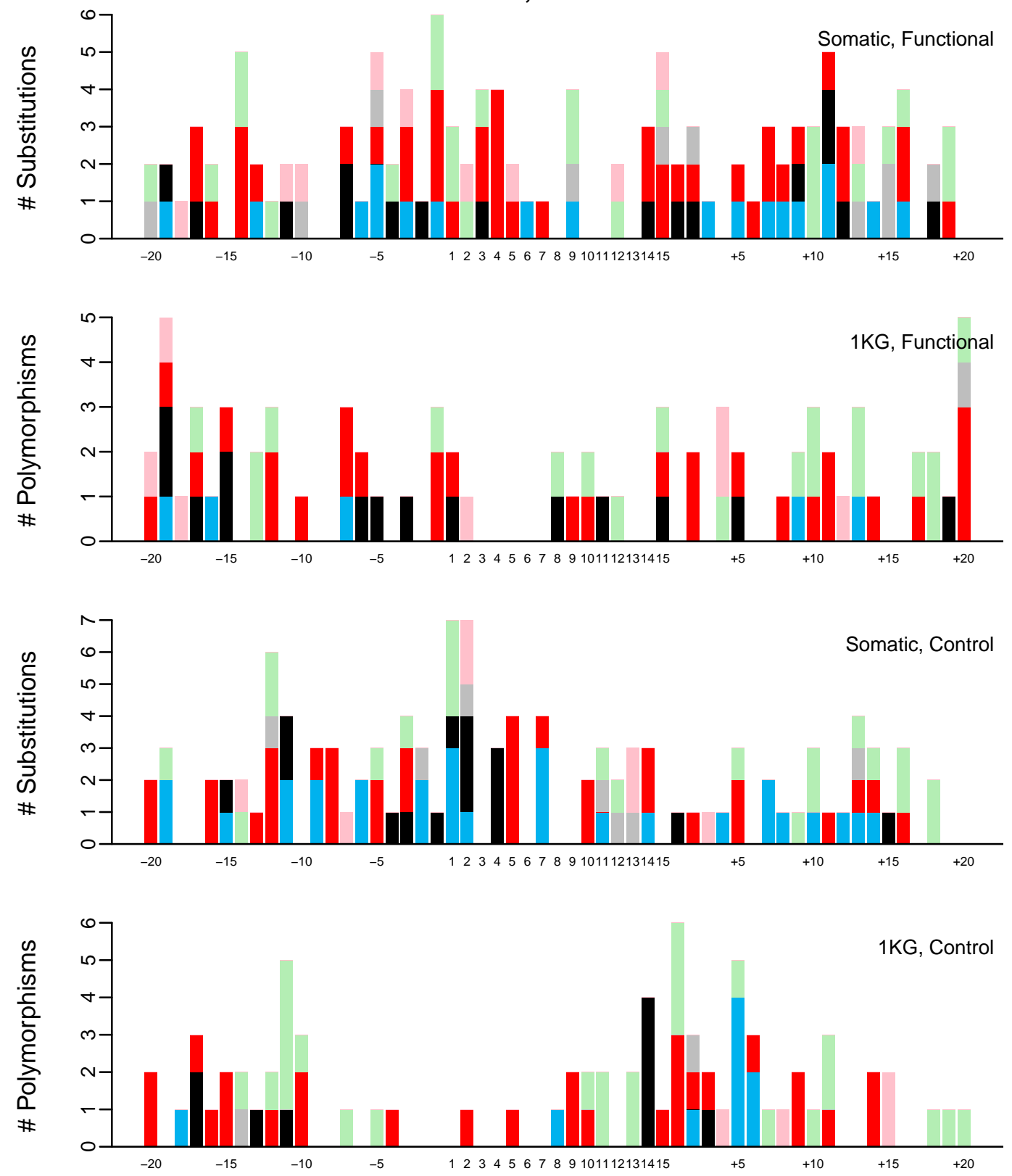


\section{CJUN, MA0488.1}
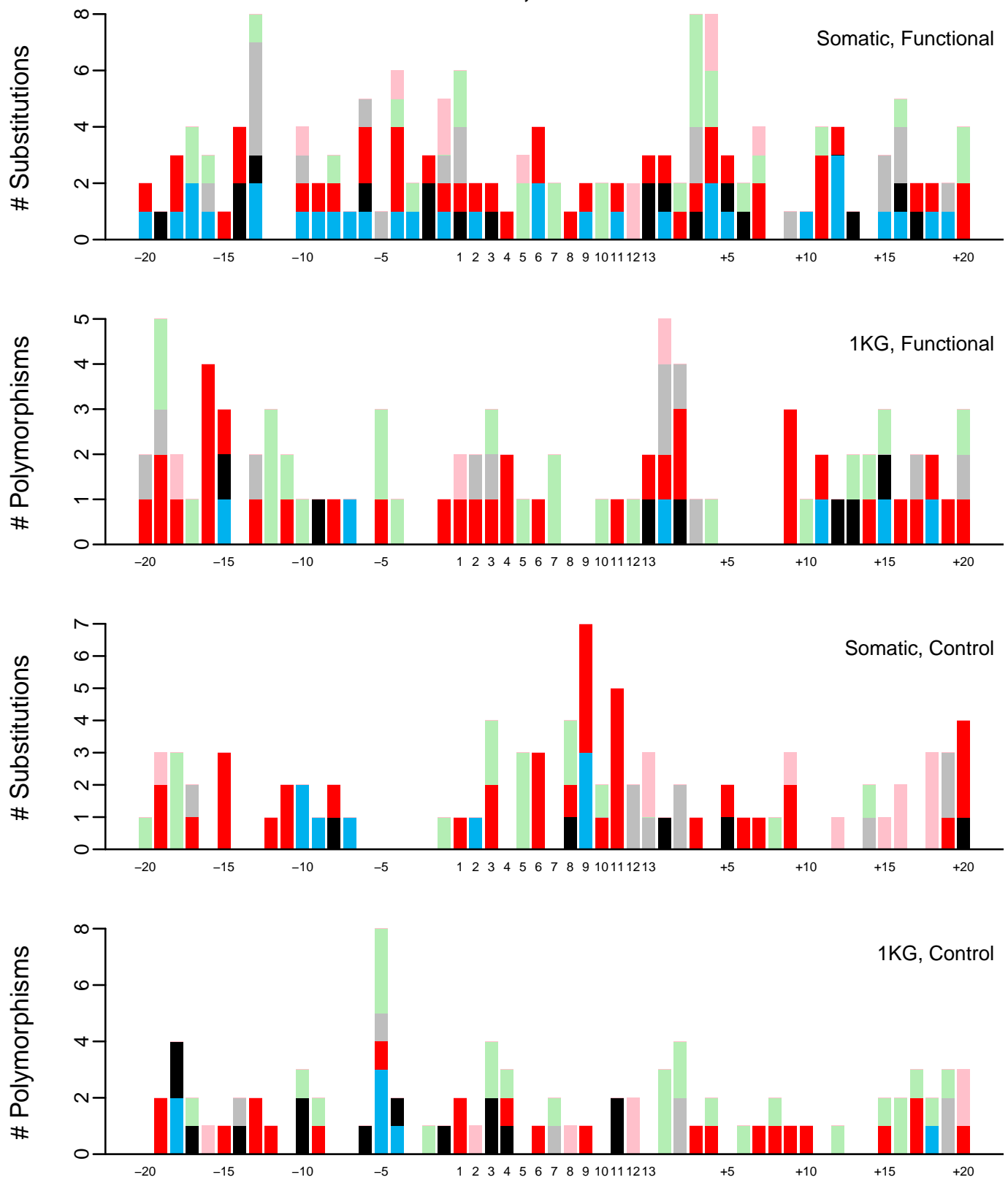


\section{CJUN, MA0489.1}
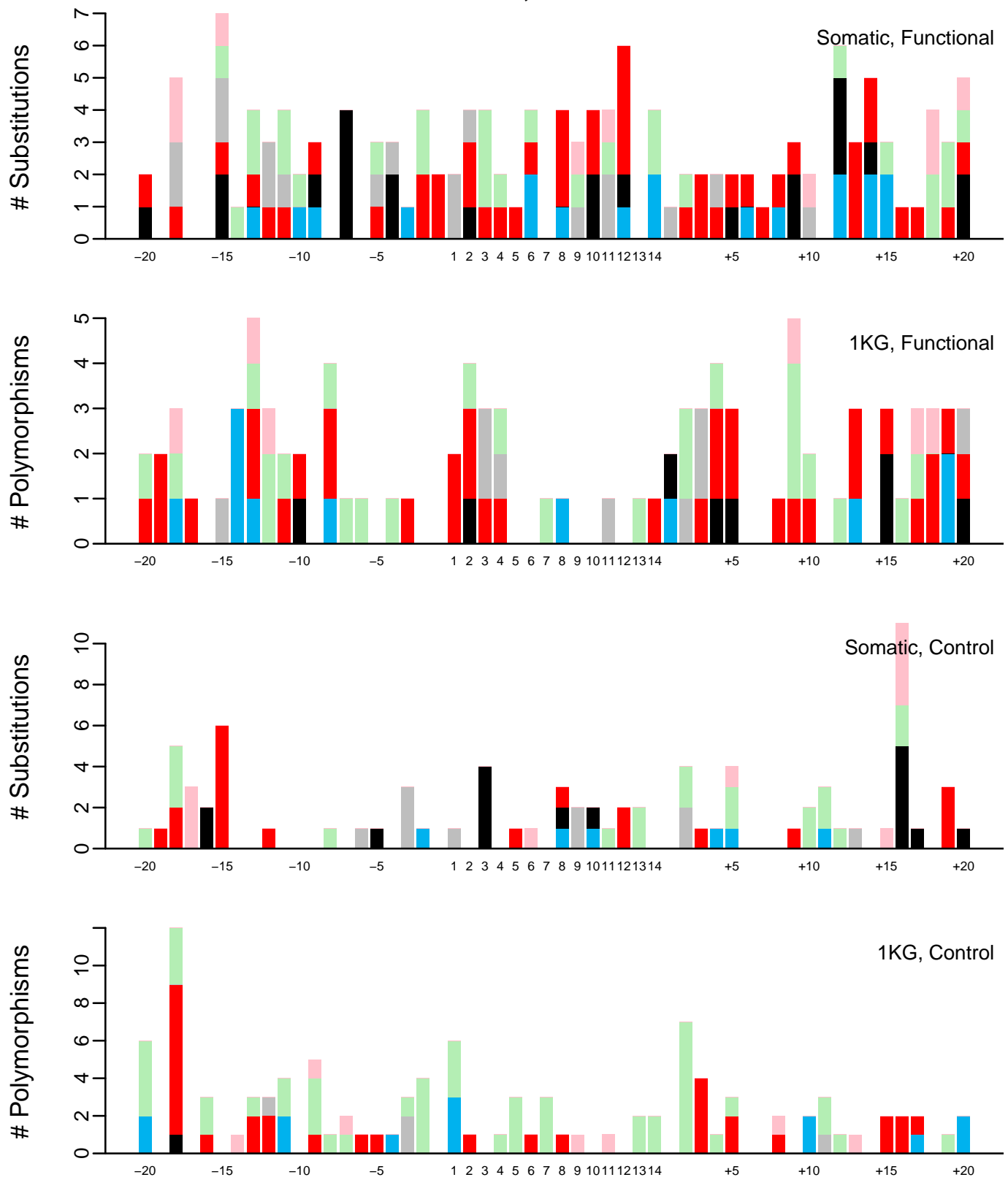


\section{JUNB, MA0490.1}
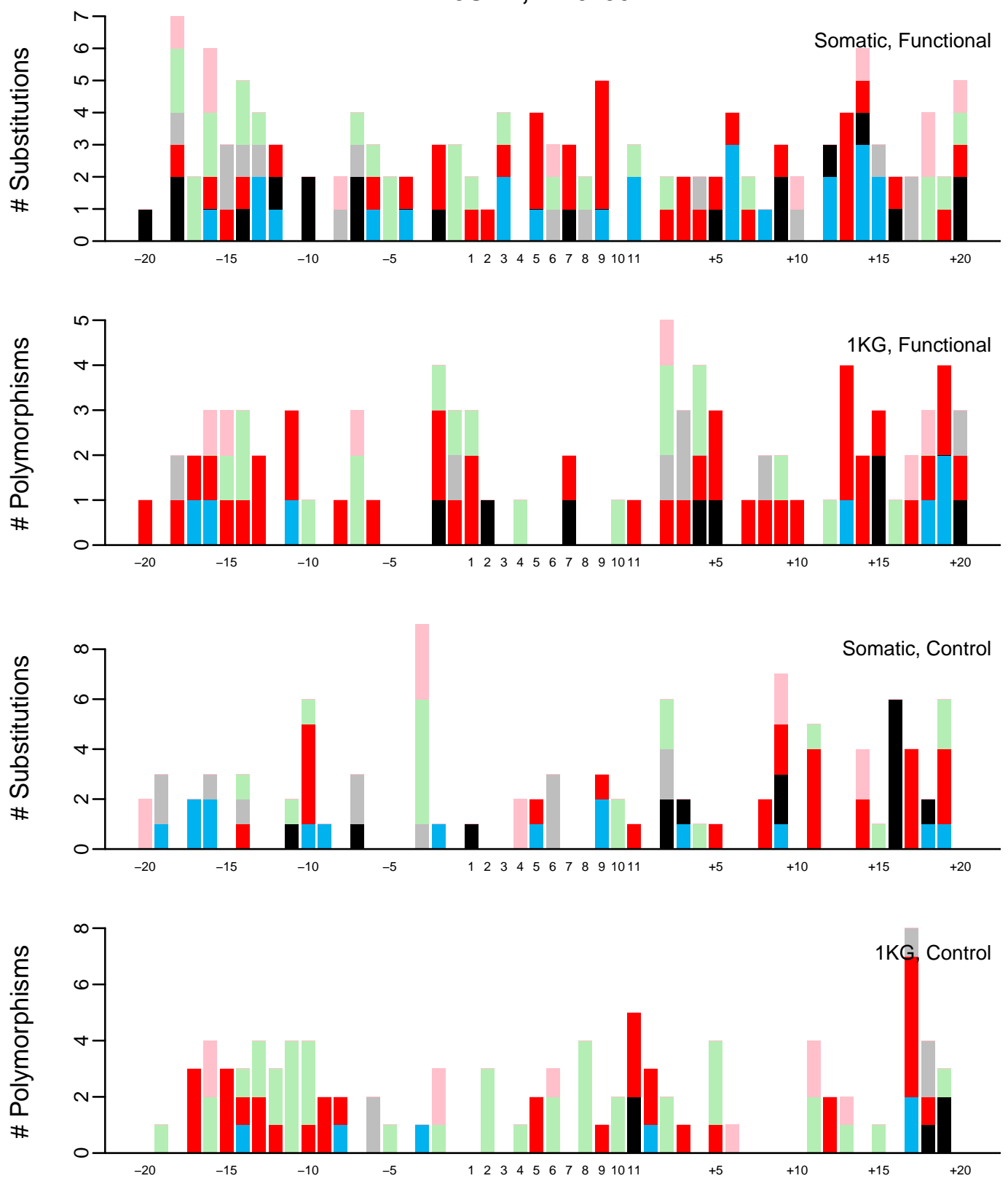


\section{JUND, MA0491.1}
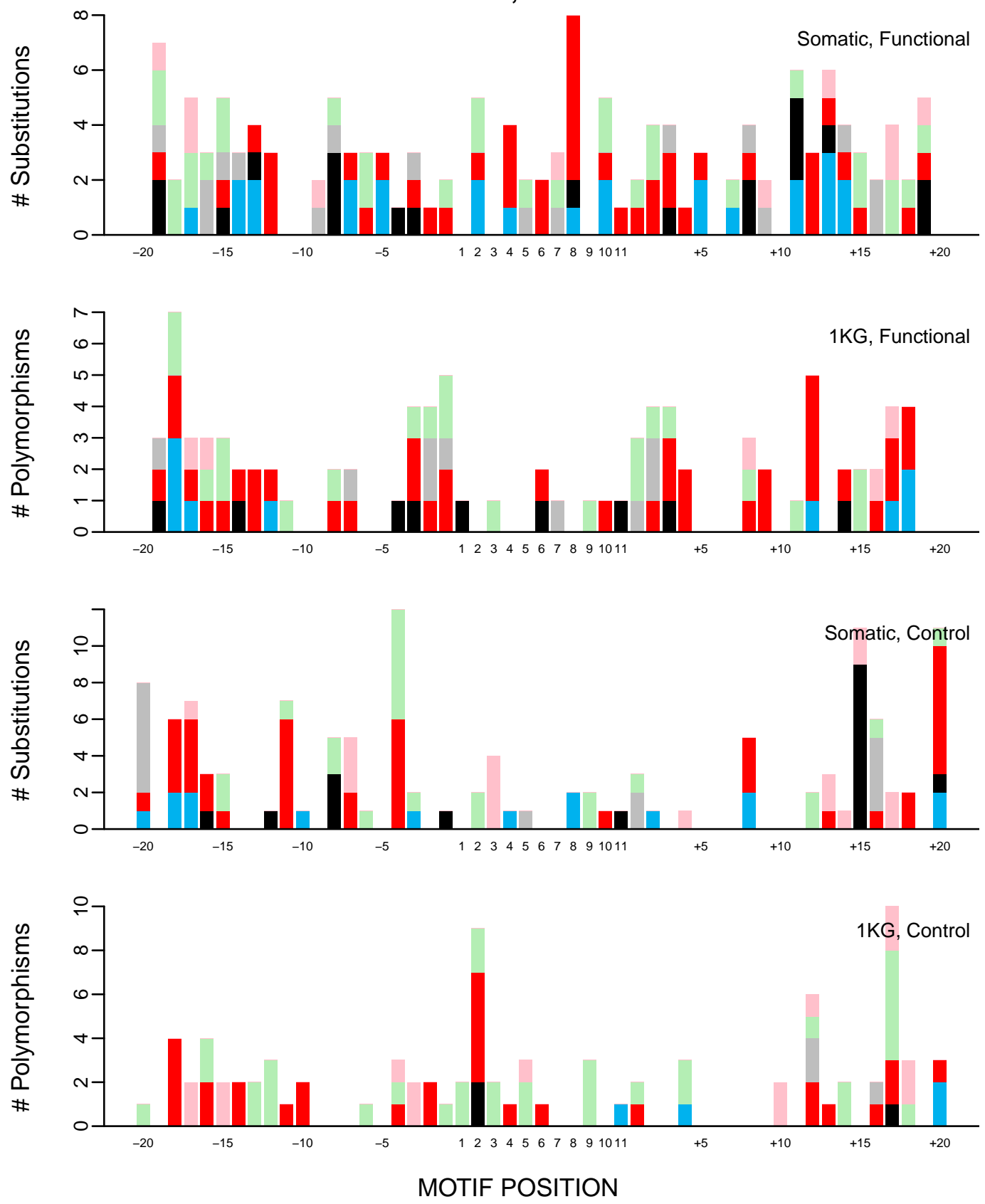


\section{JUND, MA0492.1}
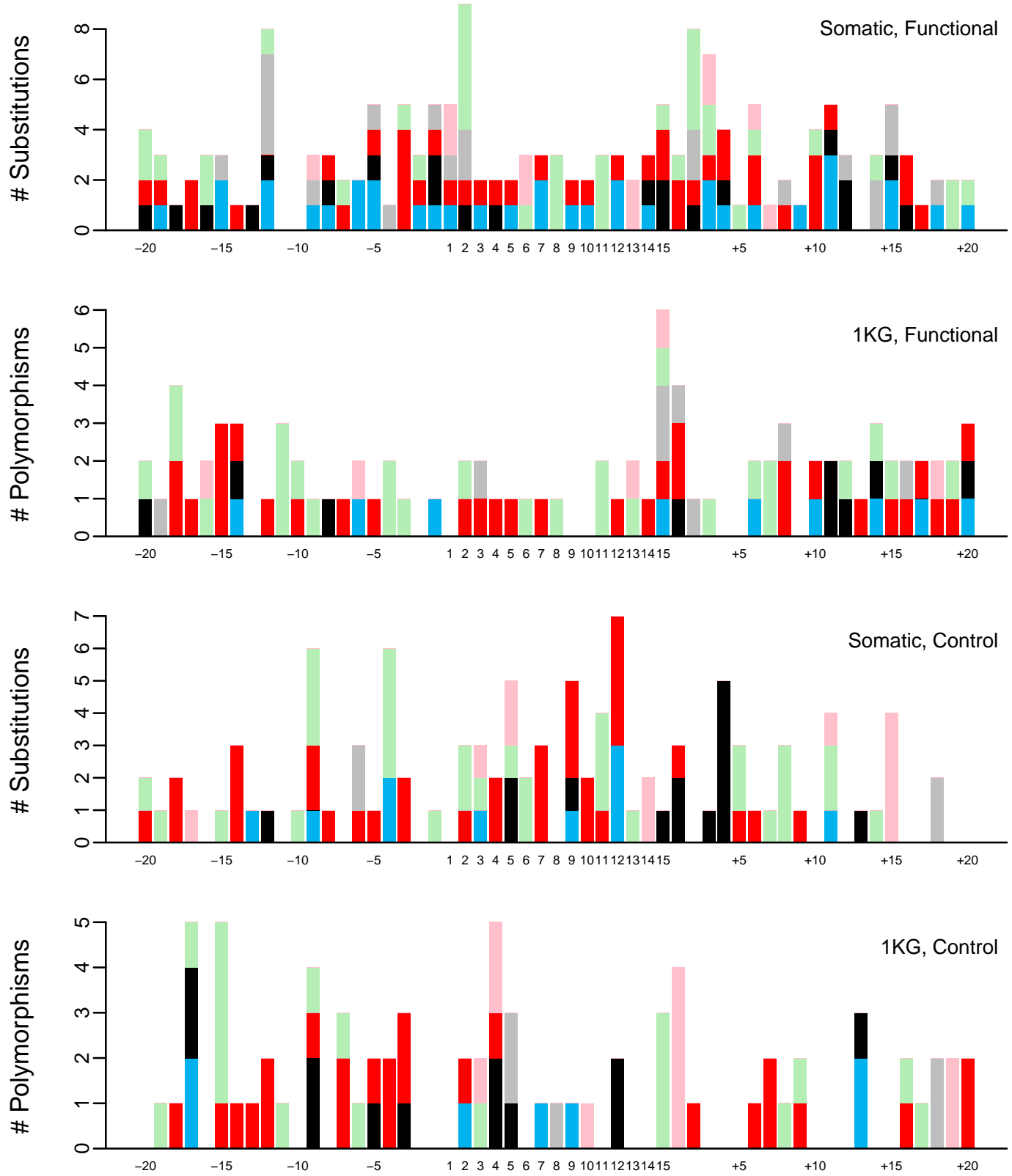

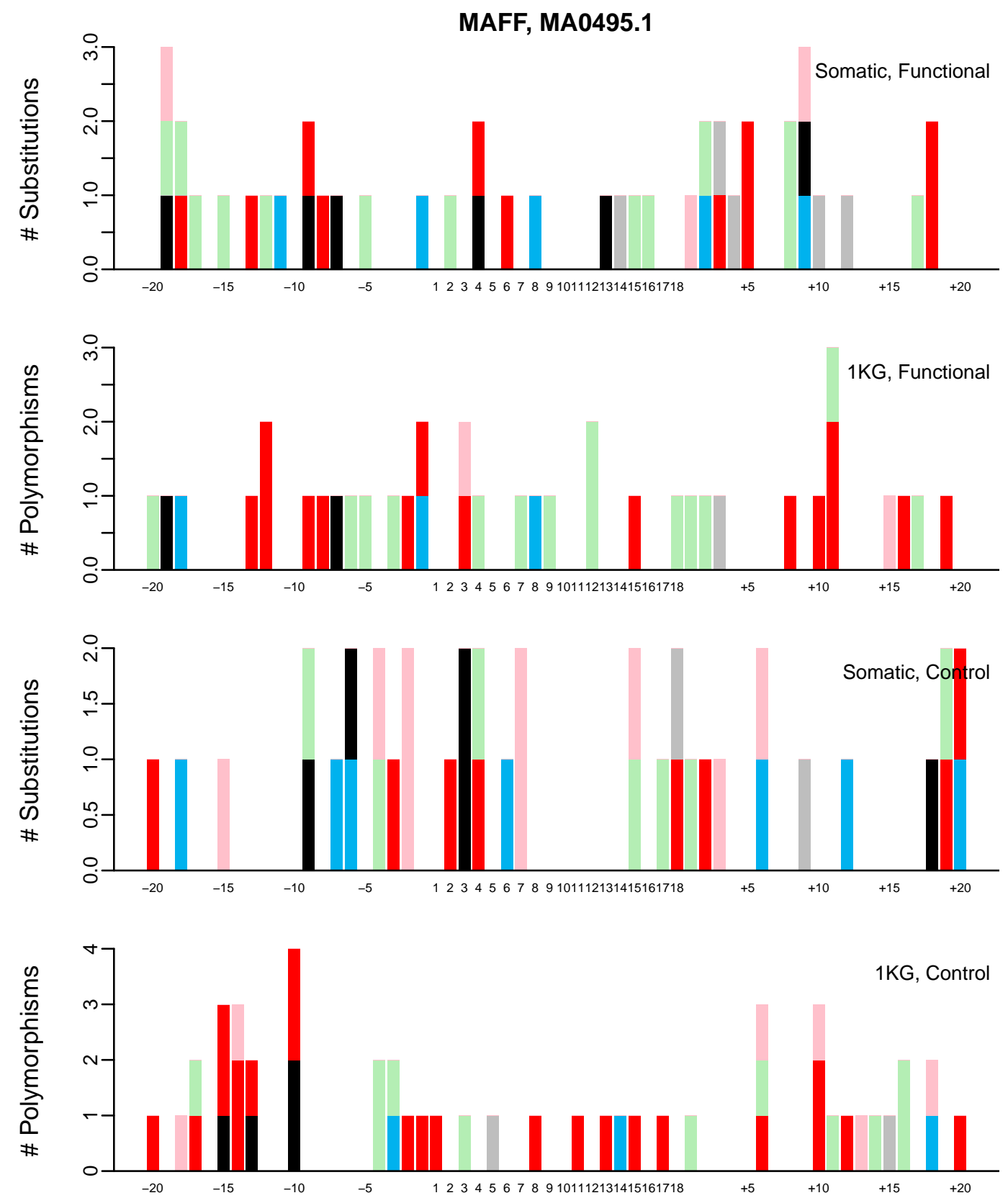
MAFK, MA0496.1
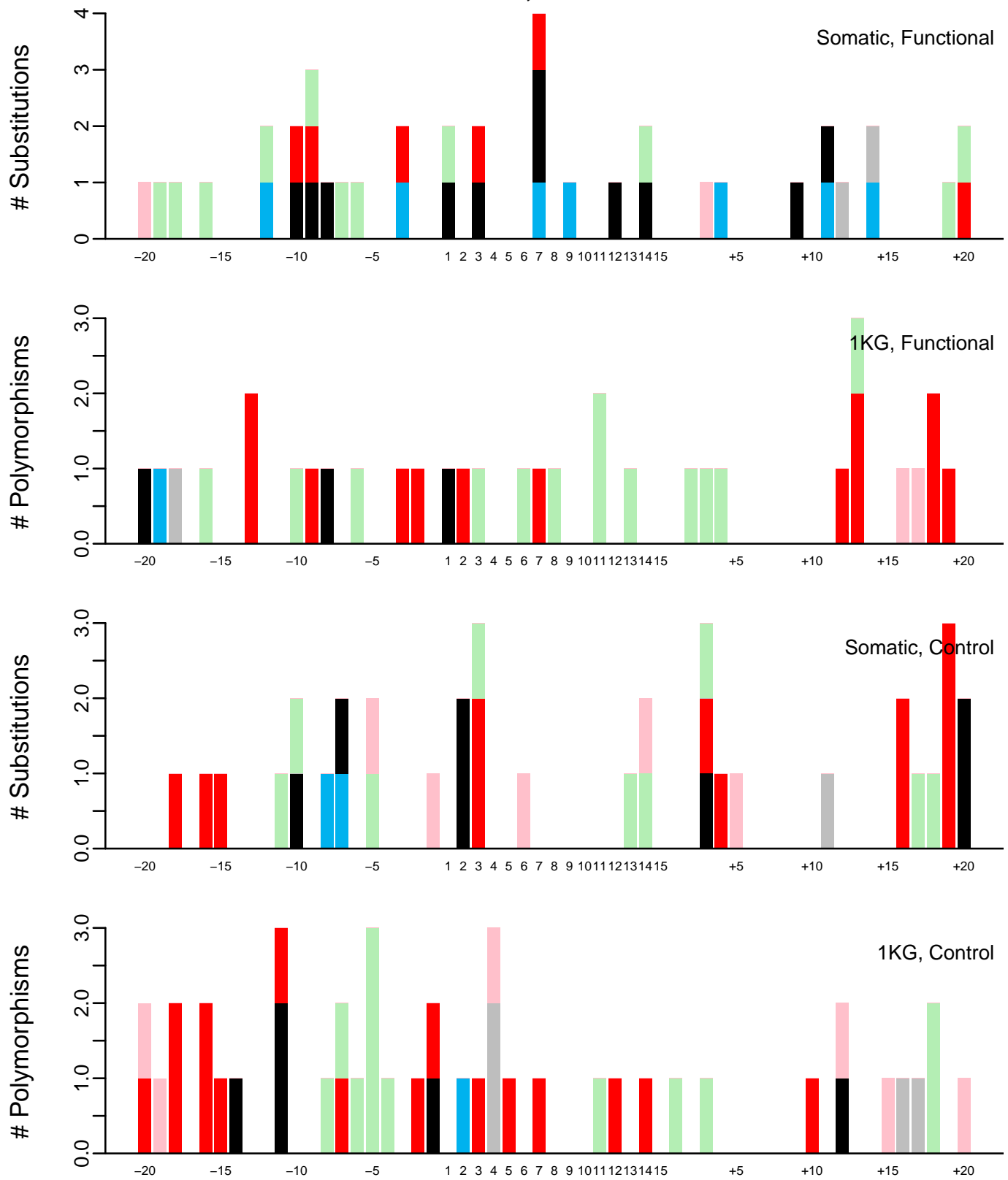

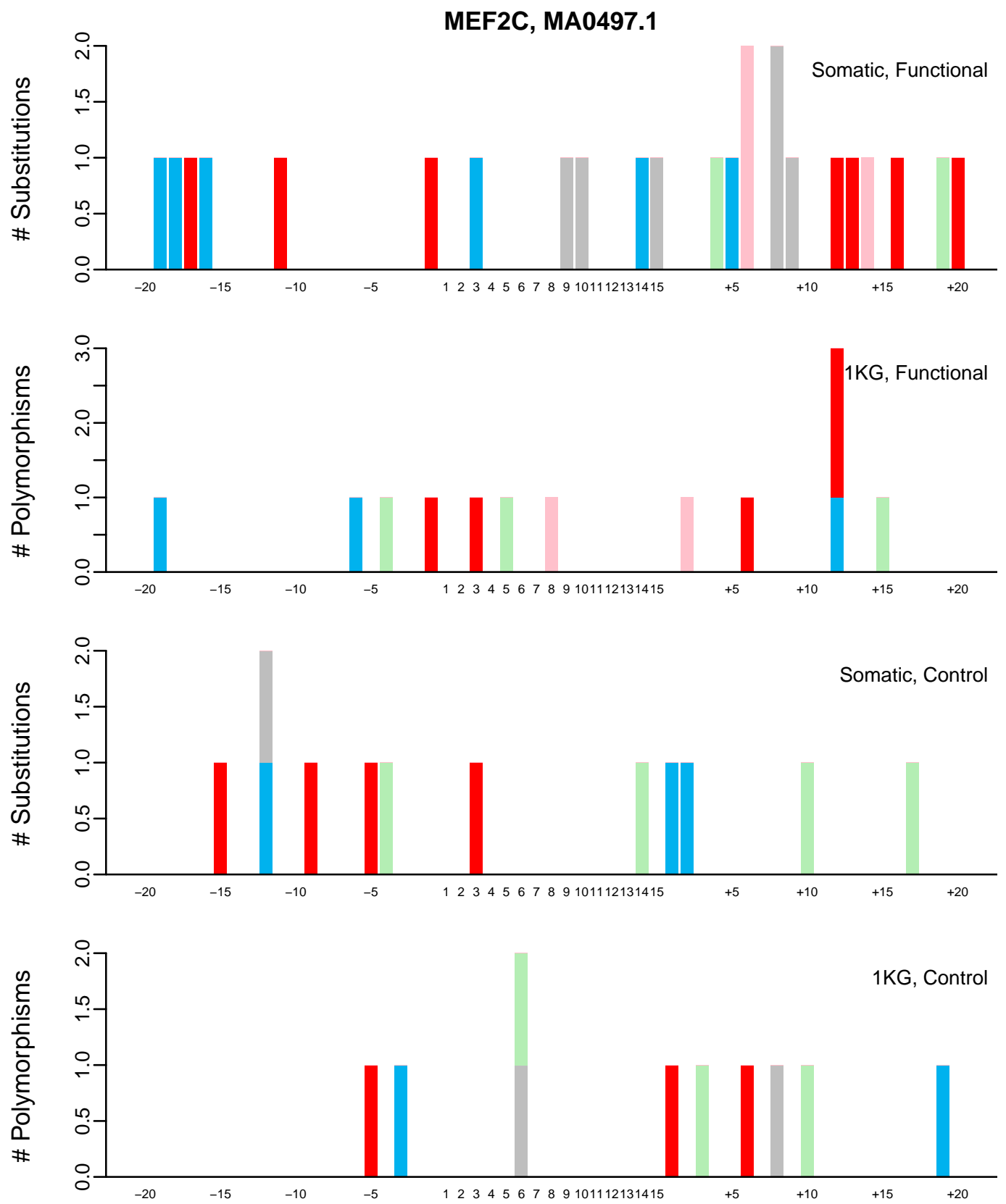

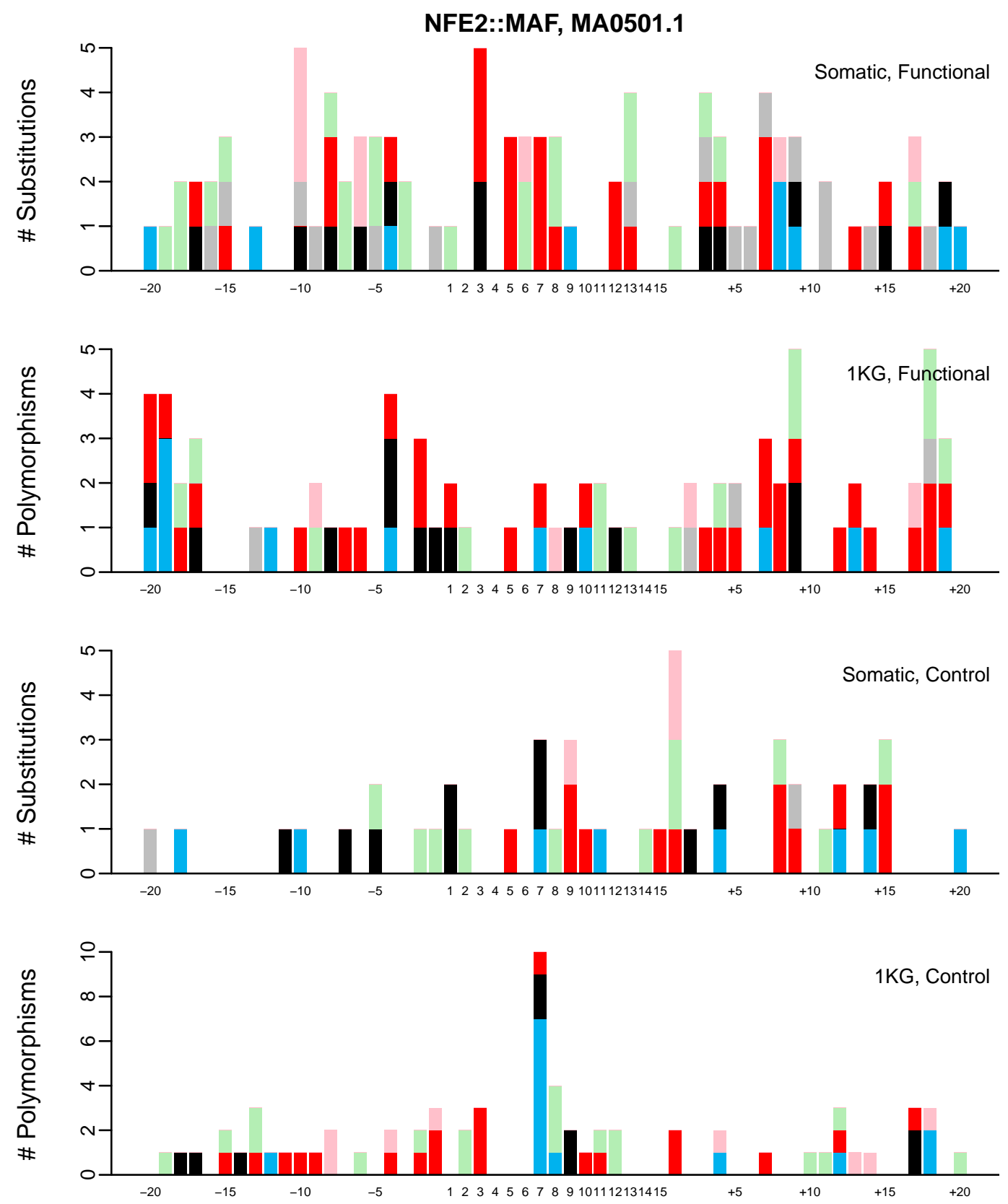
NFYB, MA0502.1
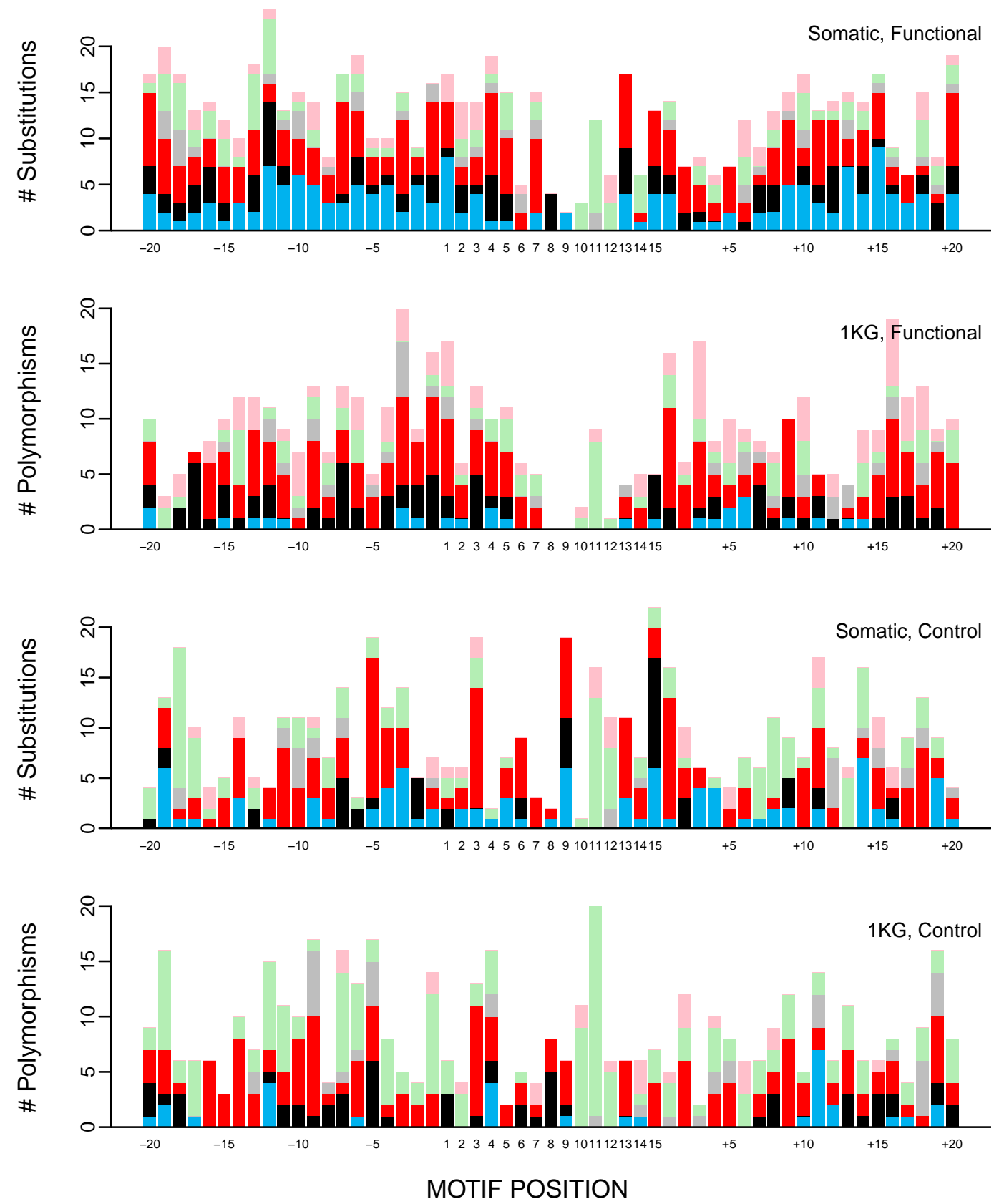
TR4, MA0504.1
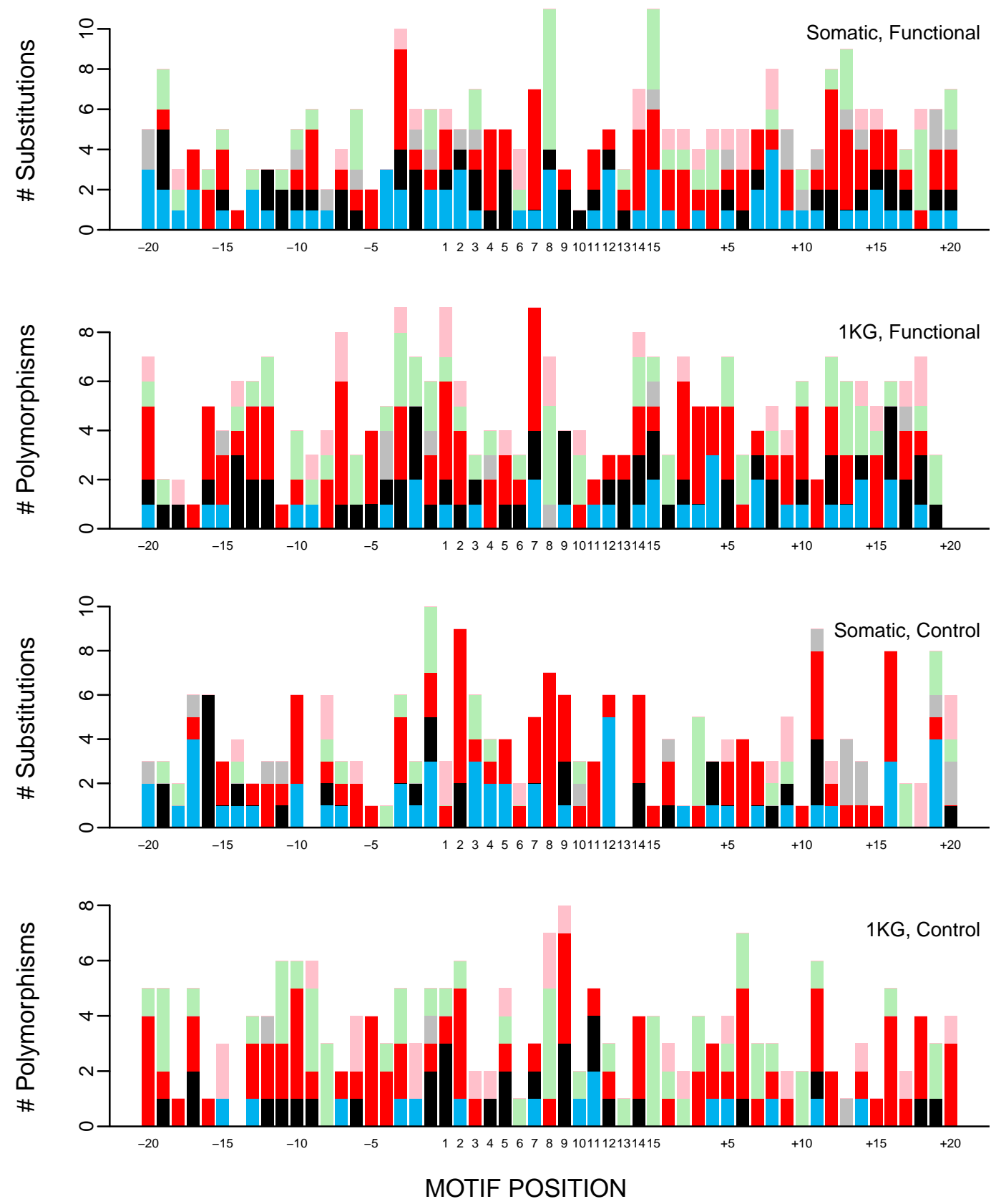
NRF1, MA0506.1
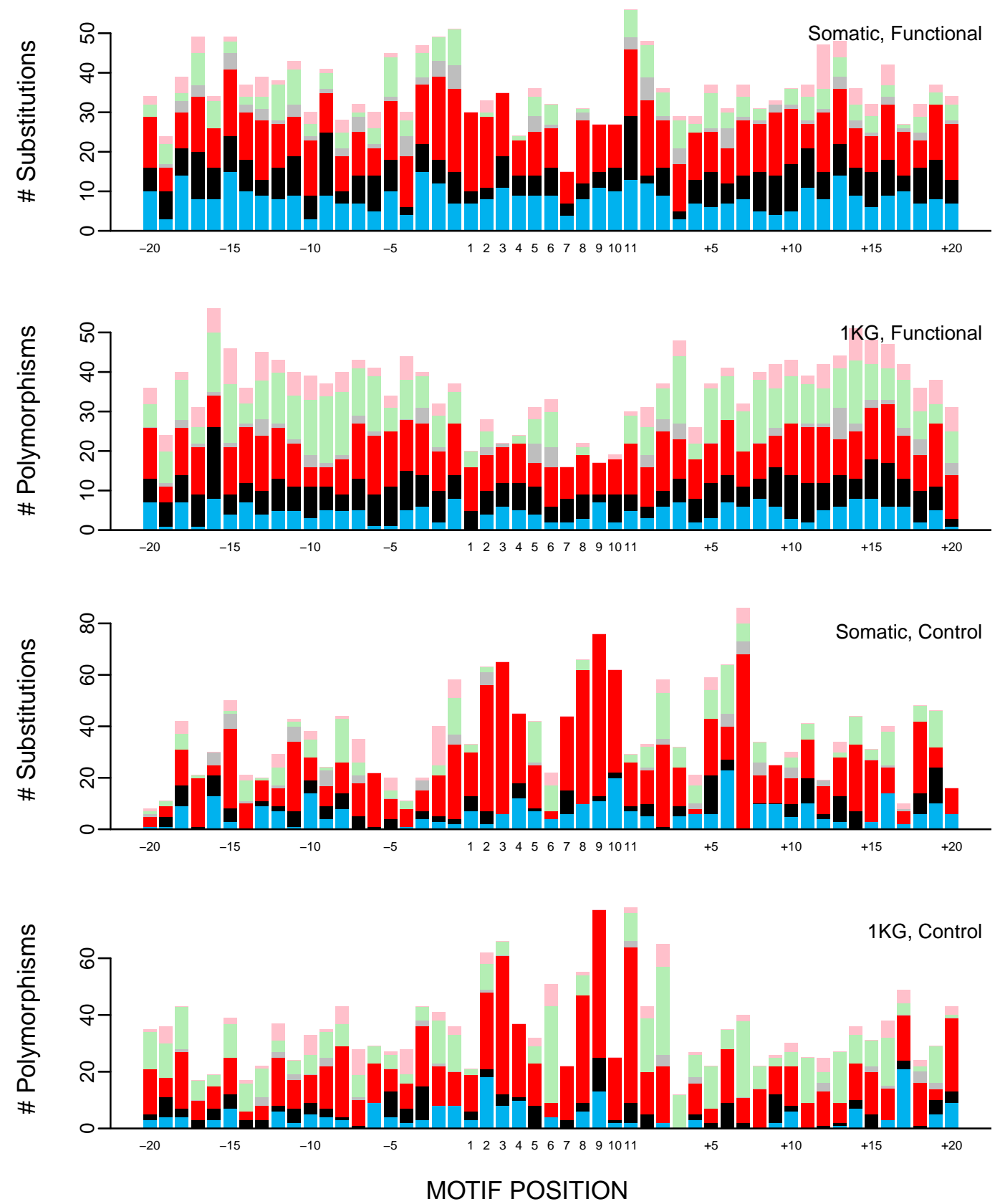
POU2F2, MA0507.1
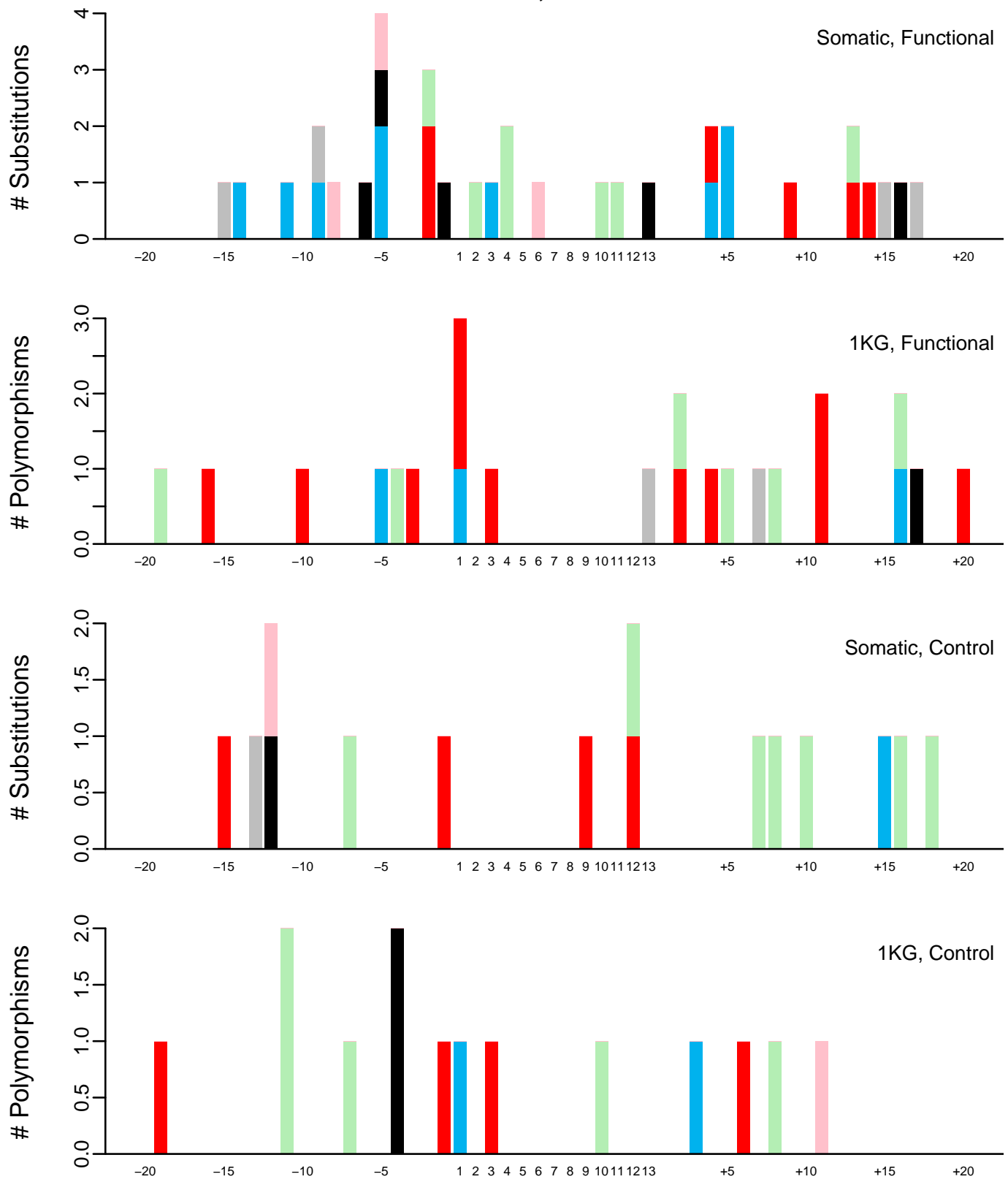
PRDM1, MA0508.1
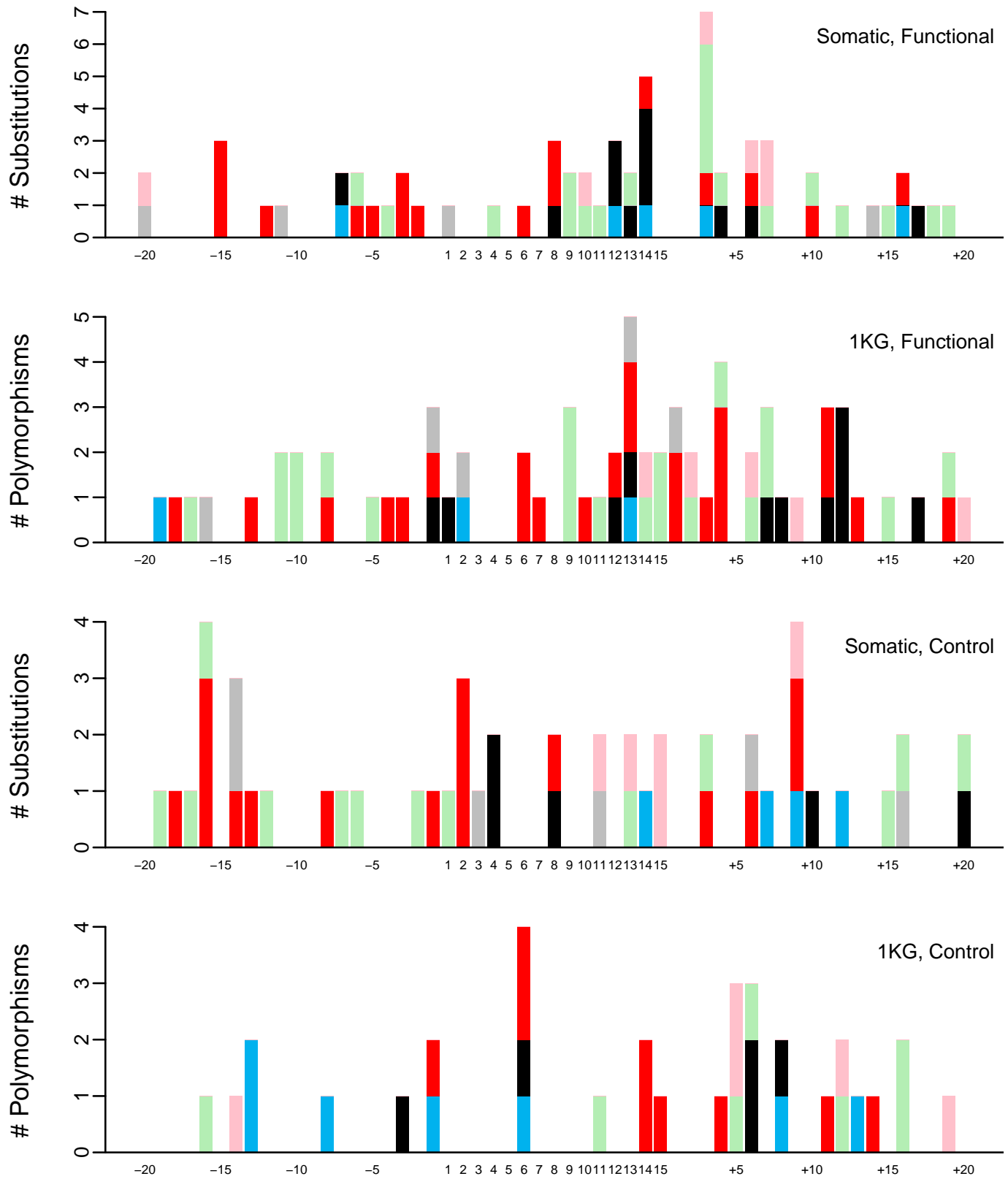
RFX5, MA0510.1
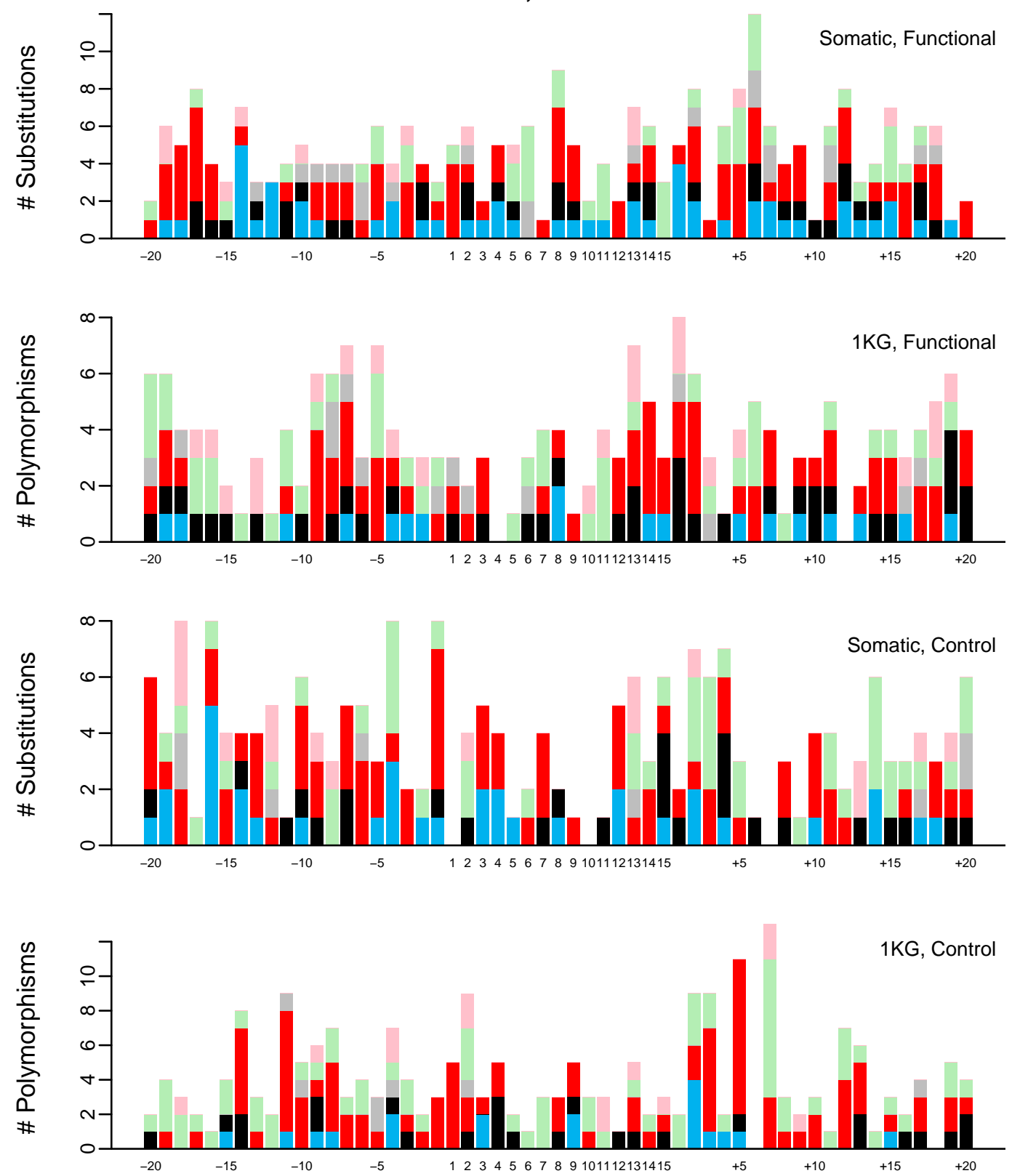
RUNX2, MA0511.1
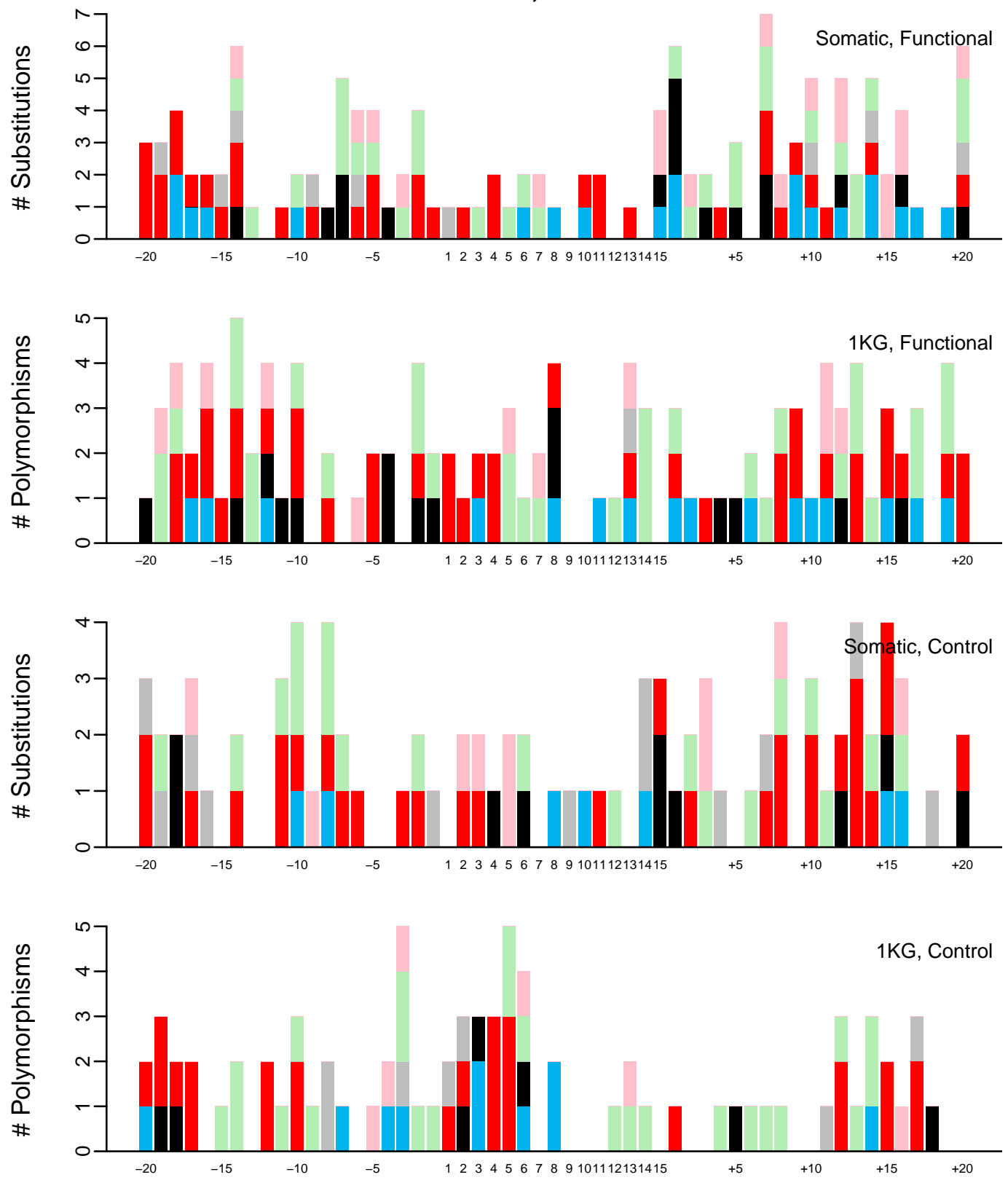
SMAD2::SMAD3::SMAD4, MA0513.1
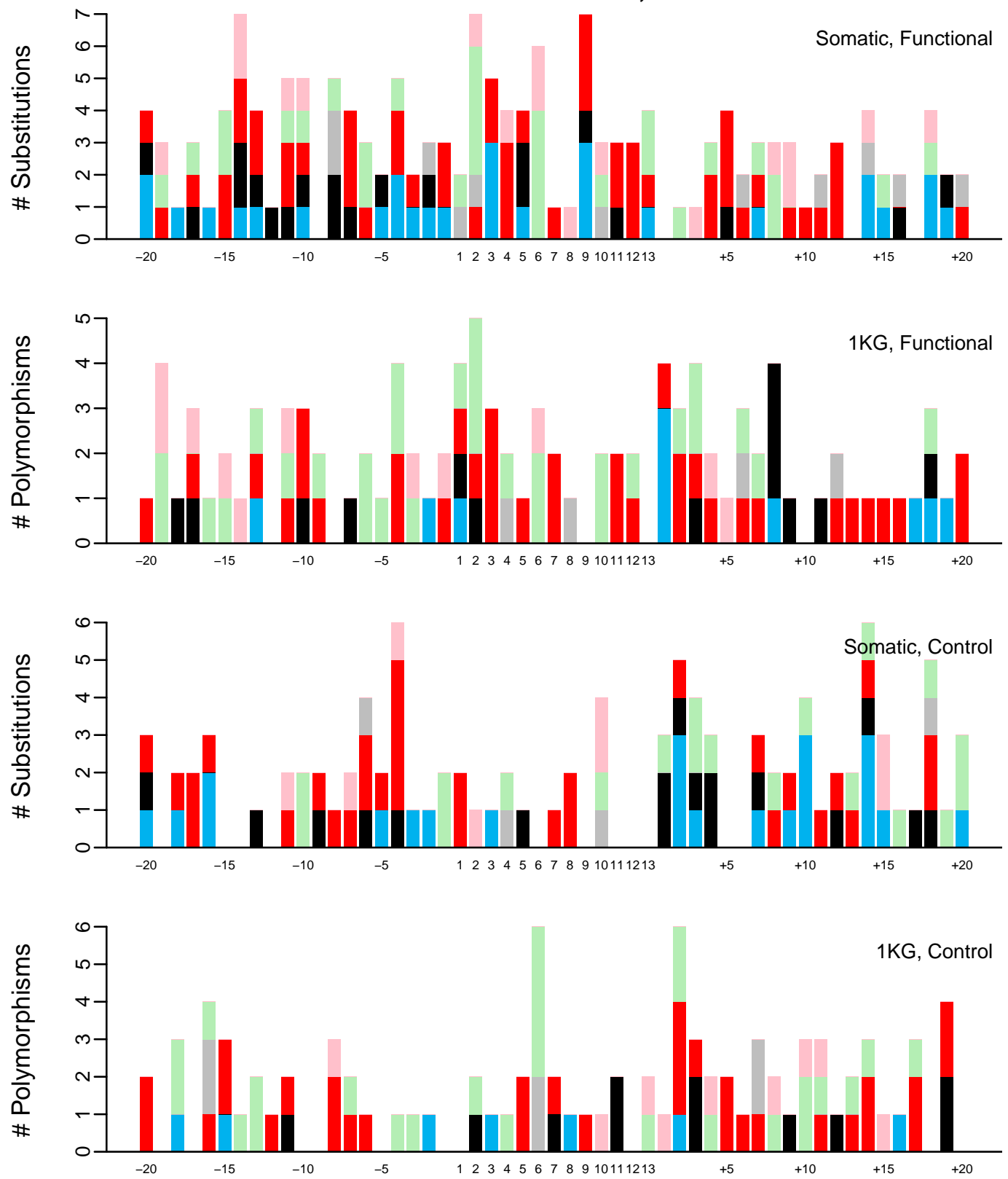
SP2, MA0516.1
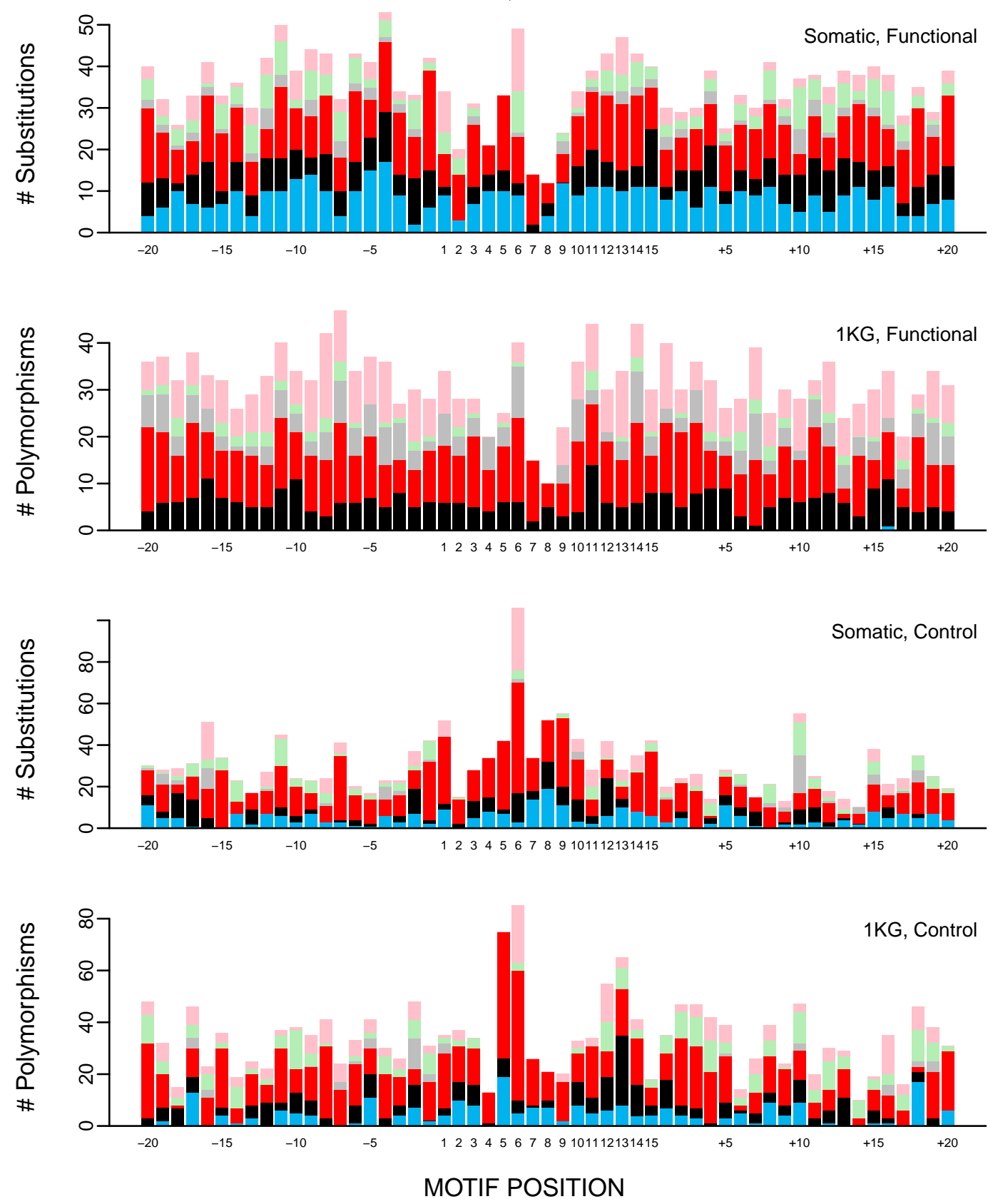
STAT2::STAT1, MA0517.1
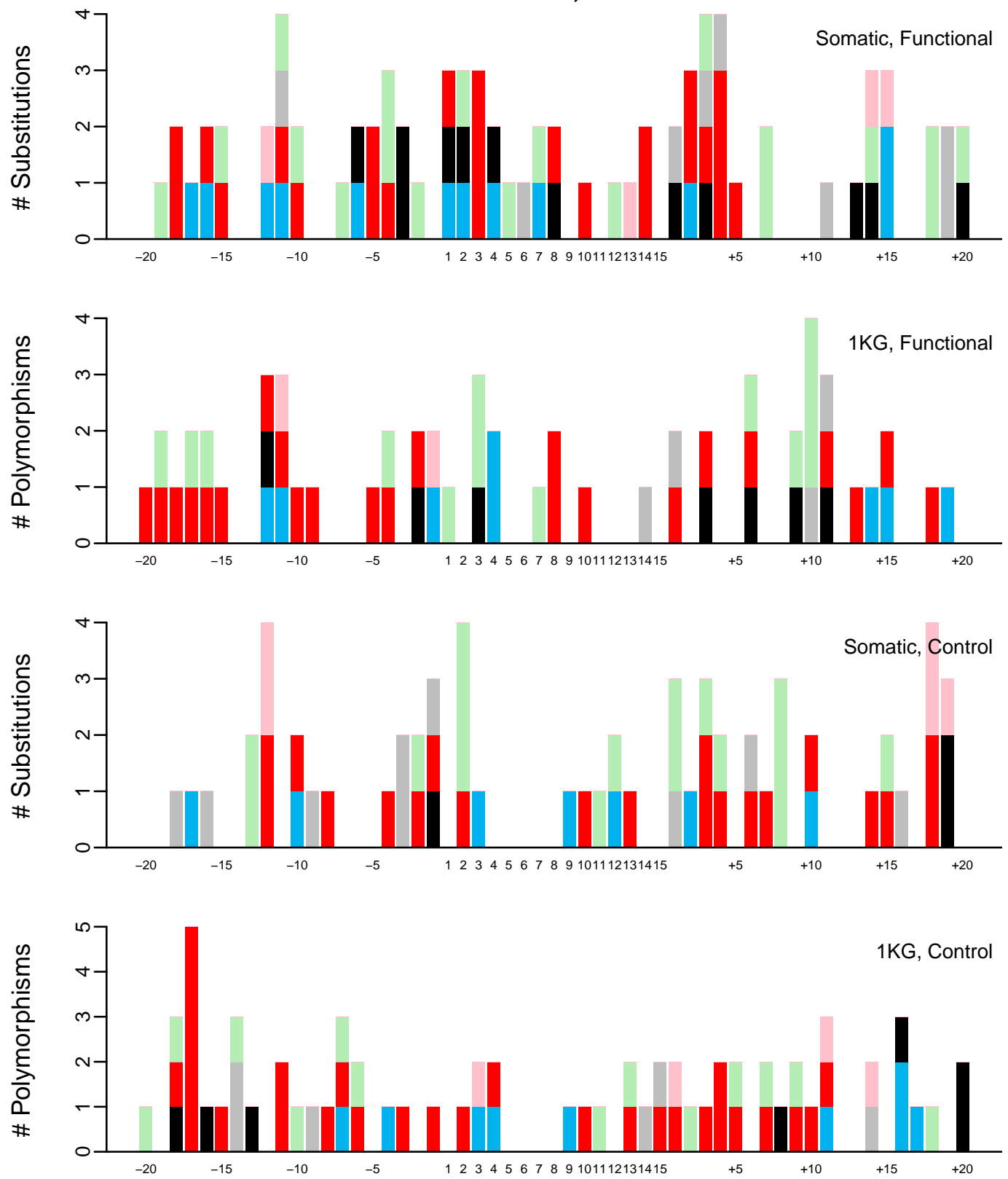
TCF12, MA0521.1
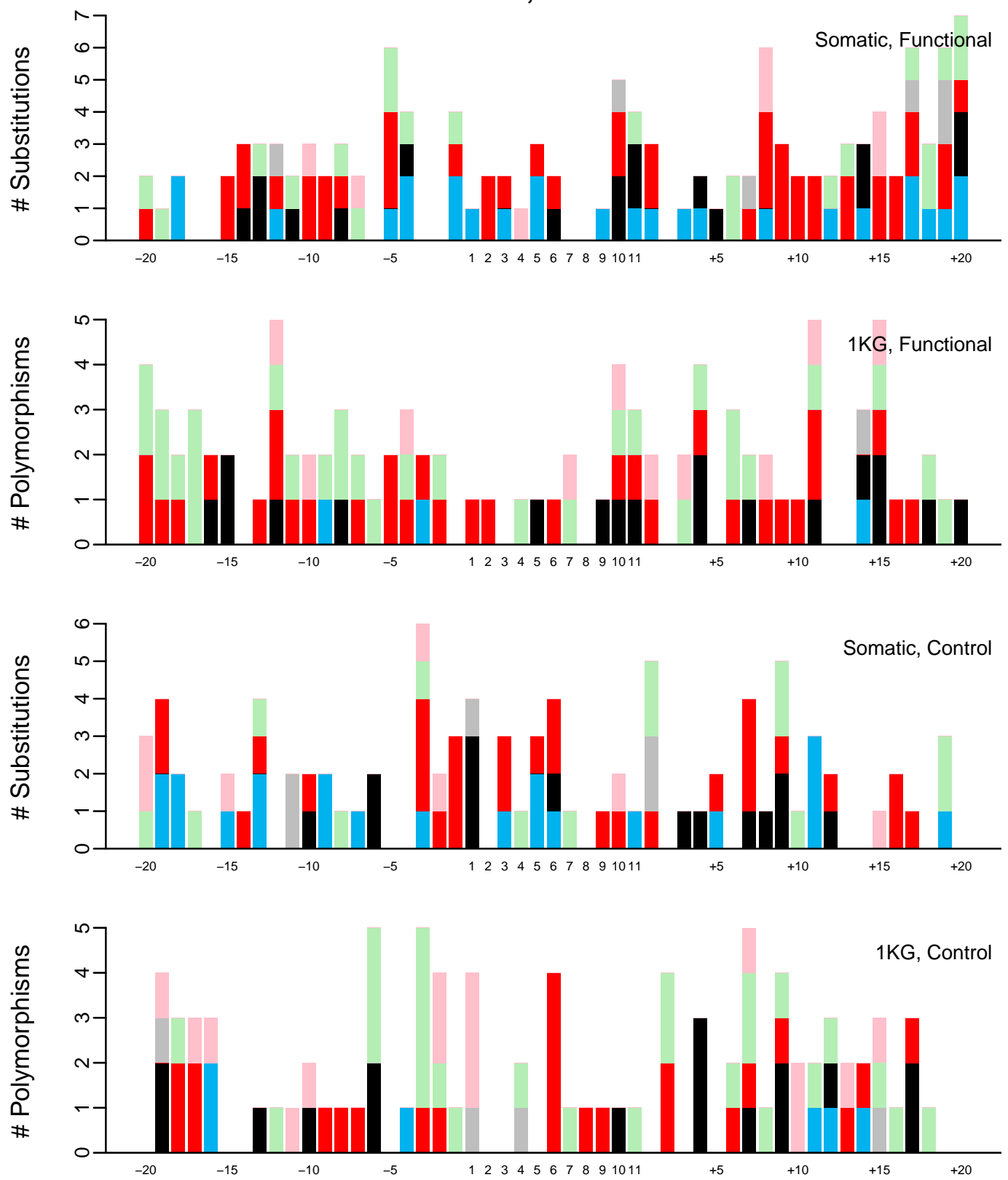
TCF7L2, MA0523.1
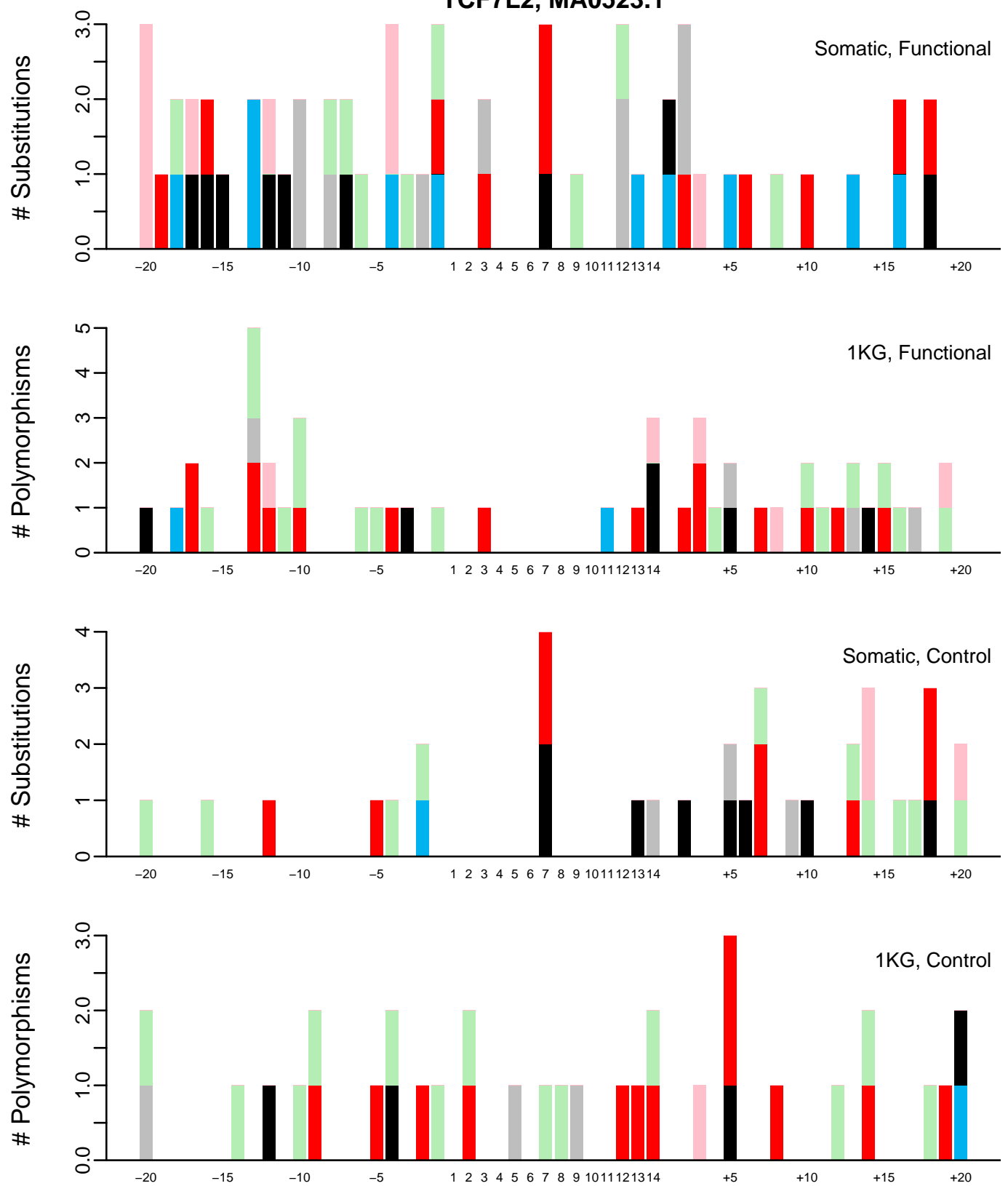
TFAP2C, MA0524.1
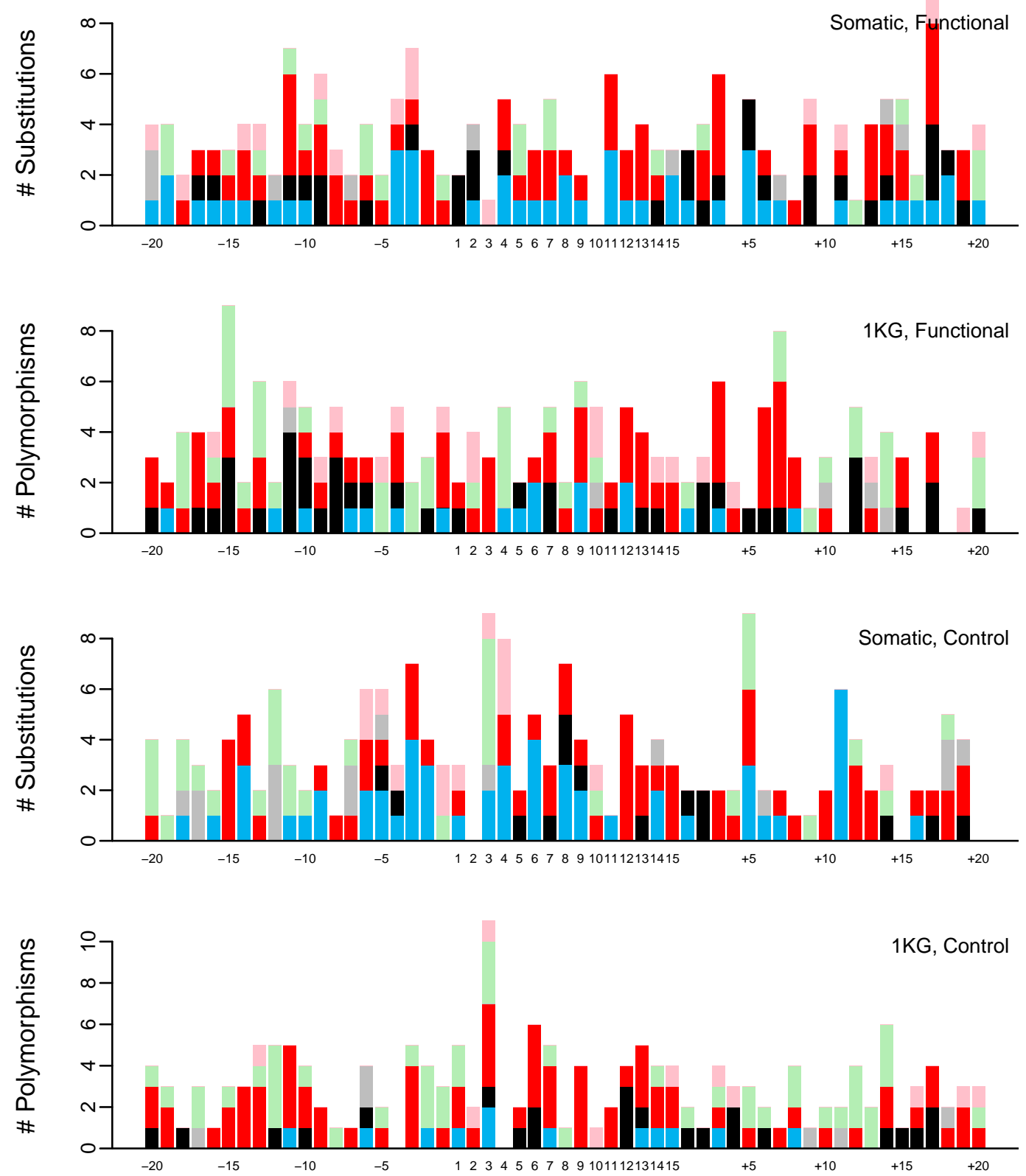
TP63, MA0525.1
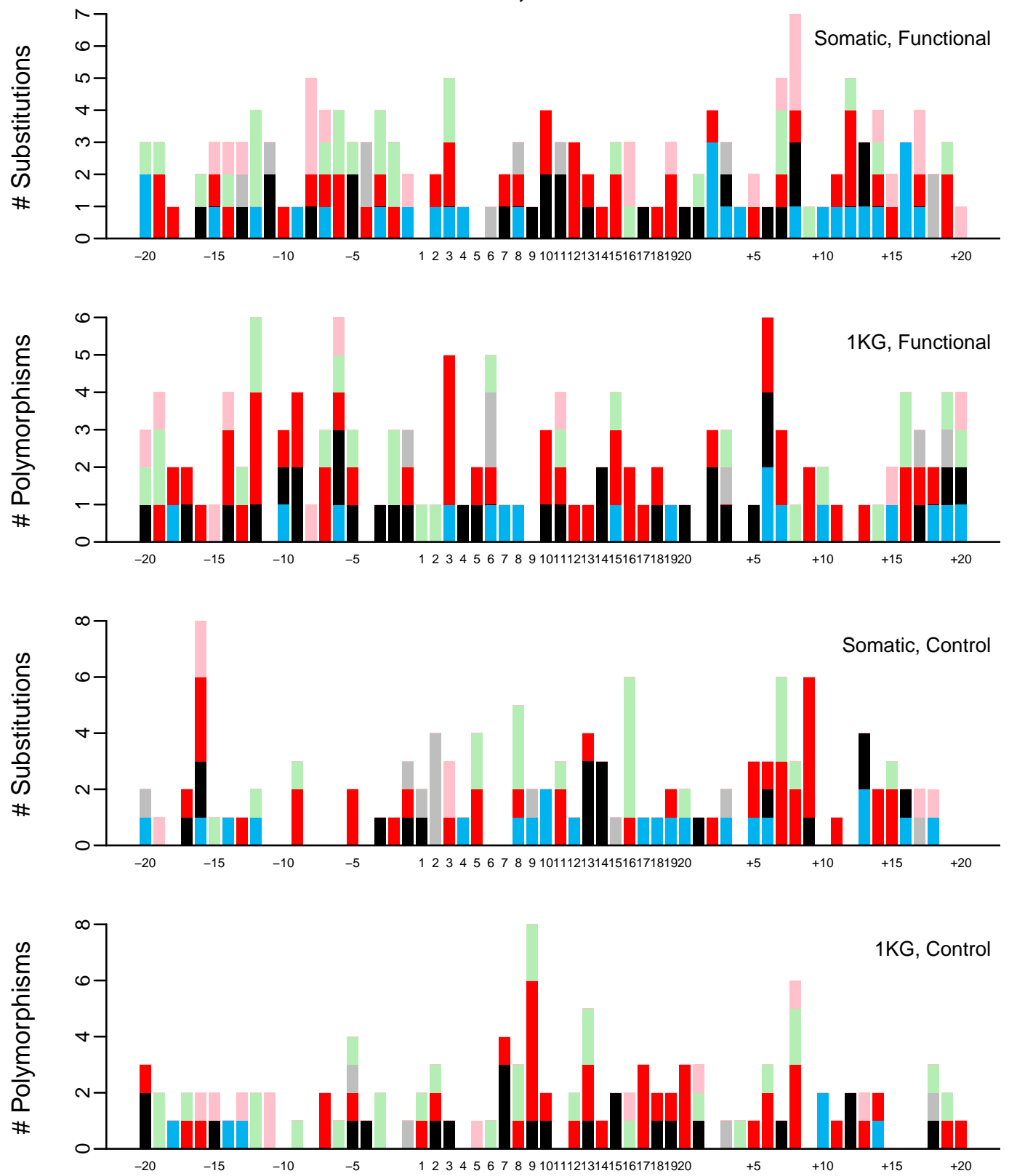

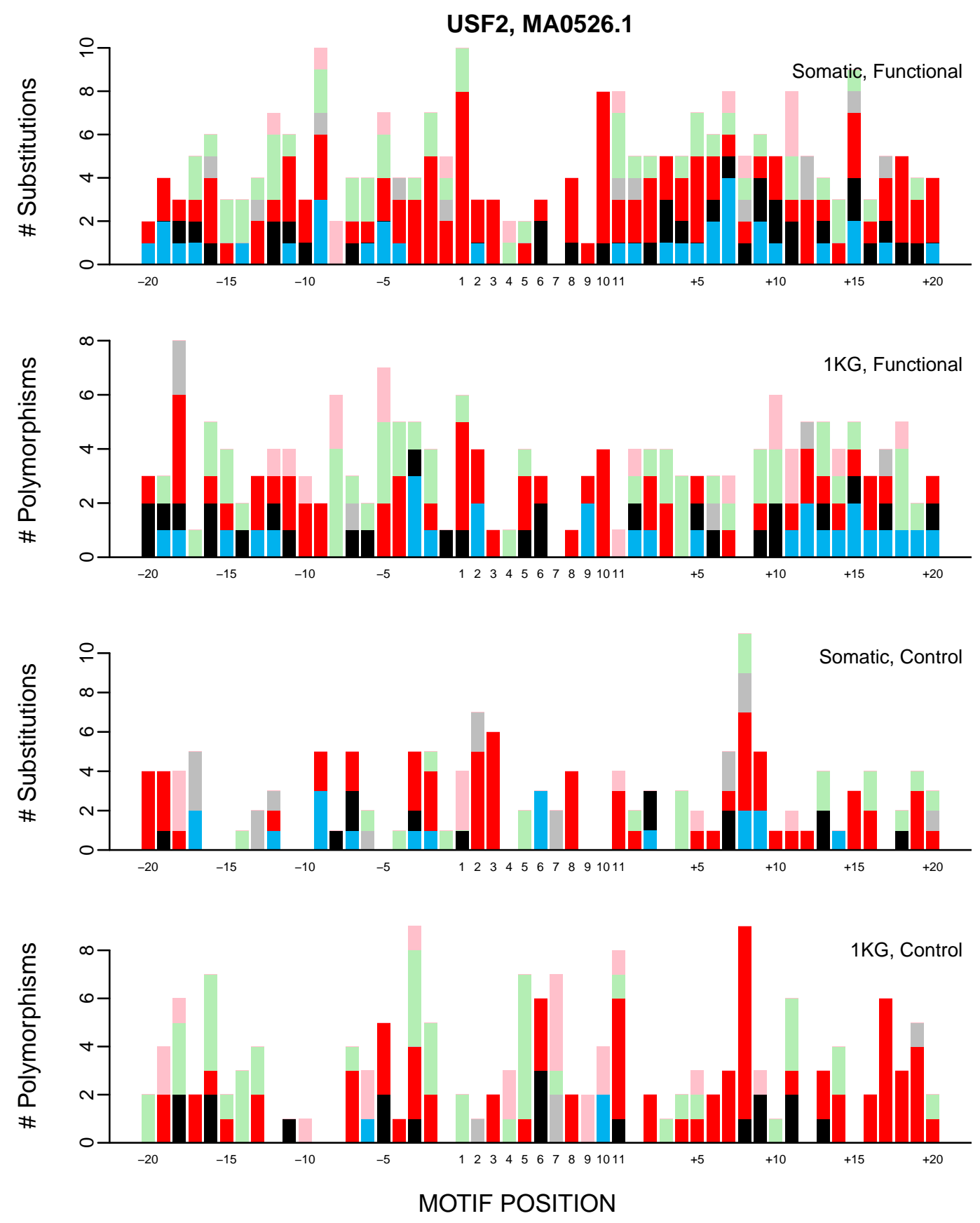
ZBTB33, MA0527.1
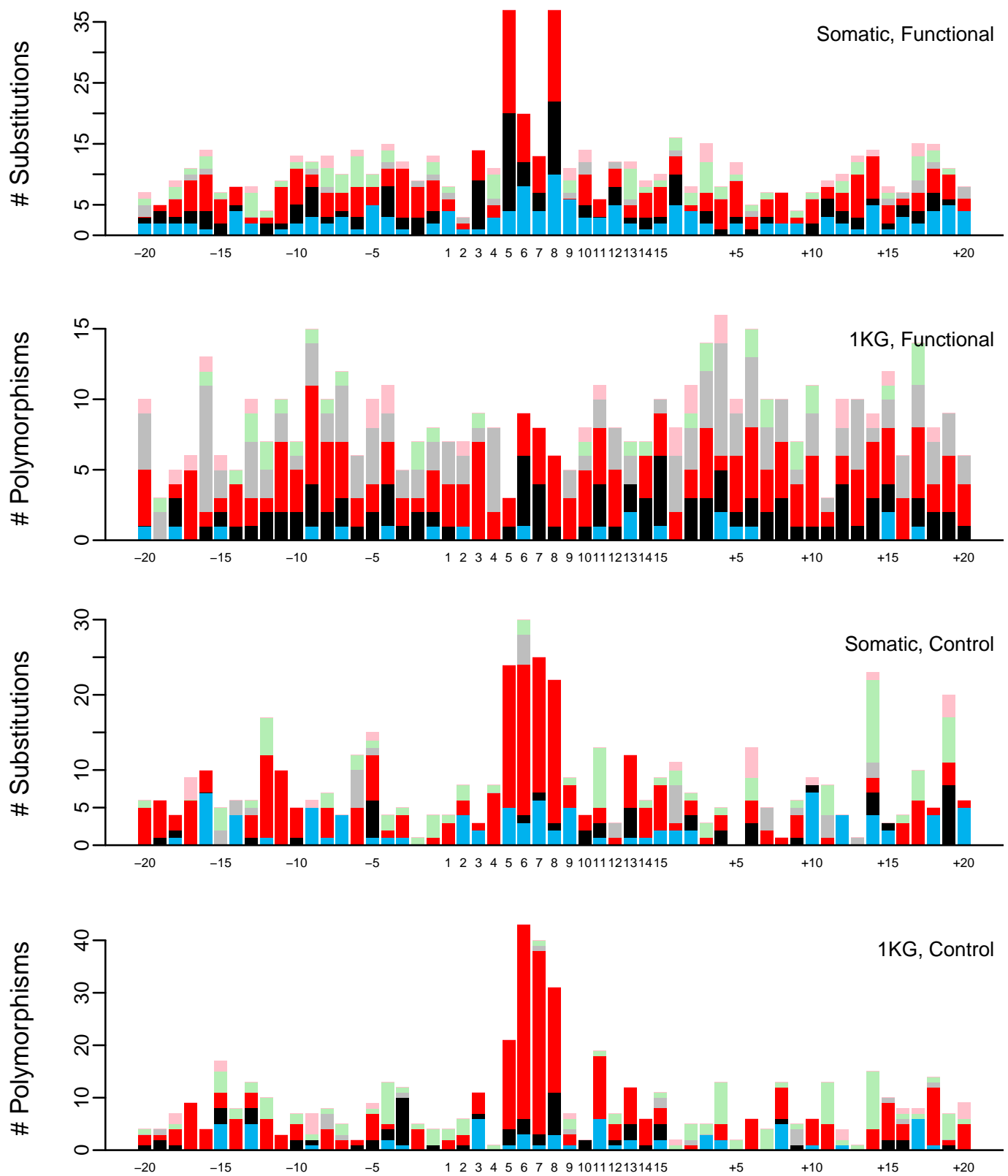
ZNF263, MA0528.1
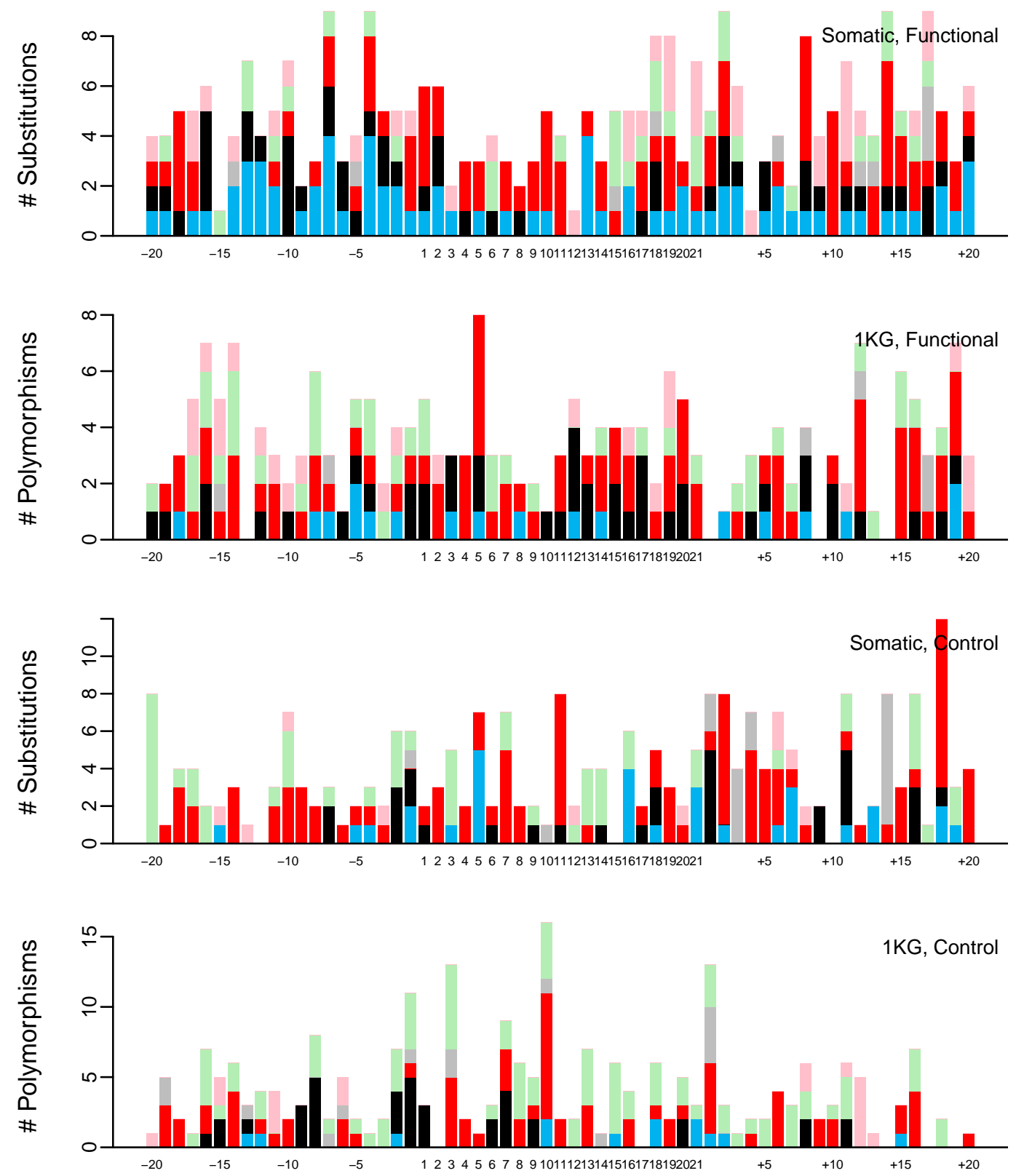
CTCFL, MA0531.1
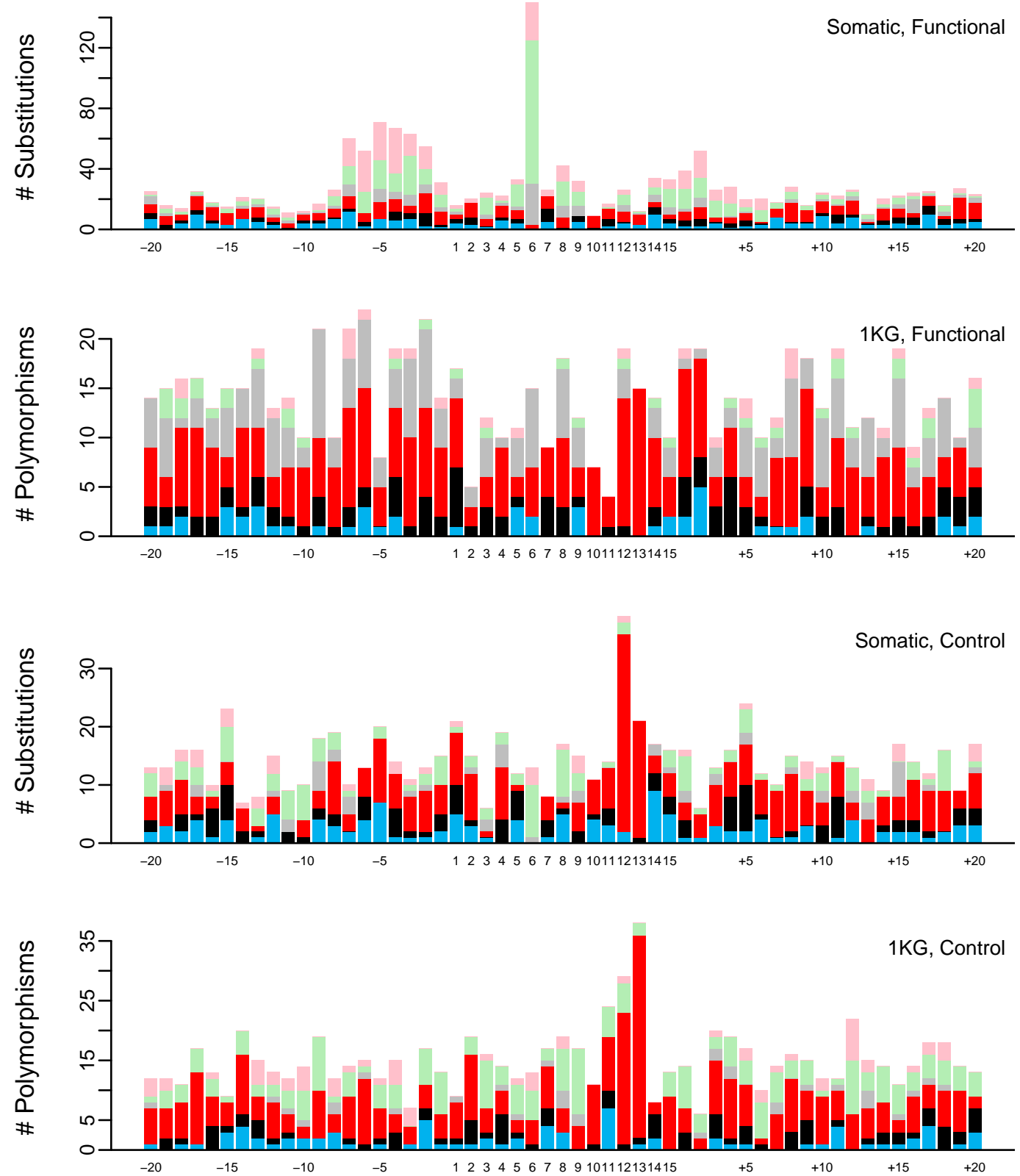
E2F4, MA0541.1
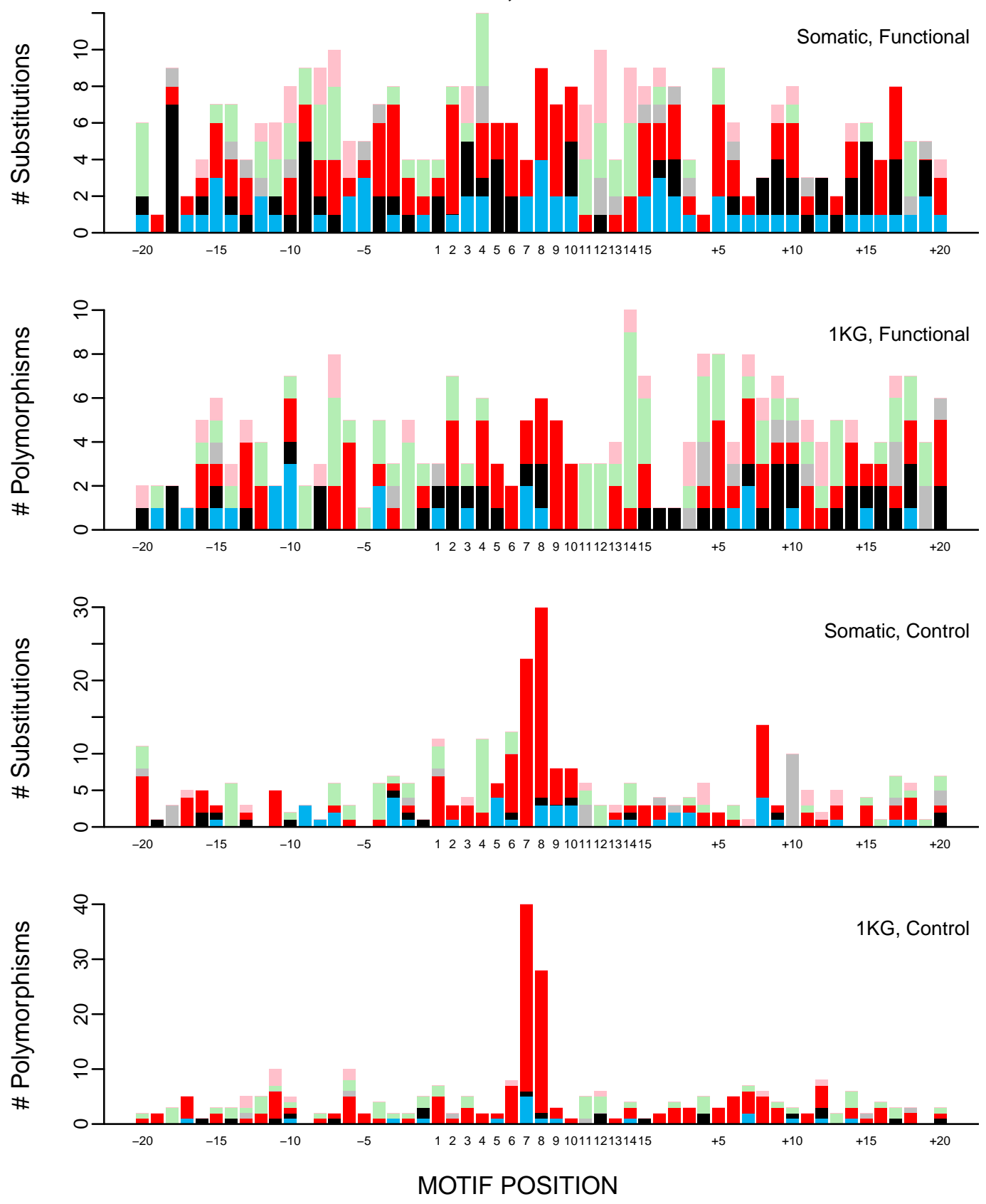

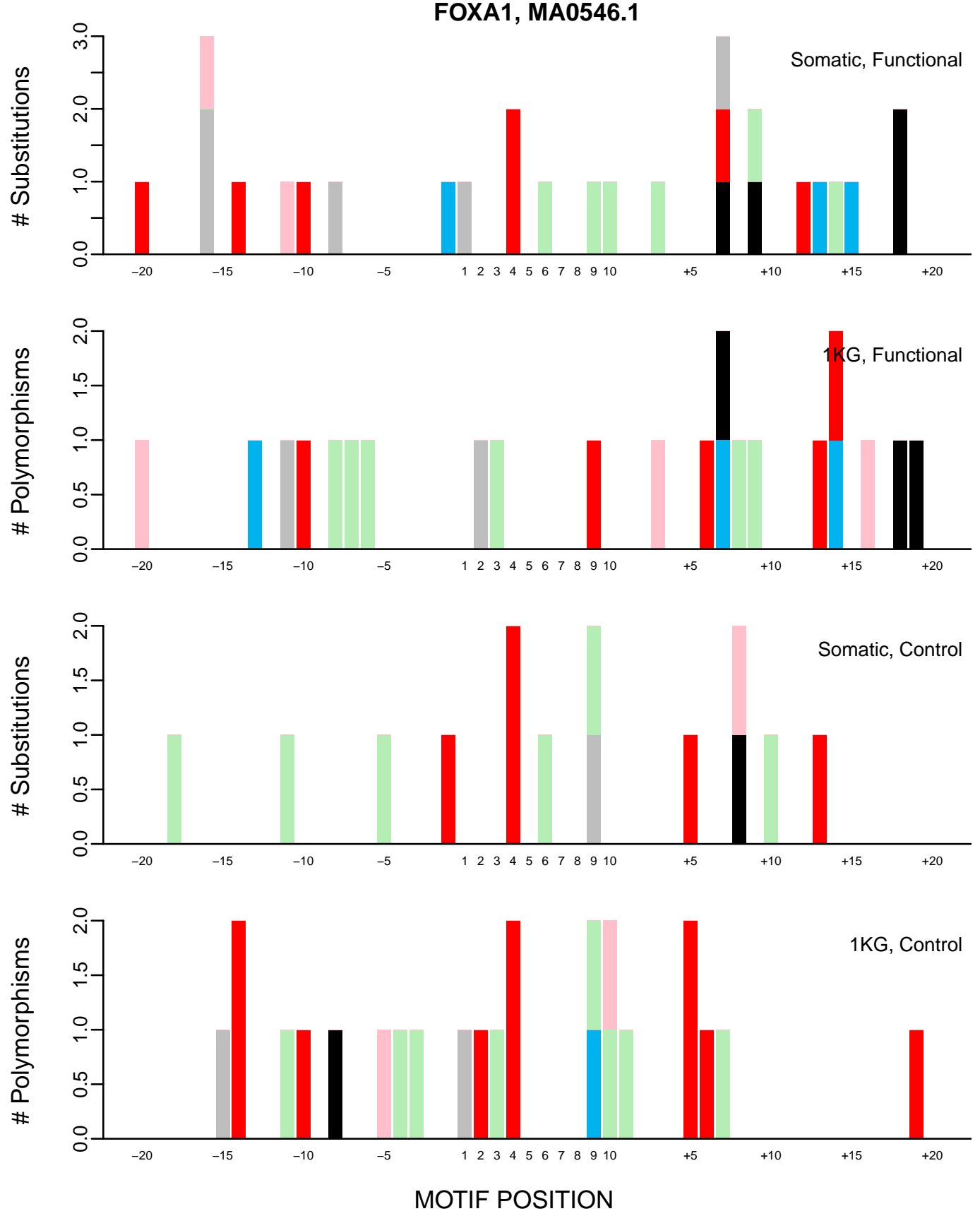
MEF2C, MA0555.1
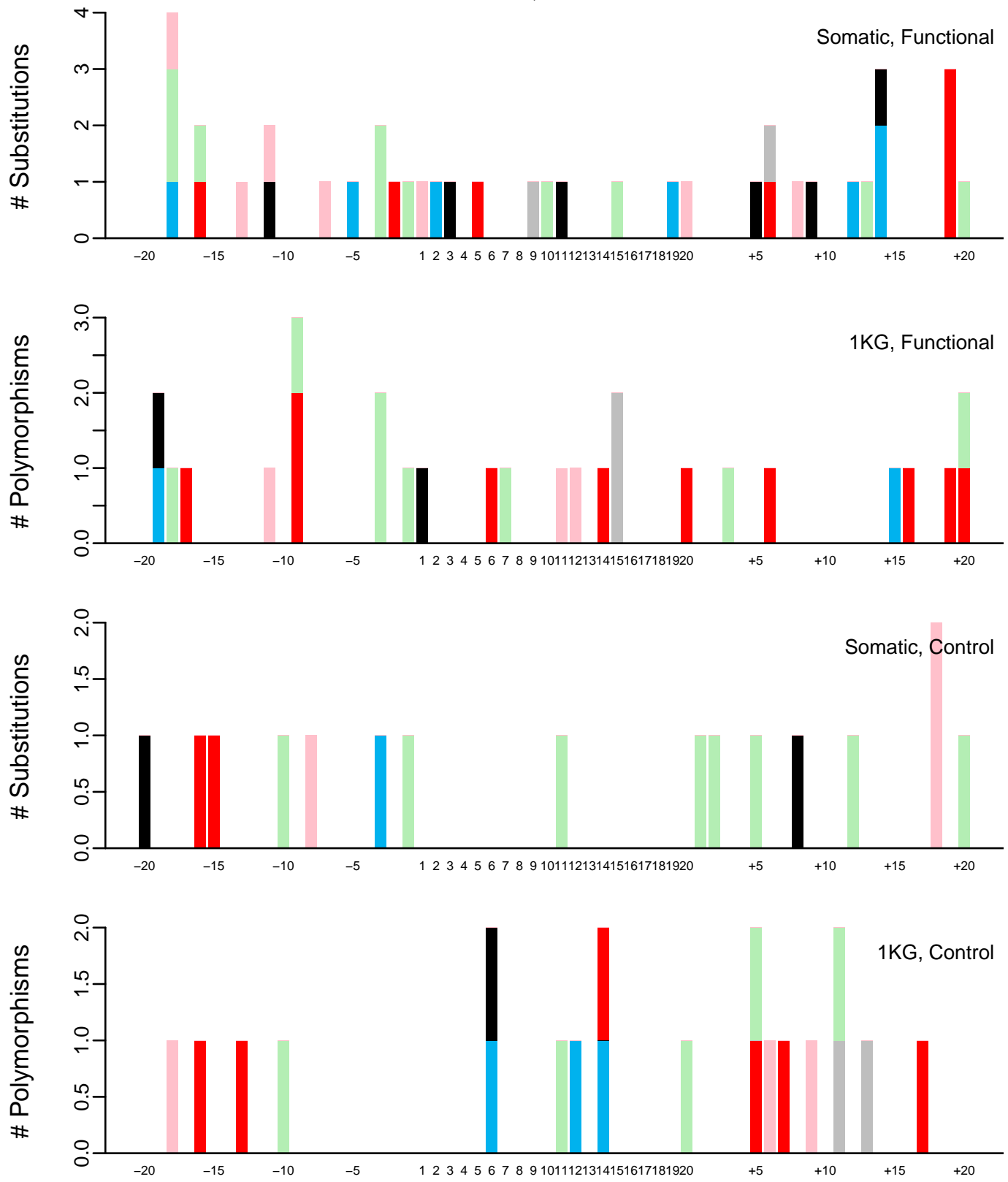

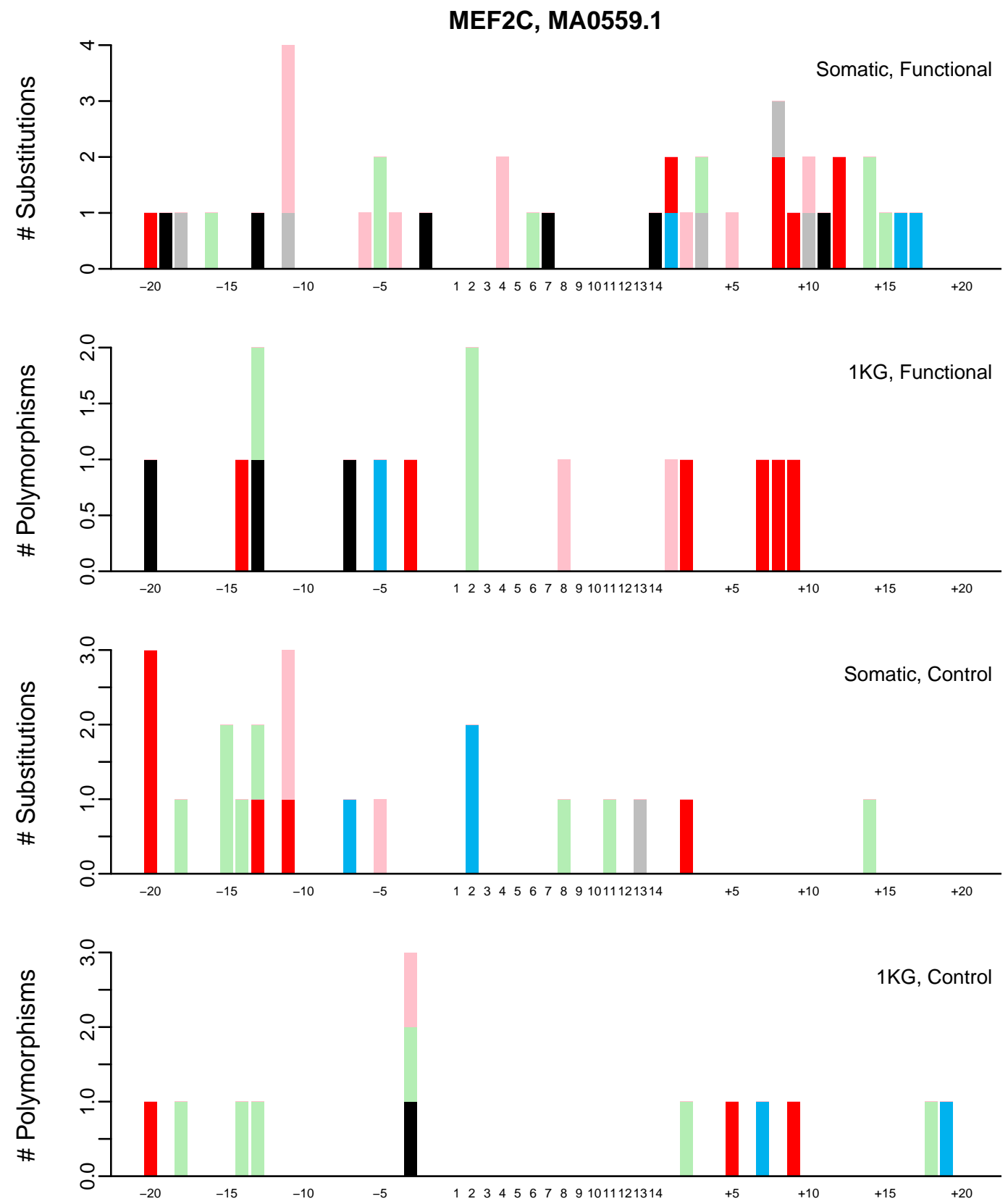
MAX, MA0568.1
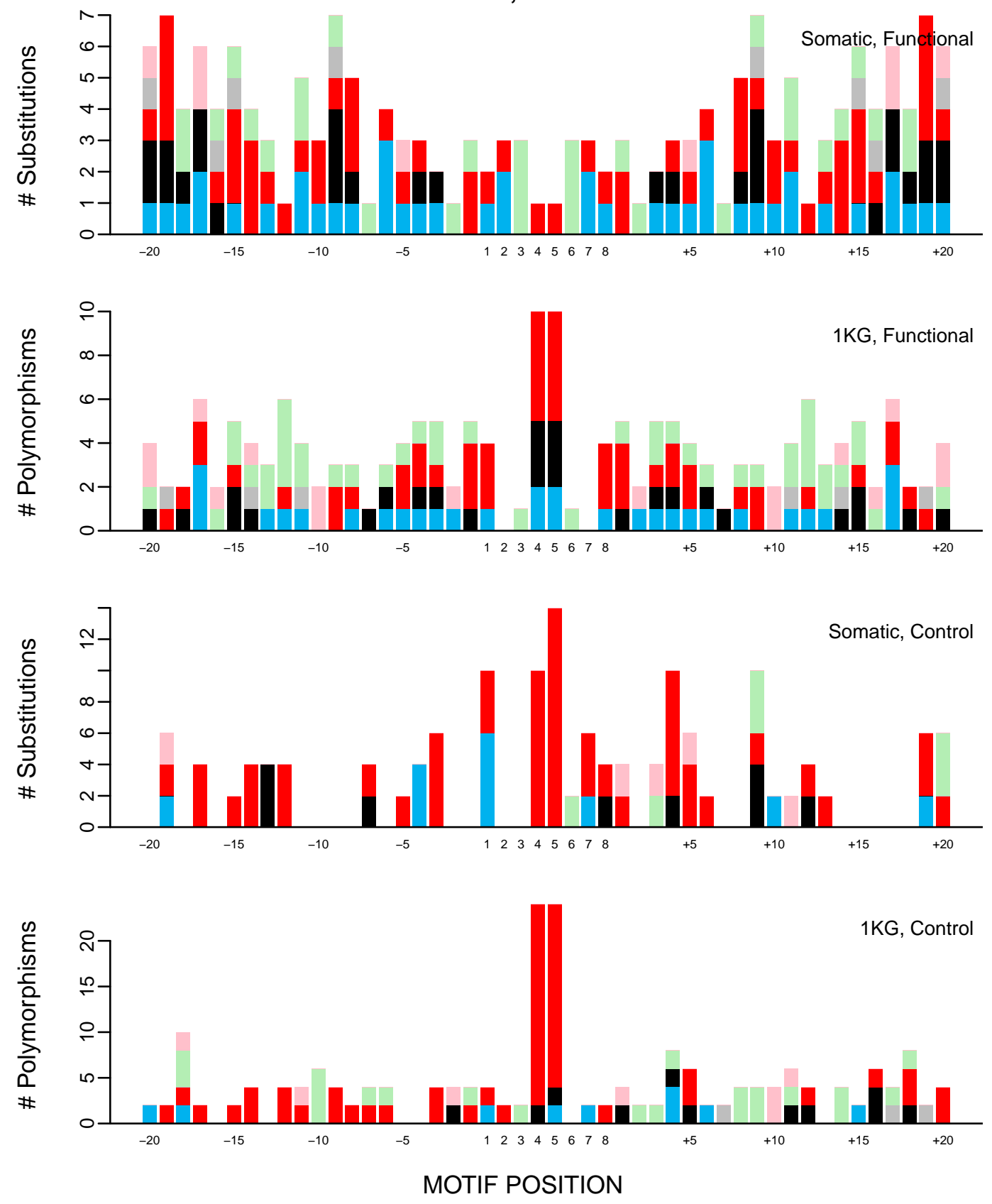
MAX, MA0569.1
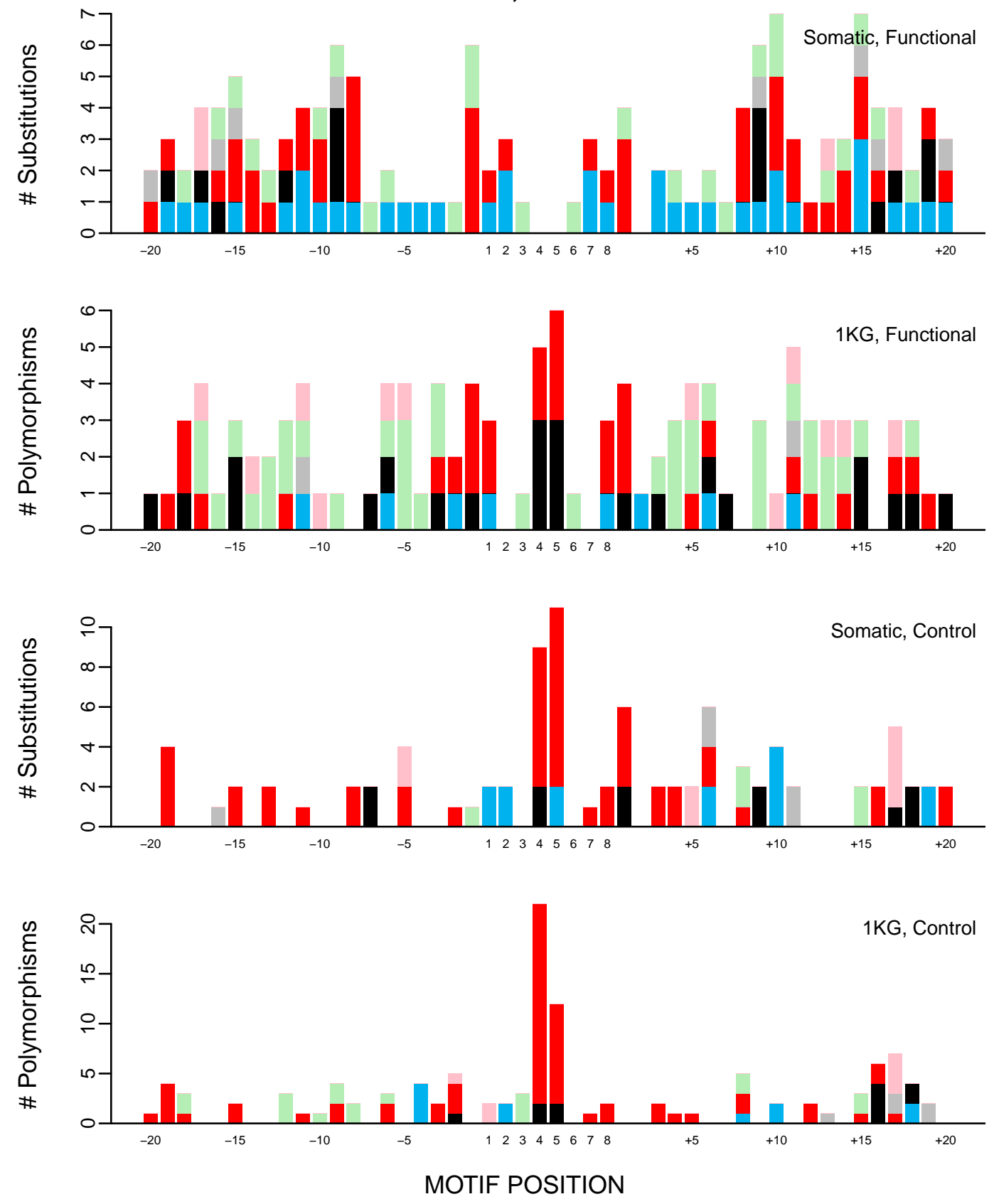

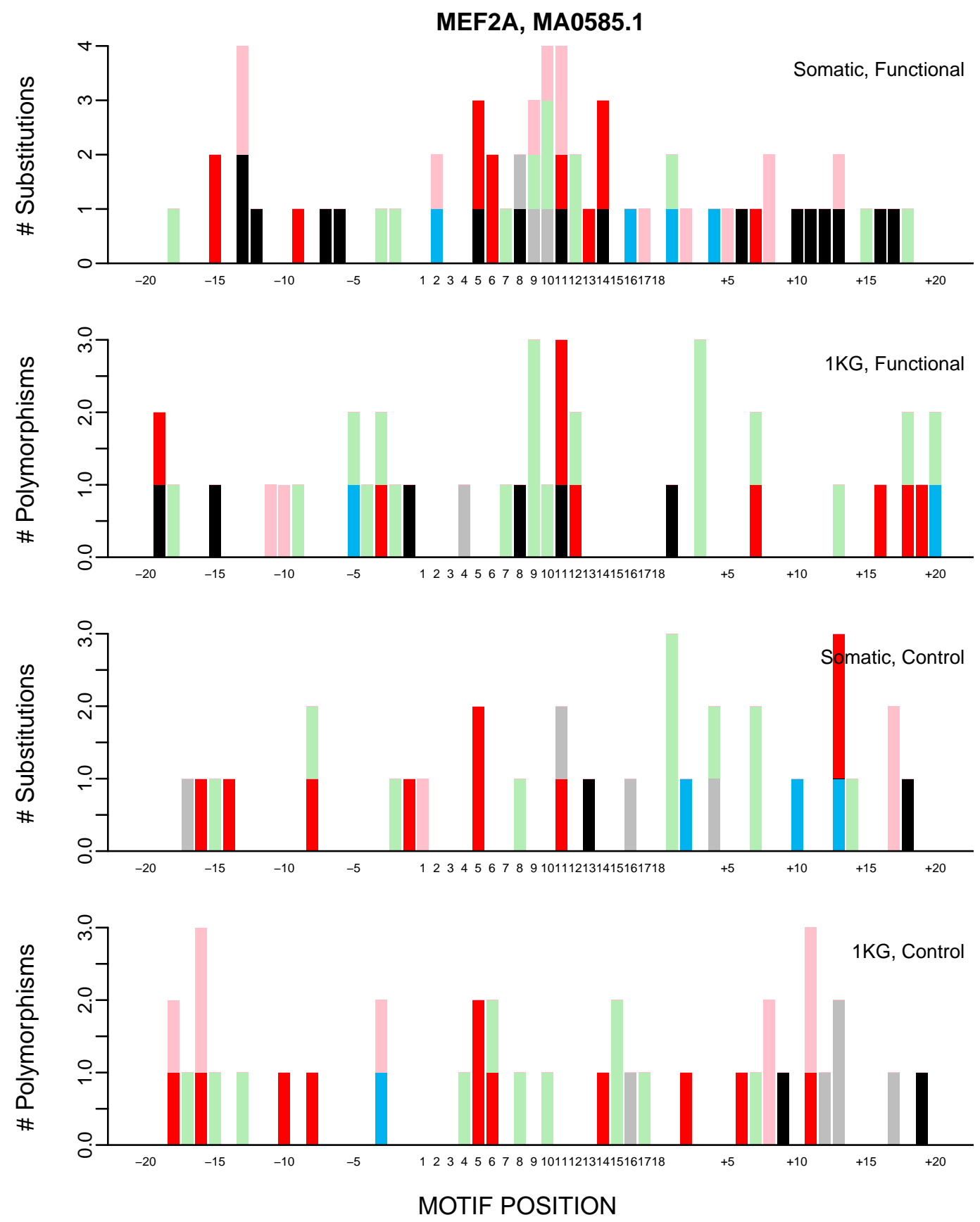
SREBP1, MA0595.1
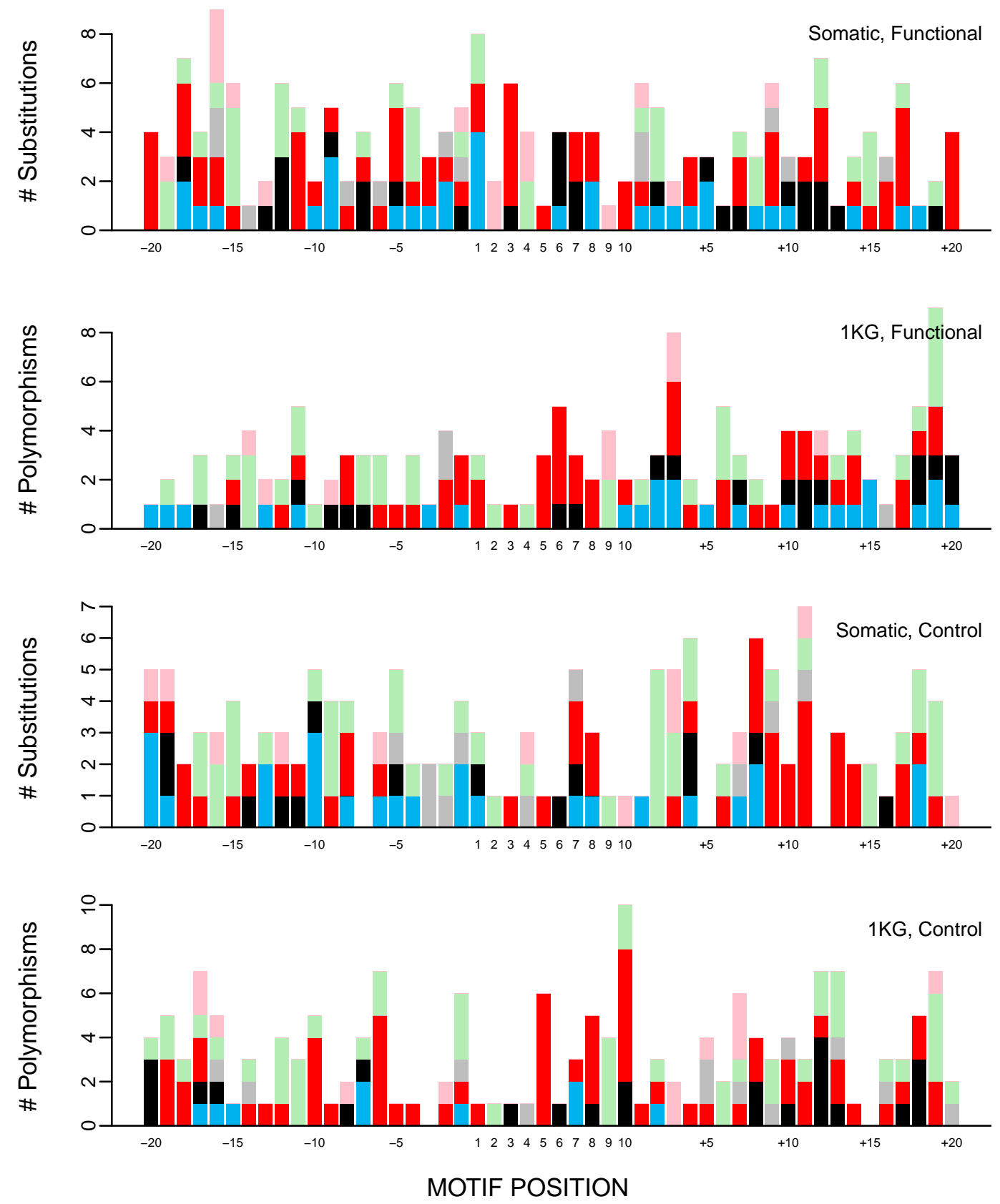
SREBP2, MA0596.1
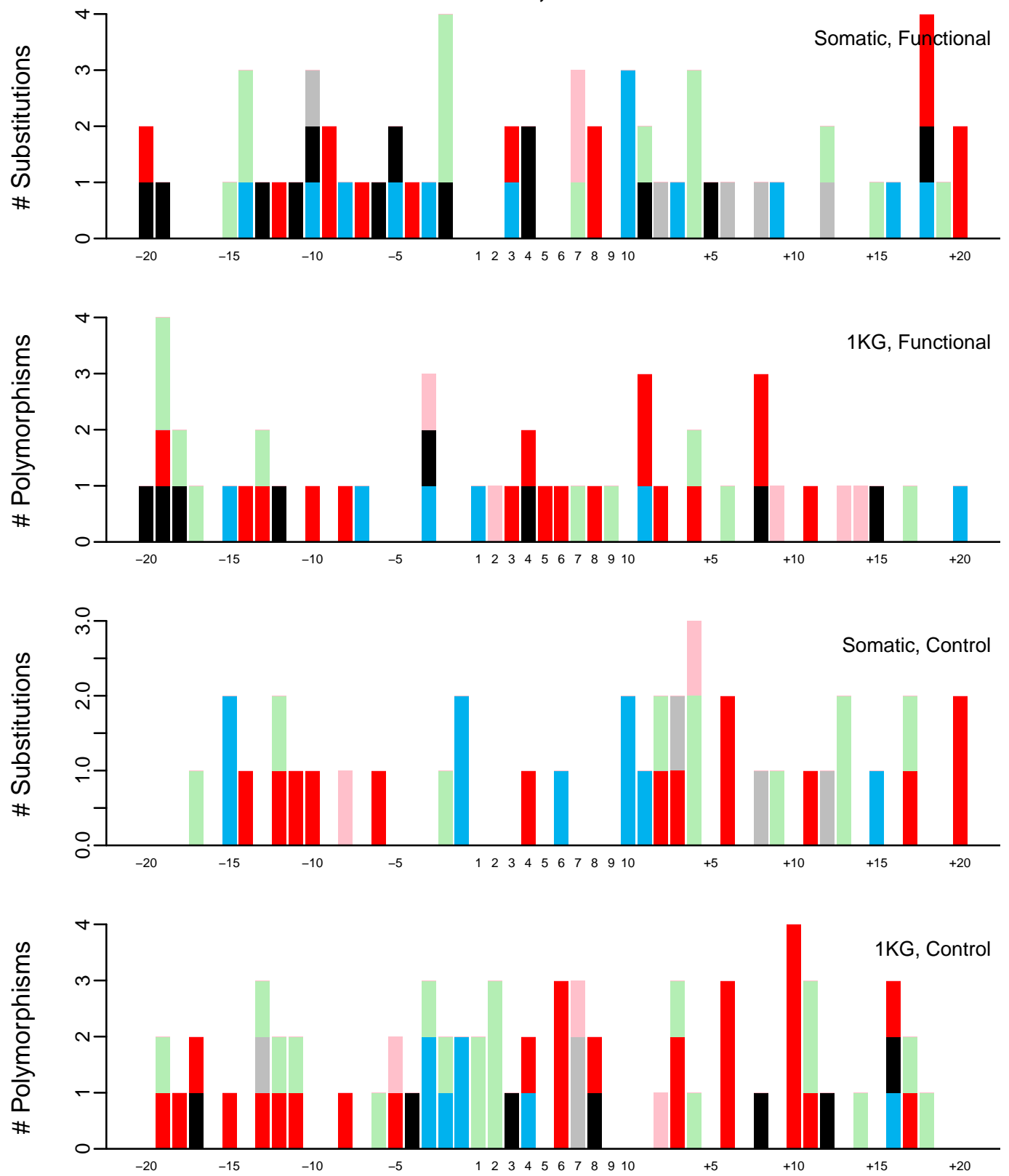
THAP1, MA0597.1
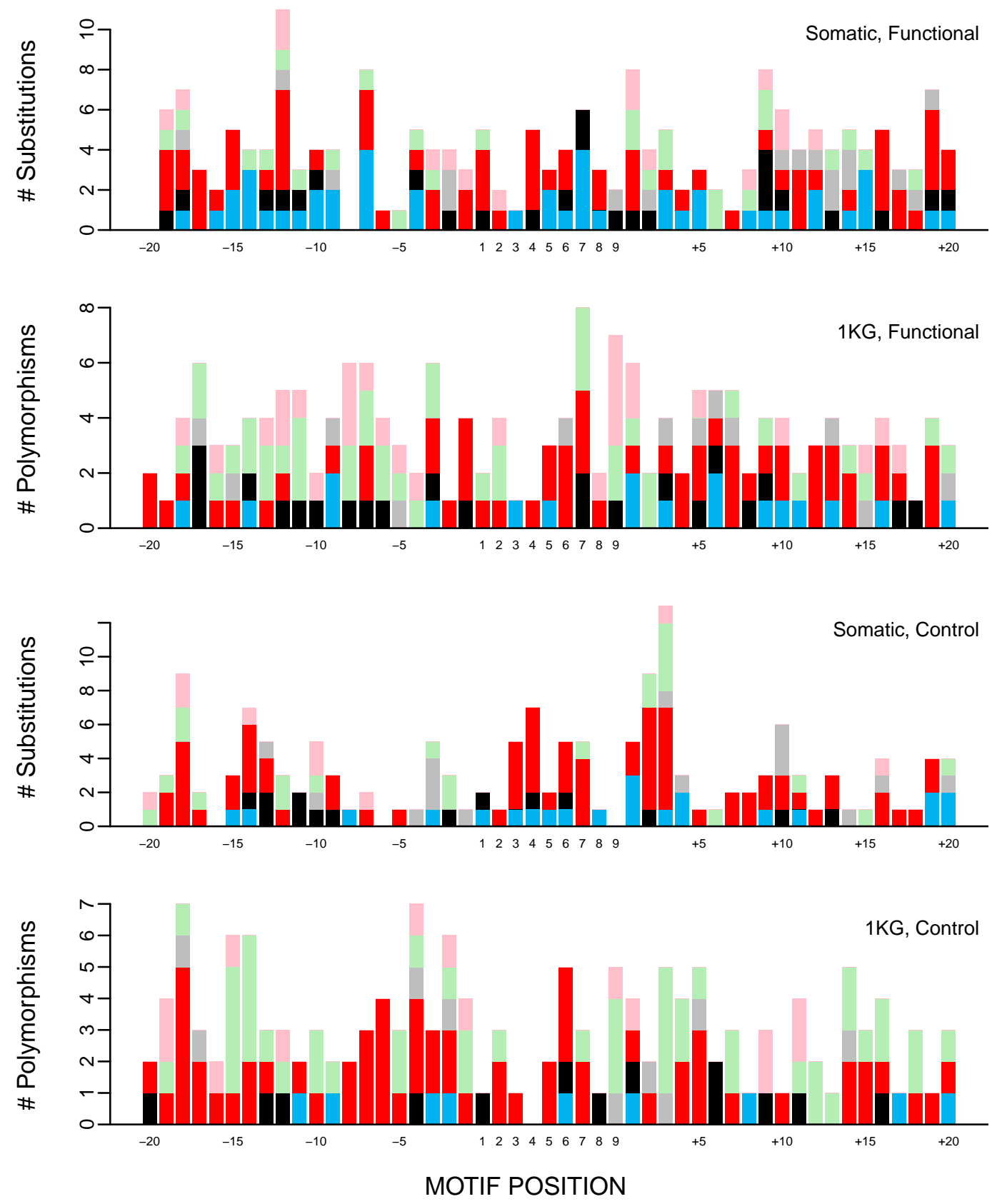
BHLHE40, PB0007.1
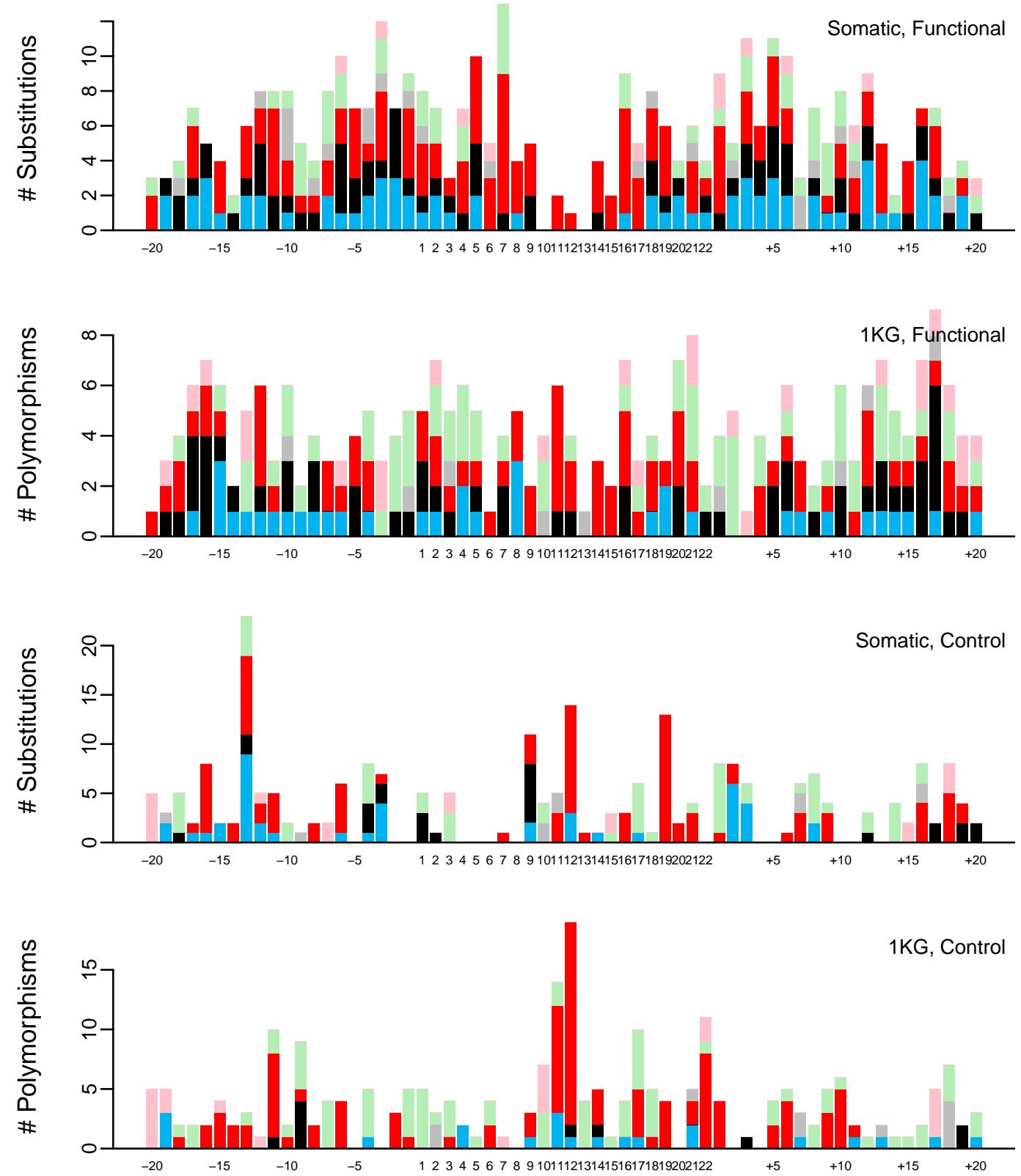
EGR1, PB0010.1
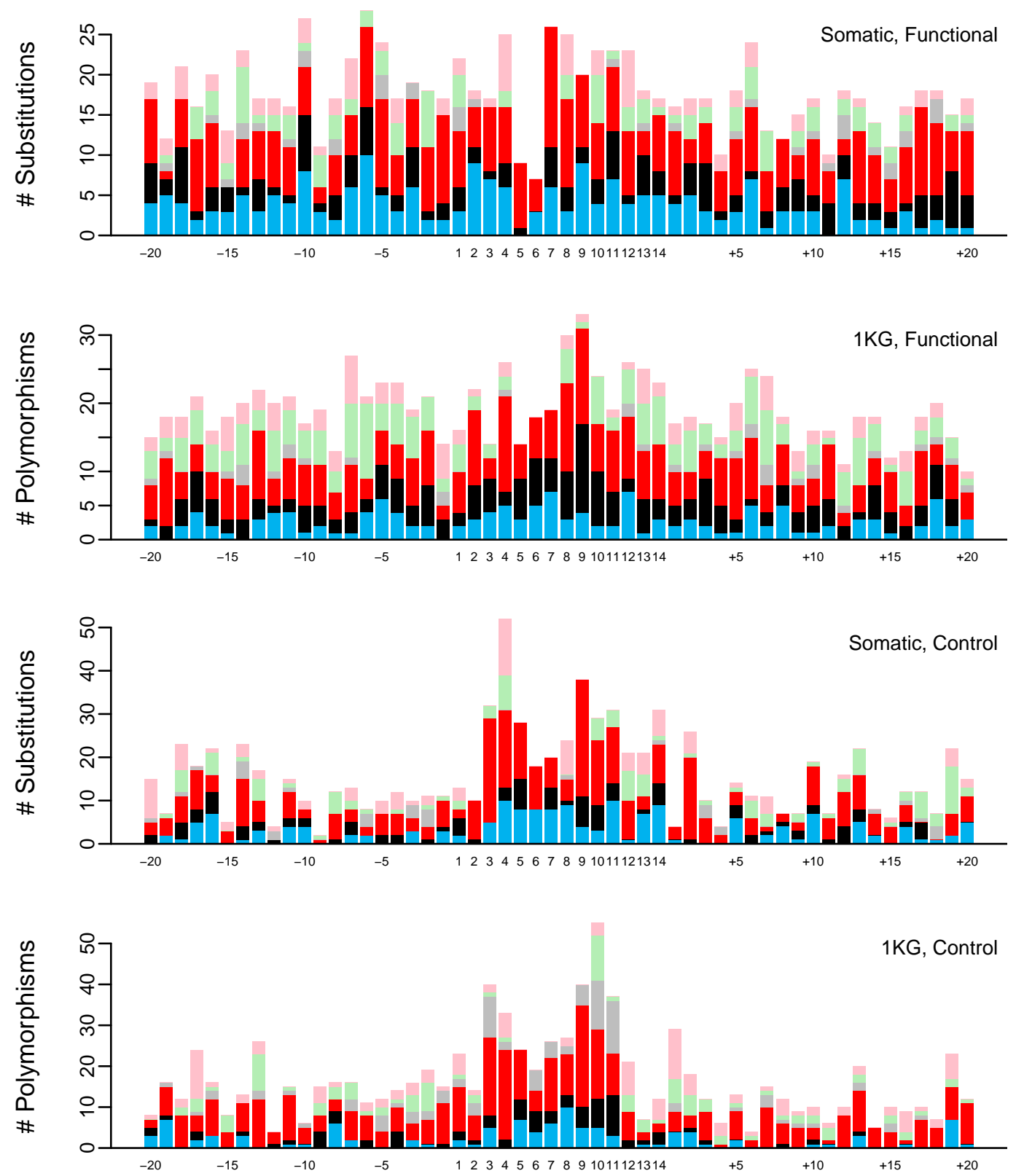
FOXA2, PB0015.1
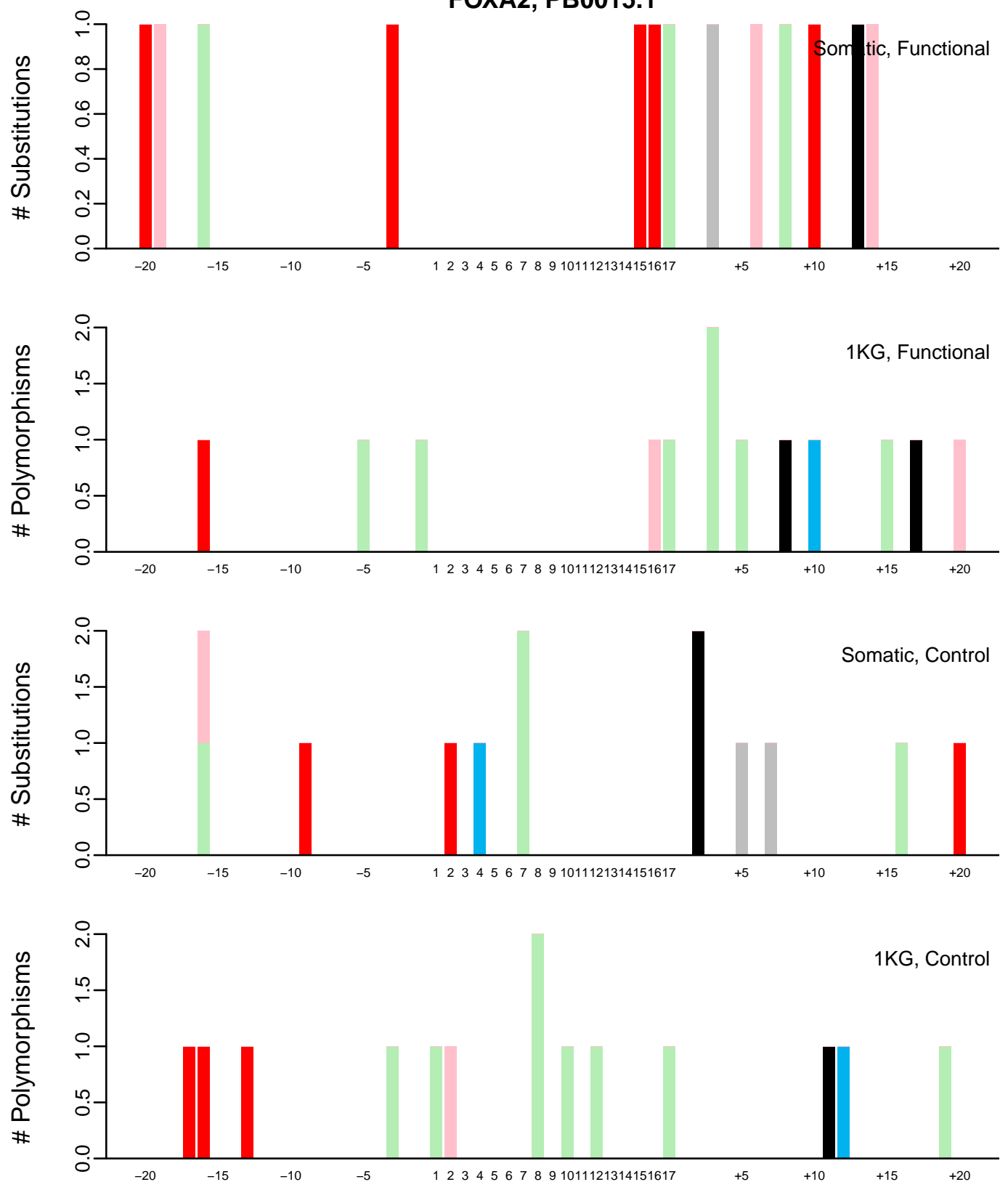
GABP, PB0020.1
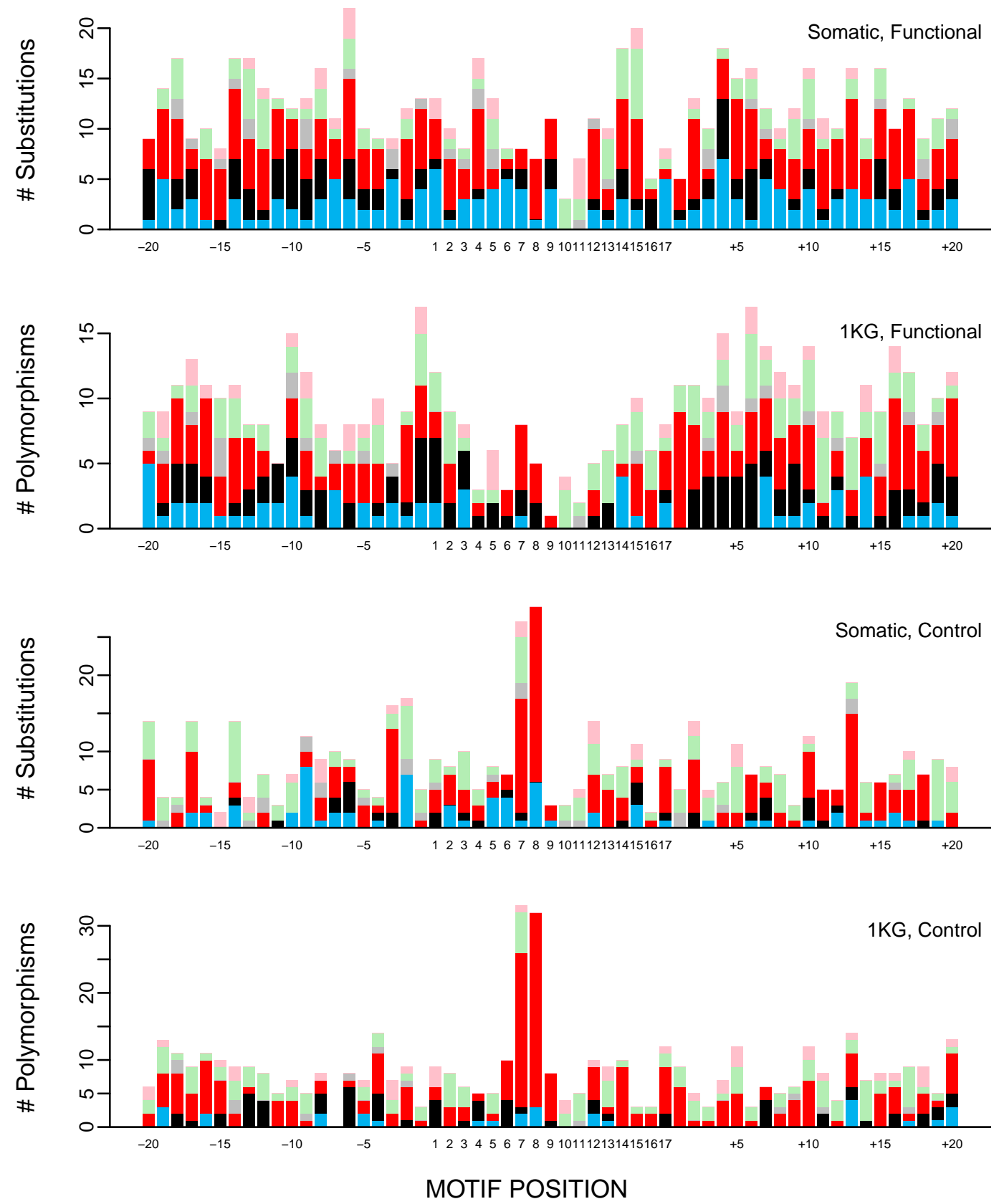
HNF4A, PB0030.1
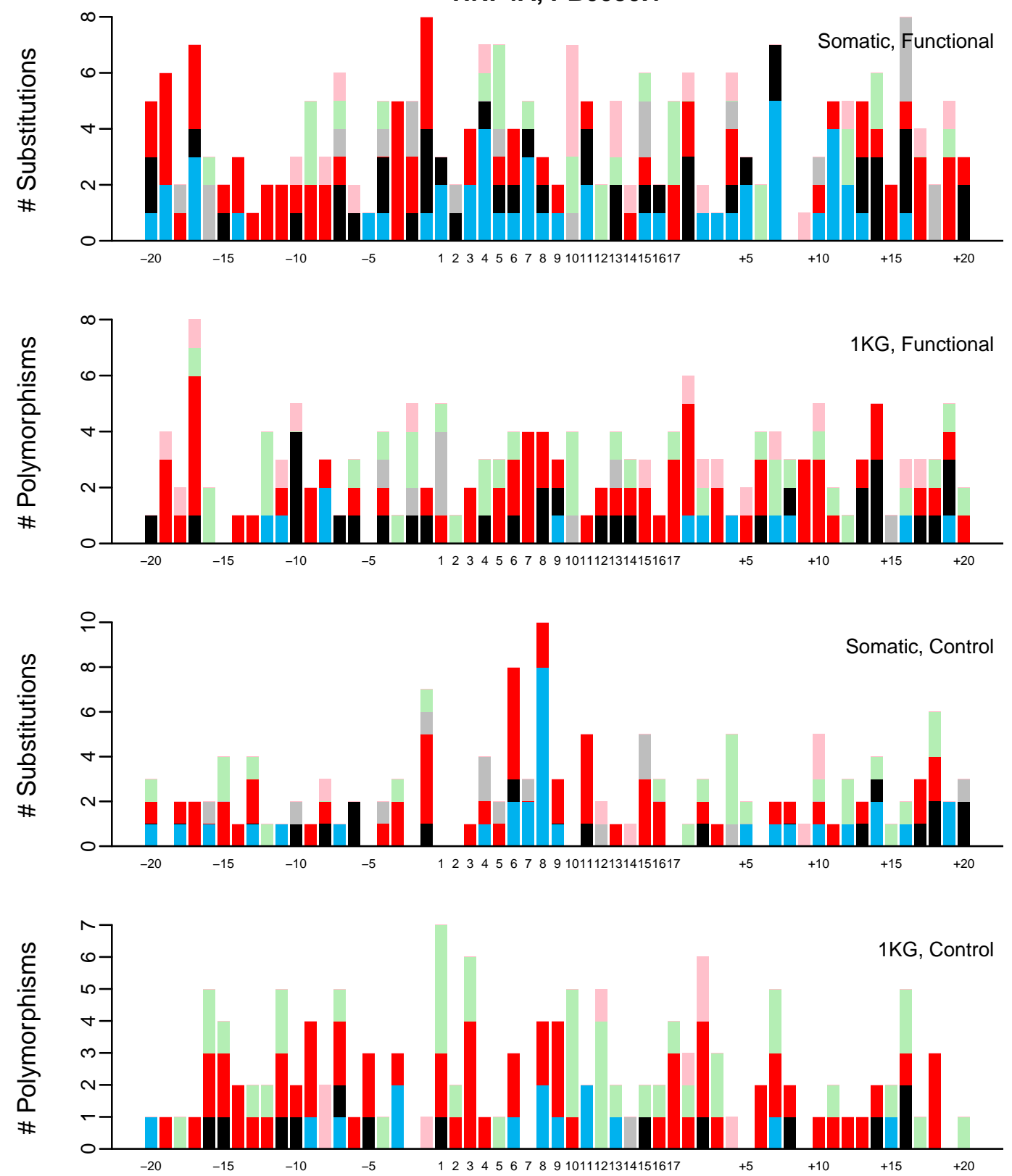
IRF4, PB0034.1
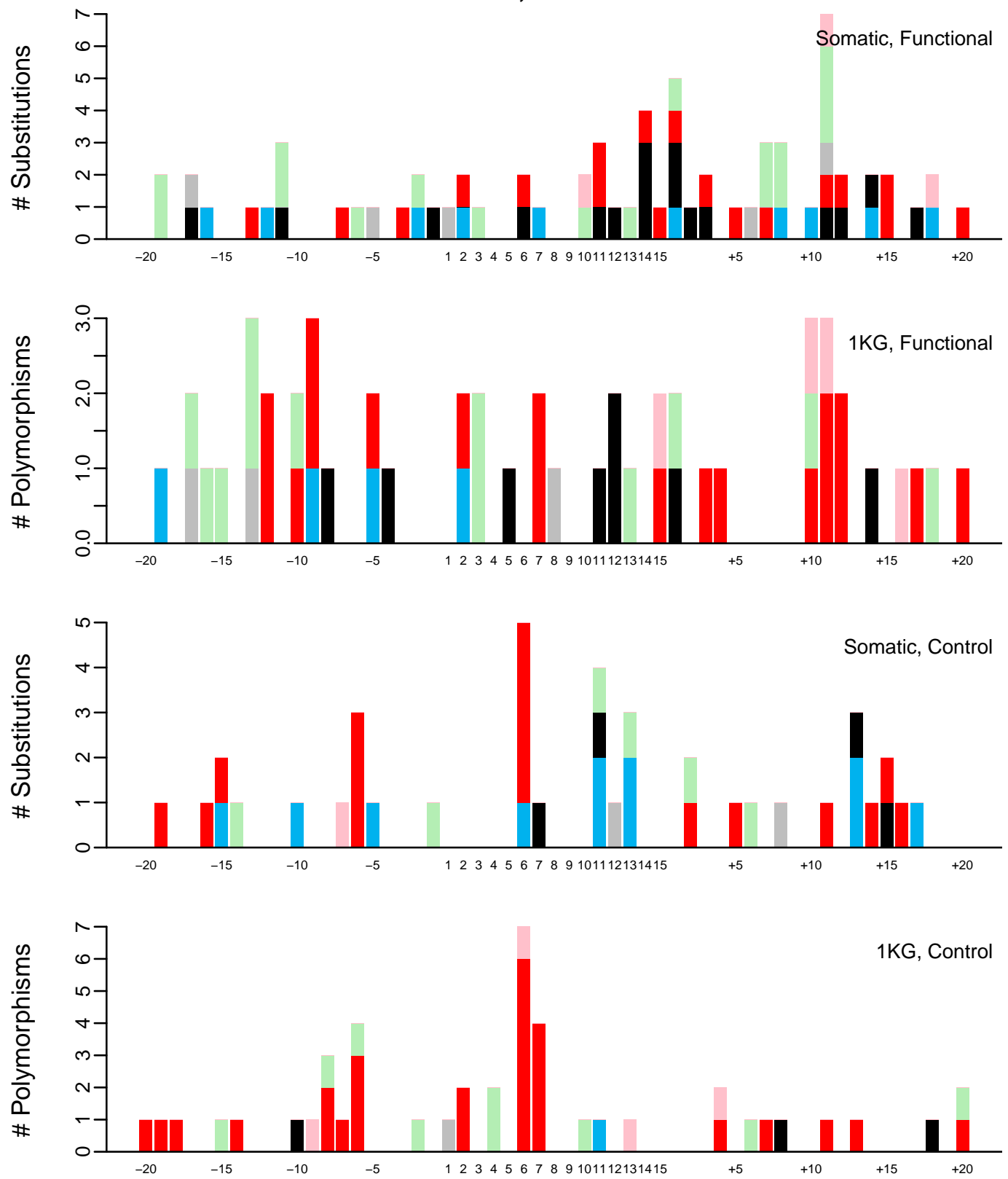
MAX, PB0043.1
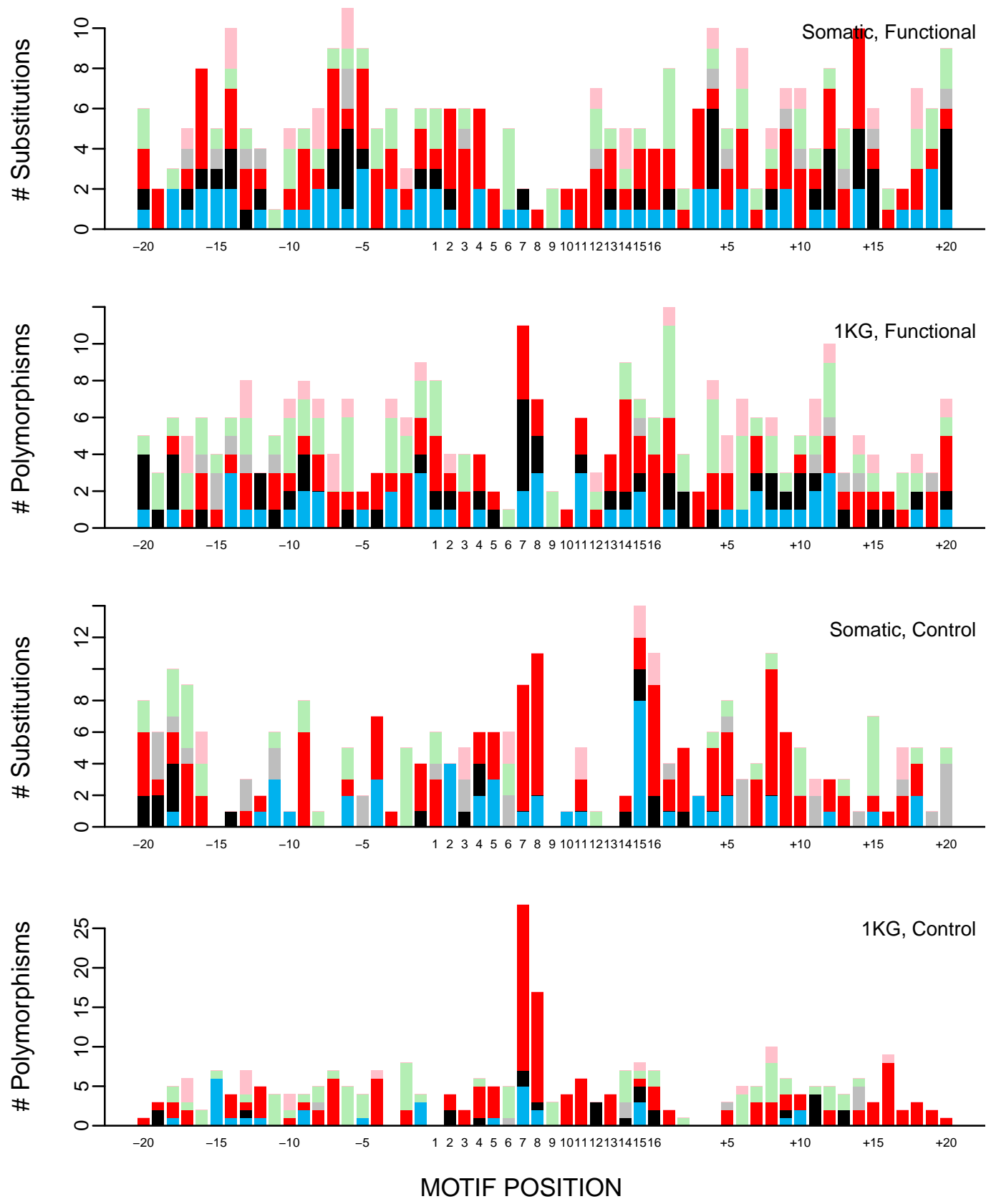


\section{PU1, PB0058.1}
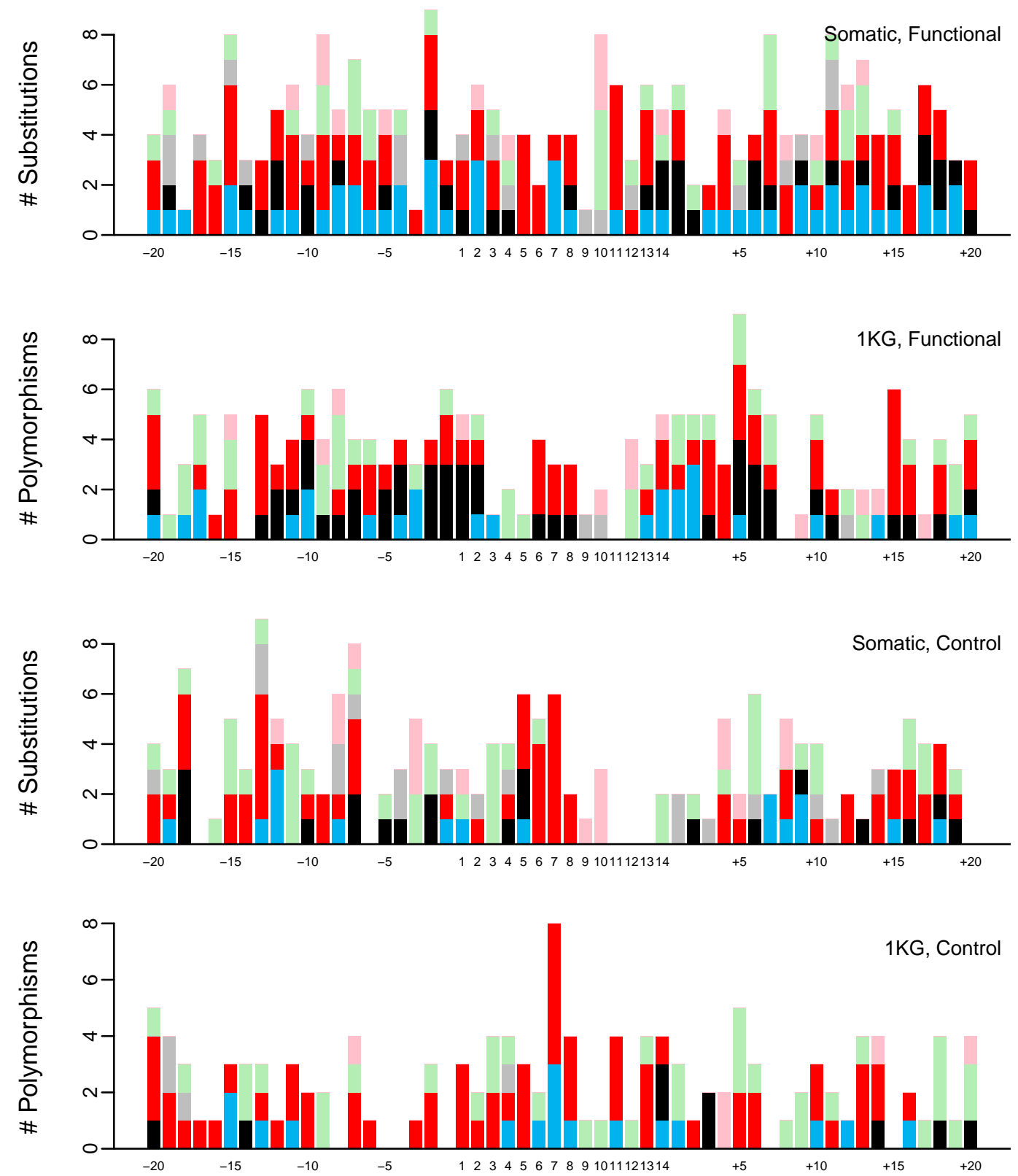

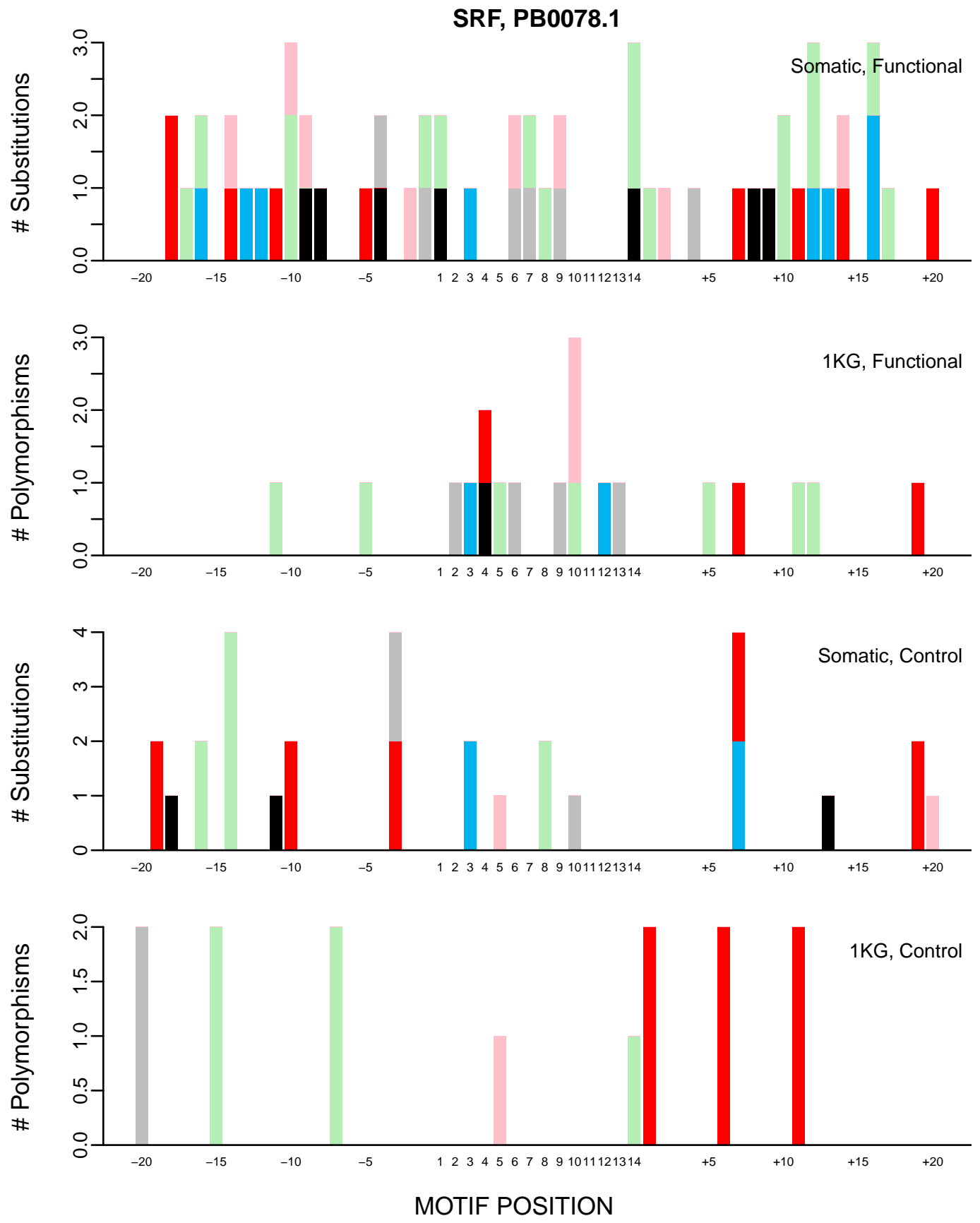


\section{BHLHE40, PB0111.1}
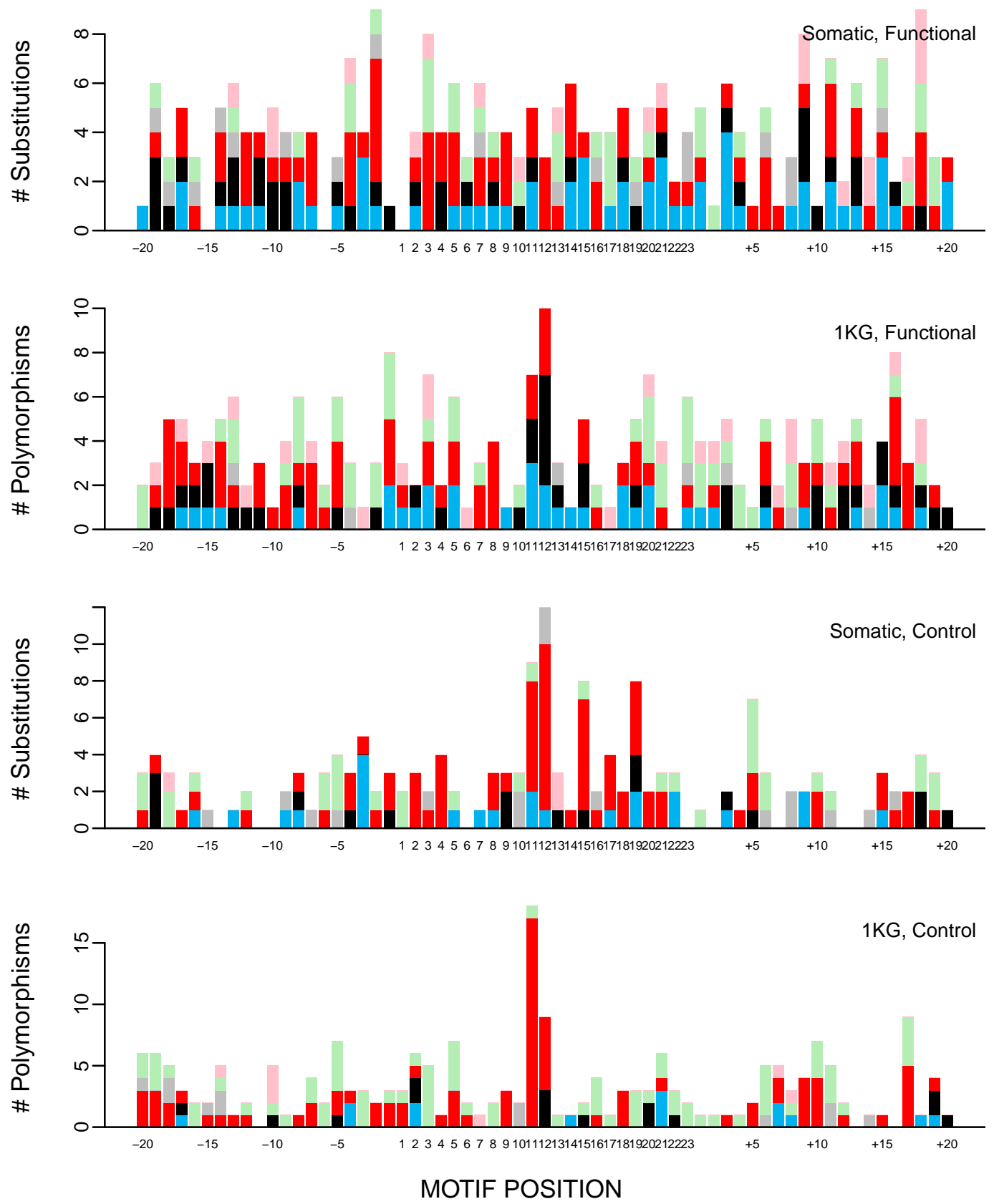


\section{EGR1, PB0114.1}
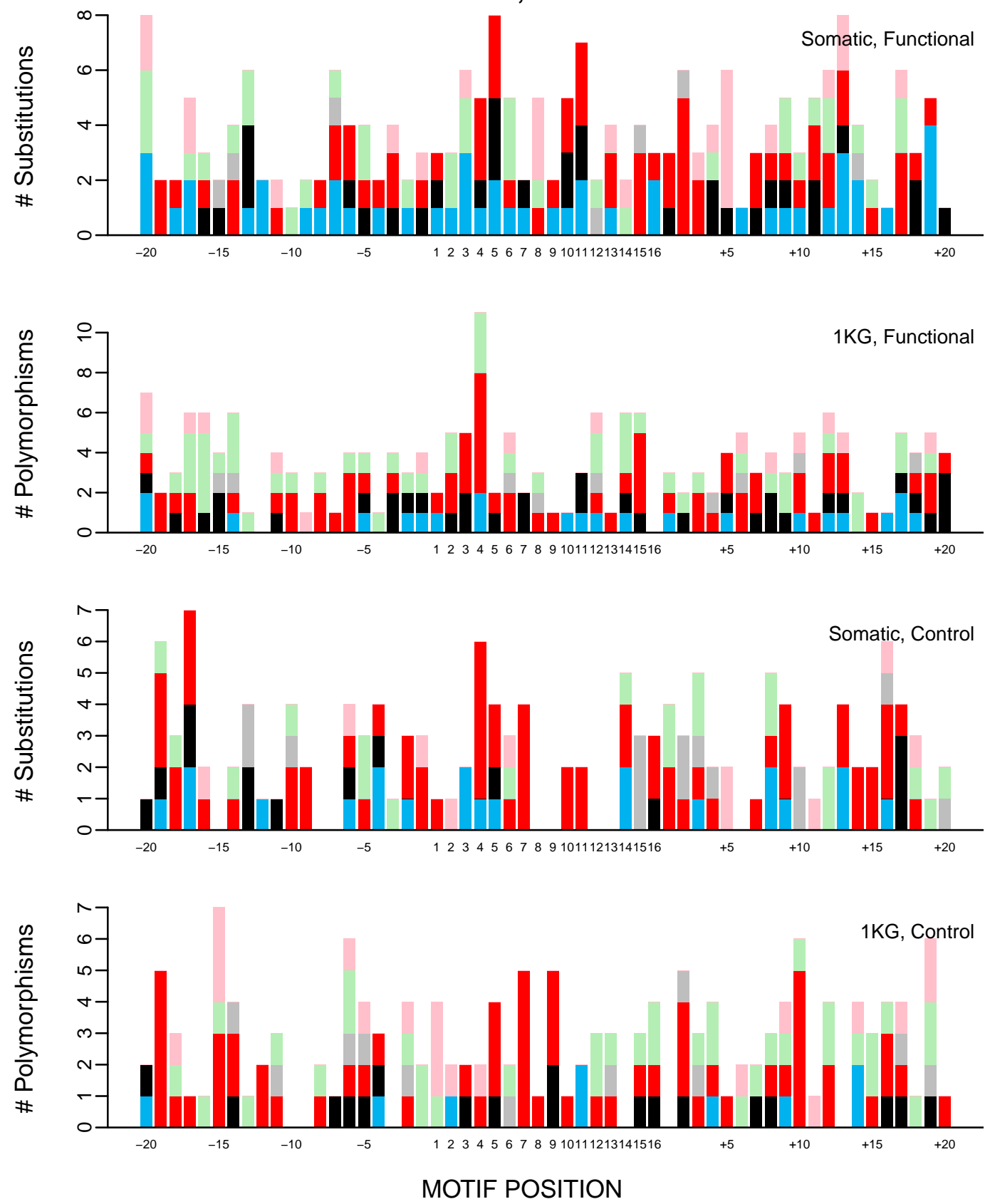
FOXA2, PB0119.1
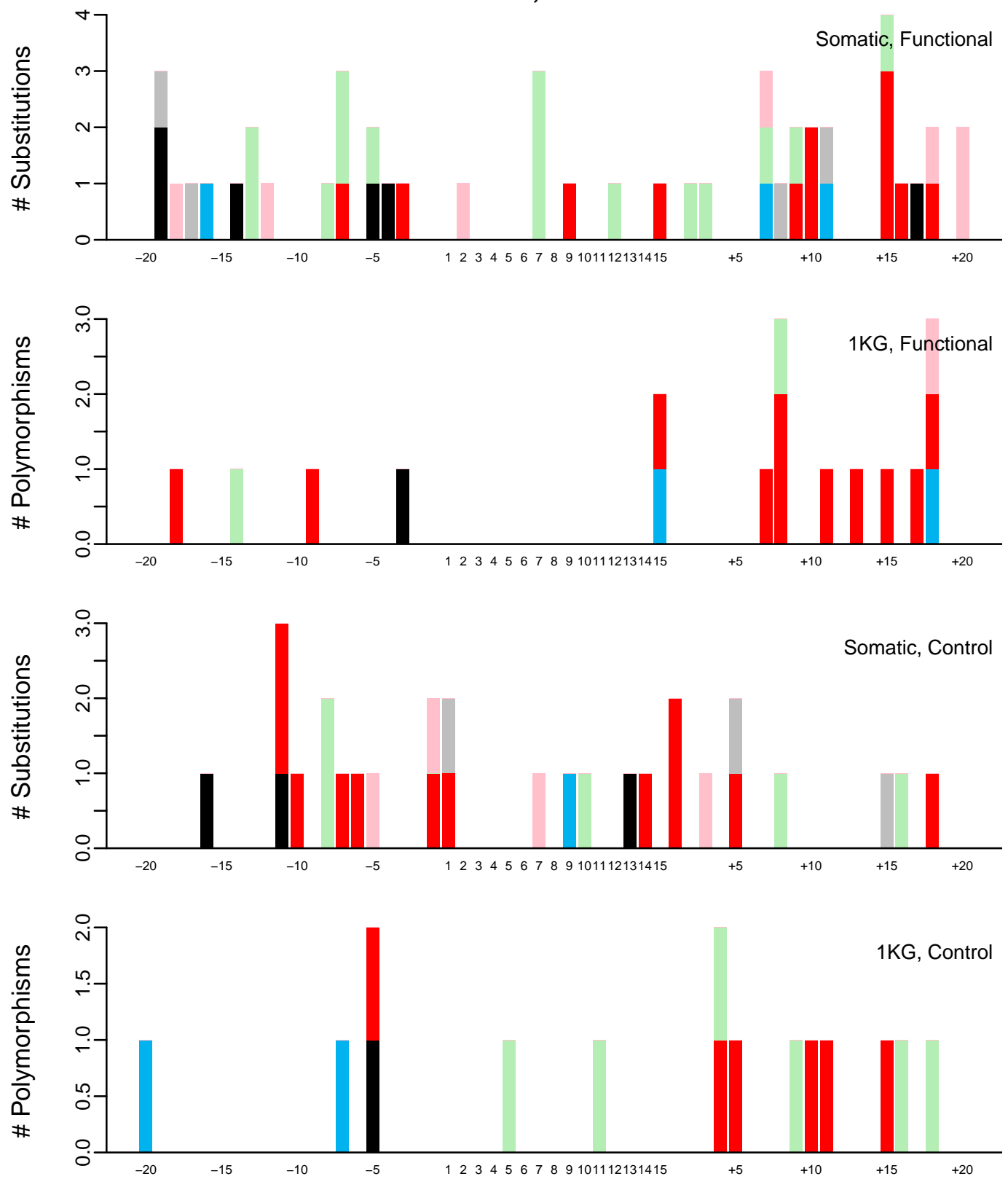
GABP, PB0124.1
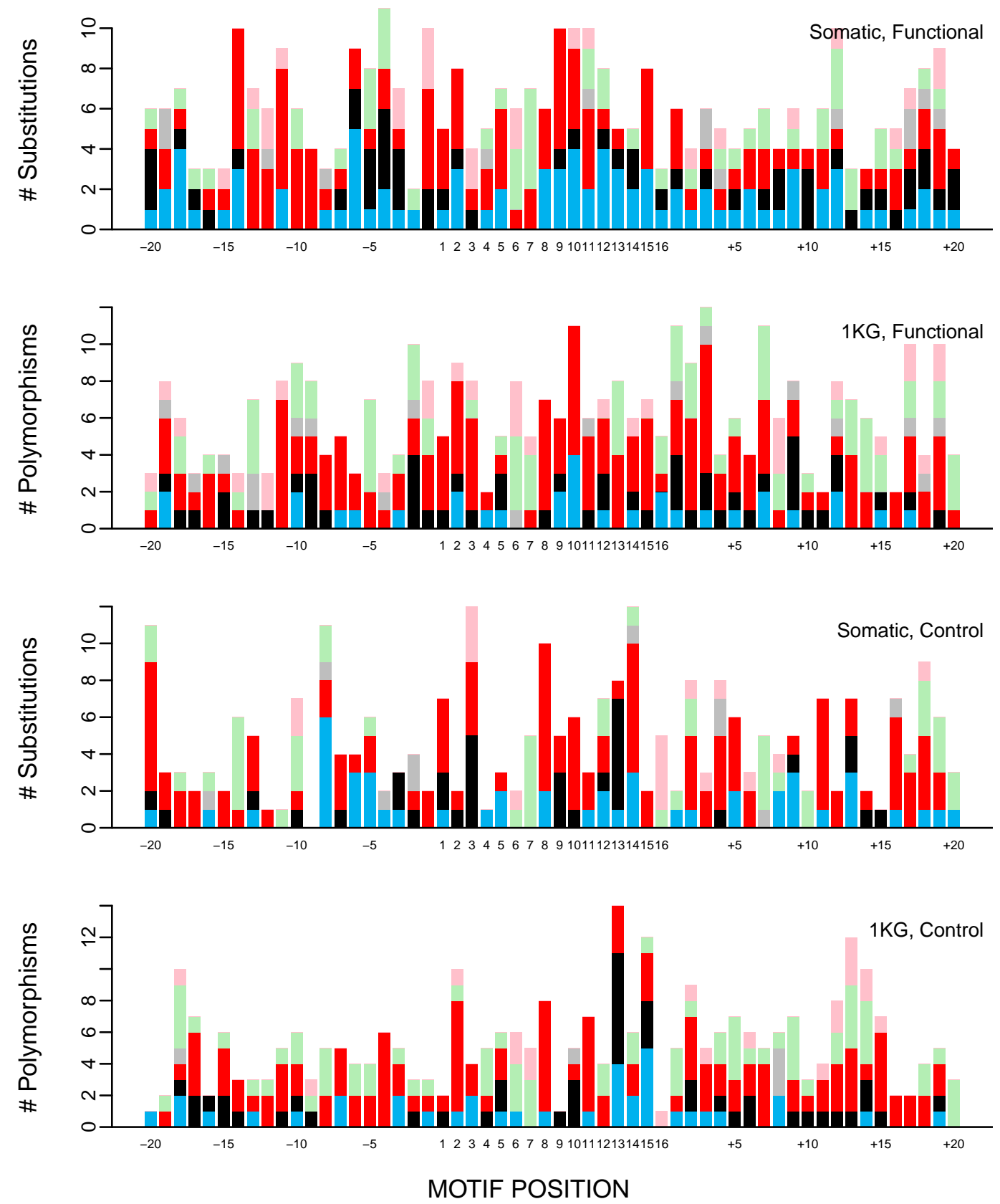
HNF4A, PB0134.1
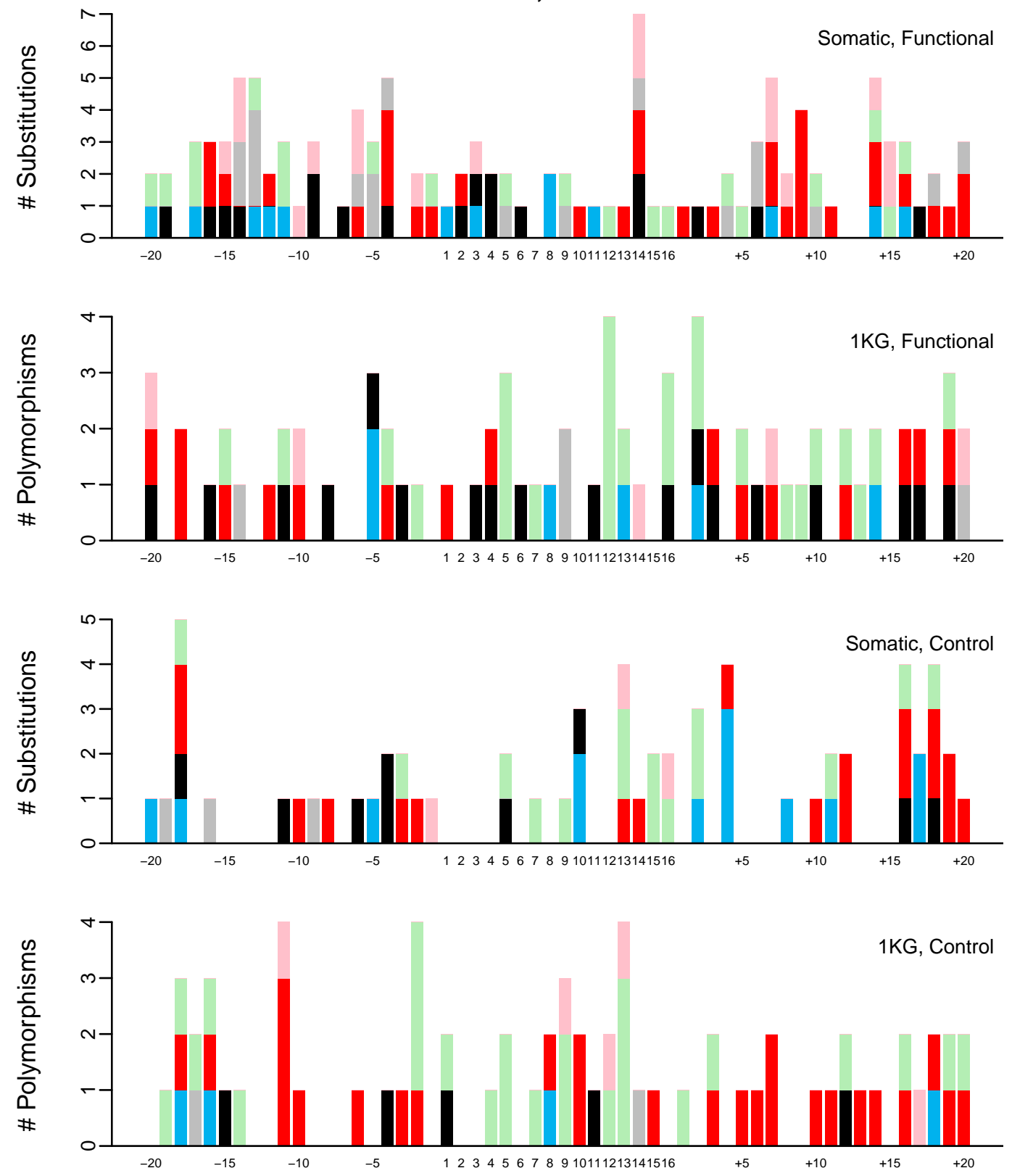
IRF4, PB0138.1
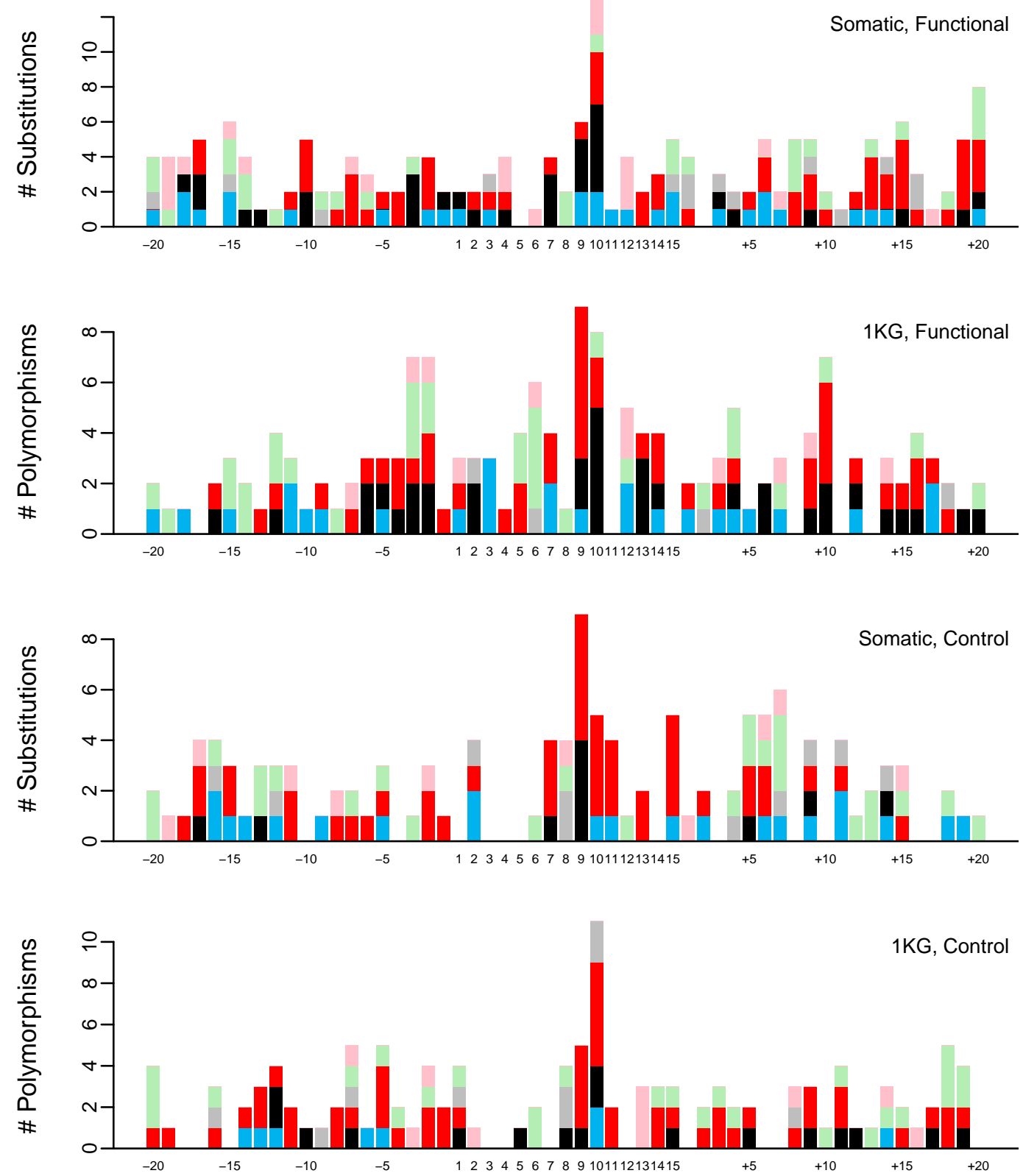


\section{MAX, PB0147.1}
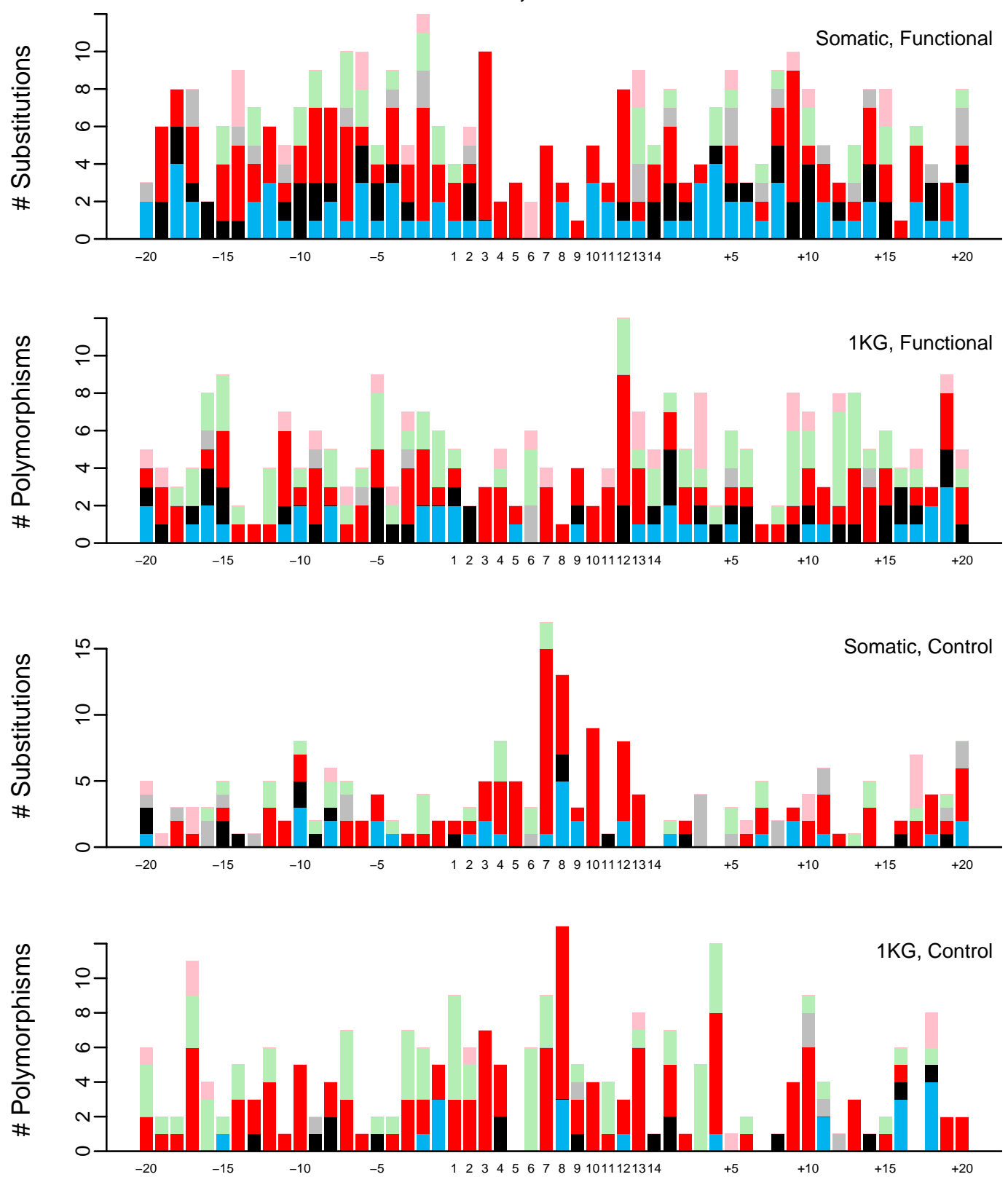


\section{PU1, PB0162.1}
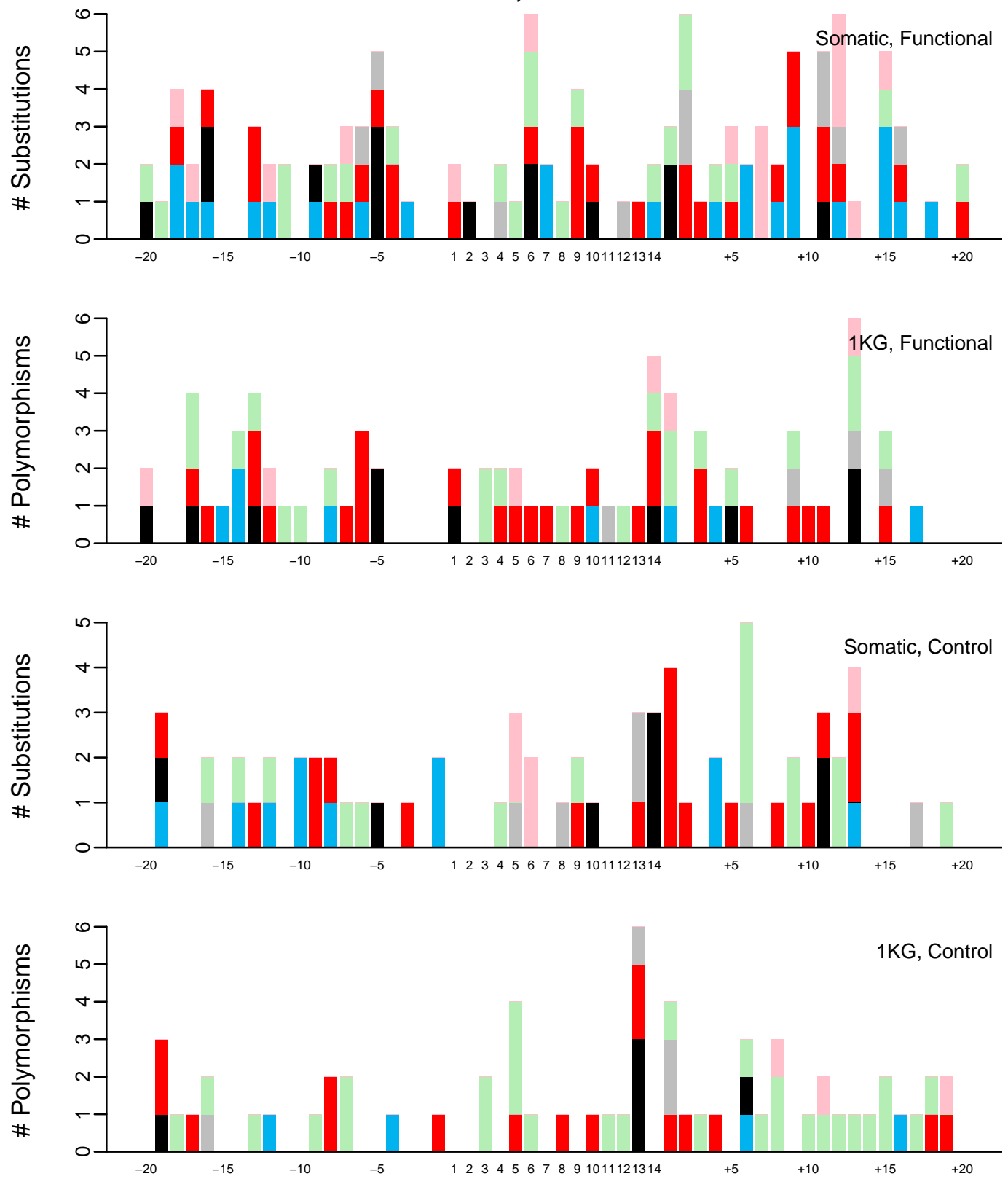


\section{SRF, PB0182.1}
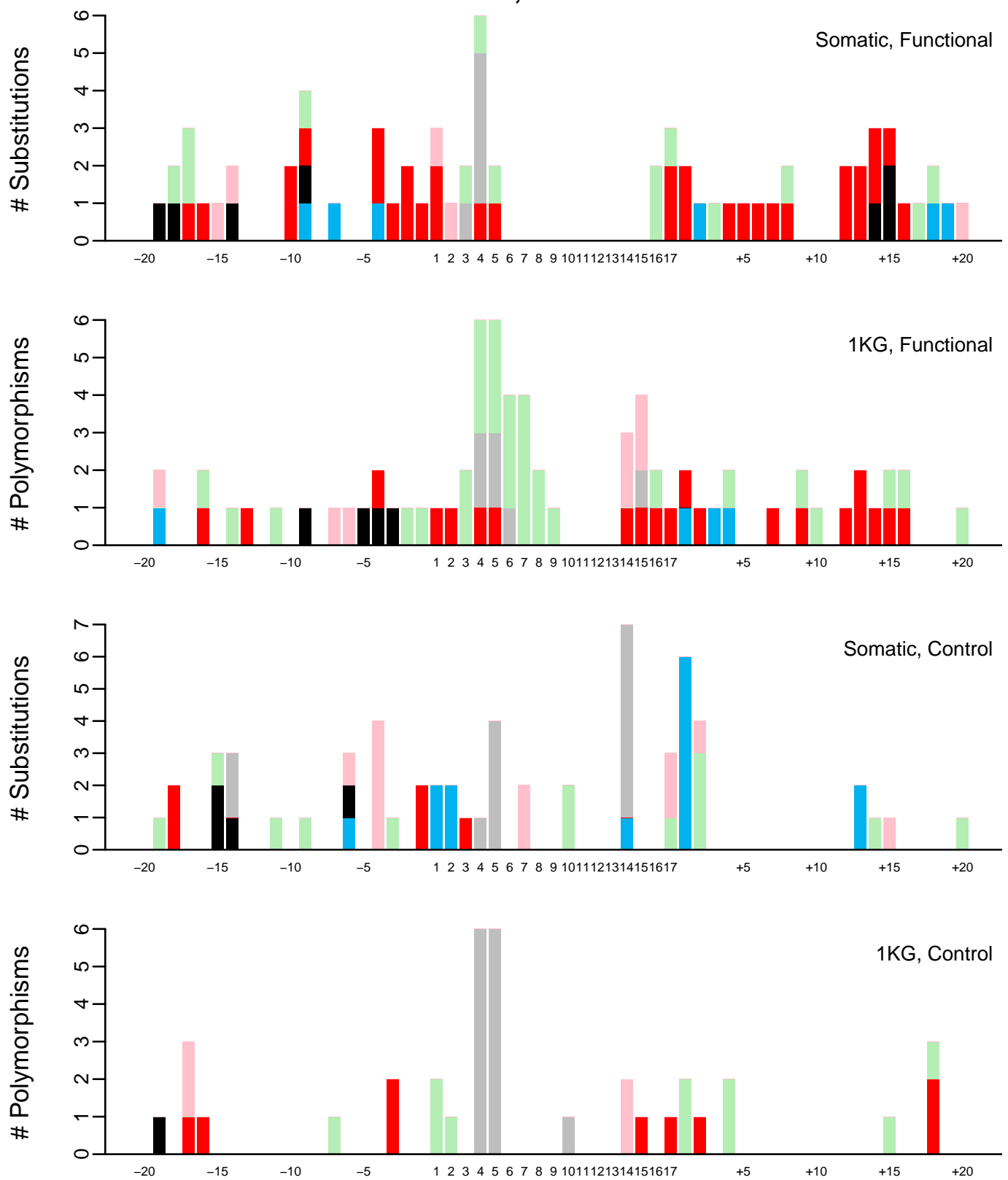